\title{
Facilities Management Models, Methods and Tools
}

\author{
Jensen, Per Anker
}

Link to article, DOI:

10.3390/books978-3-0365-2320-0

Publication date:

2021

Document Version

Publisher's PDF, also known as Version of record

Link back to DTU Orbit

Citation (APA):

Jensen, P. A. (Ed.) (2021). Facilities Management Models, Methods and Tools.

https://doi.org/10.3390/books978-3-0365-2320-0

\section{General rights}

Copyright and moral rights for the publications made accessible in the public portal are retained by the authors and/or other copyright owners and it is a condition of accessing publications that users recognise and abide by the legal requirements associated with these rights.

- Users may download and print one copy of any publication from the public portal for the purpose of private study or research.

- You may not further distribute the material or use it for any profit-making activity or commercial gain

- You may freely distribute the URL identifying the publication in the public portal

If you believe that this document breaches copyright please contact us providing details, and we will remove access to the work immediately and investigate your claim. 


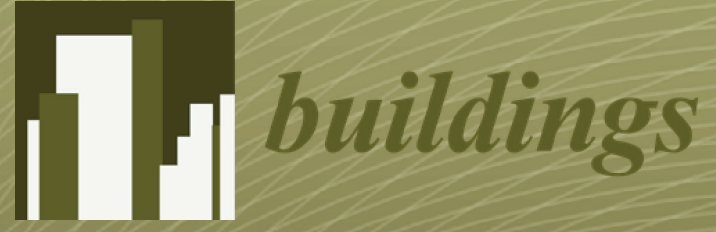

\section{Facilities}

Management

Models, Methods

and Tools

\section{Edited by \\ Per Anker Jensen}

Printed Edition of the Special Issue Published in Buildings 
Facilities Management Models, Methods and Tools 



\section{Facilities Management Models, Methods and Tools}

Editor

Per Anker Jensen 
Editor

Per Anker Jensen

Technical University of Denmark

Denmark

Editorial Office

MDPI

St. Alban-Anlage 66

4052 Basel, Switzerland

This is a reprint of articles from the Special Issue published online in the open access journal Buildings (ISSN 2075-5309) (available at: https:/ /www.mdpi.com/journal/buildings/special_issues / Facilities_Management).

For citation purposes, cite each article independently as indicated on the article page online and as indicated below:

LastName, A.A.; LastName, B.B.; LastName, C.C. Article Title. Journal Name Year, Volume Number, Page Range.

ISBN 978-3-0365-2319-4 (Hbk)

ISBN 978-3-0365-2320-0 (PDF)

(C) 2021 by the authors. Articles in this book are Open Access and distributed under the Creative Commons Attribution (CC BY) license, which allows users to download, copy and build upon published articles, as long as the author and publisher are properly credited, which ensures maximum dissemination and a wider impact of our publications.

The book as a whole is distributed by MDPI under the terms and conditions of the Creative Commons license CC BY-NC-ND. 


\section{Contents}

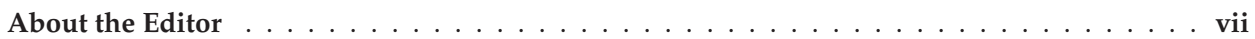

\section{Per Anker Jensen}

Facilities Management Models, Methods and Tools

Reprinted from: Buildings 2021, 11,490, doi:10.3390/buildings11100490 . . . . . . . . . . . . . 1

Brenda Groen and Hester van Sprang

Perceptions of Hospitality and Safety Are Two Sides of the Same Coin

Reprinted from: Buildings 2021, 11,113, doi:10.3390/buildings11030113 . . . . . . . . . . . 5

Natalia Echeverri, Tuuli Jylhä and Philip Koppels

Searching for Flexibility in Corporate Real Estate Portfolio: Six Co-Working Strategies for User Corporations

Reprinted from: Buildings 2021, 11, 115, doi:10.3390/buildings11030115

Marko Lahti and Suvi Nenonen

Design Science and Co-Designing of Hybrid Workplaces

Reprinted from: Buildings 2021, 11, 129, doi:10.3390/buildings11030129 . . . . . . . . . . . . 37

Abiodun Olatunji Abisuga, Cynthia Changxin Wang and Riza Yosia Sunindijo

Organisational Justice Analysis of Facility Managers' Responses to User's Post-Occupancy

Feedback

Reprinted from: Buildings 2021, 11, 144, doi:10.3390/buildings11040144

Knut Boge, Amin Haddadi, Ole Jonny Klakegg and Alenka Temeljotov Salaj

Facilitating Building Projects' Short-Term and Long-Term Value Creation

Reprinted from: Buildings 2021, 11, 332, doi:10.3390/buildings11080332 



\section{About the Editor}

Per Anker Jensen holds MSc, PhD, and MBA degrees in civil engineering. He has 20 years of experience practicing as a consultant, project manager, and facilities manager. Since 2005, he has conducted research and taught Facilities Management at the Technical University of Denmark. From 2008 to 2019, he was head of the externally funded Centre for Facilities Management-Realdania Research (CFM). In 2020, he became professor emeritus at DTU Management. 



\title{
Facilities Management Models, Methods and Tools
}

\author{
Per Anker Jensen
}

Citation: Jensen, P.A. Facilities Management Models, Methods and Tools. Buildings 2021, 11, 490. https://doi.org/10.3390/ buildings 11100490

Received: 14 October 2021 Accepted: 15 October 2021 Published: 18 October 2021

Publisher's Note: MDPI stays neutral with regard to jurisdictional claims in published maps and institutional affiliations.

Copyright: (c) 2021 by the author Licensee MDPI, Basel, Switzerland. This article is an open access article distributed under the terms and conditions of the Creative Commons Attribution (CC BY) license (https:// creativecommons.org/licenses/by/ $4.0 /)$.
DTU Management, Technical University of Denmark, Akademivej Building 358, 2800 Lyngby, Denmark; pank@dtu.dk

The starting point for this Special Issue was the book "Facilities Management Models, Methods and Tools: Research Results for Practice" [1], edited by the guest editor. The book presents research on facilities management (FM) since 2008 at a research centre in Denmark, with particular focus on models, methods and tools applicable for practice. The research covered the following six themes:

- Facilities that support users and activities;

- Sustainability from goal to action;

- Innovation and partnerships;

- Transfer of knowledge from FM to building projects;

- $\quad$ FM and added value;

- FM organisation and development.

The book also presents five main challenges and processes for facilities managers, and shows how the different models, methods and tools can be used to manage one or more of these processes. The five processes are:

- $\quad$ Strategy development;

- Organisational design;

- Space planning;

- $\quad$ Building project;

- Optimisation.

The Special Issue aims to expand this research with further models, methods and tools of relevance to FM. This could include research with a practical application, but it could also include more genuine theoretical models, which contribute to a deeper understanding of the field of FM. Five papers have been accepted and are included in this Special Issue.

Groen and van Sprang [2] present an exploratory qualitative study of hospitality and safety in relation to the entrances and reception areas of corporate buildings. The methodology for data collection combined a pilot group interview and telephone interviews with staff and visitors. The group interview included three managers responsible for hospitality and security in reception areas working for a major FM supplier in the Netherlands. The interviews with staff and visitors focused on collecting critical incidents and narratives. A total of 51 descriptions of situations were collected for analysis, and 46 of these were classified as critical incidents, while five were classified as narratives. The results show that hospitality and safety are two sides of the same coin. Usually, people do accept security measures, provided that staff act in a hospitable way. A lack of security measures may seem inviting, but also decreases the perception of care for your visitor, and may cause uncertainty and therefore decrease comfort. A correct risk perception, the flexible appliance of security measures and a friendly approach connect aspects of safety and hospitability, such that they complement each other. The paper provides interesting insights into how FM can deal with the partly contradictory concerns for control and care in buildings' reception areas.

Echeveri et al. [3] investigate corporate strategies for utilizing co-working spaces. Coworking is a fairly new phenomena and has experienced an exponential growth. It is estimated to have doubled from 2016 to 2019, when there were more than 22,000 spaces 
and 2,000,000 members worldwide. Co-working spaces are usually occupied by freelancers, entrepreneurs and start-ups. However, this study shows that co-working spaces are increasingly also being used by larger corporations to provide flexibility in their real estate portfolio. The study is exploratory and based on five case studies from the Netherlands, including in-depth, semi-structured interviews with corporate real estate managers and related case documentation. The results suggest that companies in different stages of the organization's life-cycle can implement co-working as the main office location or as a temporary or complementary space solution, through six different strategies:(1) swing space, (2) expansion space, (3) core and flex, (4) touchdown space, (5) testing market and (6) temporary projects and staff. Each strategy plays a specific role in the corporate real estate portfolio and implies different sources of flexibility. The paper provides novel information on how co-working can be utilized as part of corporate real estate portfolio management.

Lahti and Nenonen [4] present a study of co-design of digitally and physically integrated hybrid working environments. New information and communication technologies enable spatial reconfiguration of work, opening possibilities for work to take place across multiple locations. The paper applied a conceptual framework of design-science research in information systems. The methodology was based on action design research. The empirical data included two case studies of university facilities, with a case from a university in Finland and a case established by the same Finnish university at a university in Namibia. Both cases had intensive user participation and their developments were investigated and analysed step by step based on a process model for usability briefing. Multiple methods of data collection were used, including participatory workshops, documents analysis, observation and experience mapping questionnaires. The results include four recommendations for the co-designing of hybrid working environments. The use of hybrid working environments, the design of spatial solutions, the identification of iterative processes and the user experiences of presence and distance are significant. The study contributes to the traditions of usability and design studies, and it provides interesting insights on designing hybrid workplaces.

Abisuga et al. [5] investigate how facility managers handle user feedback to drive collaboration between facility managers and users during occupancy. The paper draws on theoretical insights from organizational justice, organizational response and service quality studies. Empirically, it is based on a case study of a faculty building in an Australian university using various methods, including document analysis, interviews and observations. There was a total of 29 interviews with users covering students, academics and administrative staff. The analysis of the interviews identified five themes that are applicable to FM services and could influence user post-feedback behaviour. The themes were: facilitation, timeliness, redress, apology and explanation, and attentiveness and efforts. Current responses to user feedback were not satisfactory, resulting in a poor relationship between facility managers and users that negated service acceptance and the engagement in positive word-of-mouth behaviour. To foster more facility manager-user collaborative relationships in post-occupancy evaluation, and position FM as a service organisation, there is a need for improvements in current FM responses to user feedback and the effective management of user post-feedback behaviours. This could be achieved by the provision of effective means of communication, a clearly defined FM policy and procedures, acceptable FM redress, giving sincere apologies and credible explanations, and paying attention to and extending efforts to resolve user needs. The paper provides interesting insights into understanding and analysing building users' relationships with FM.

Boge et al. [6] present a study of the factors that are the most important for building and renovation projects' short-term and long-term value creation. The focus is not primarily financial and on a building's asset value, but instead on the completed building's effect for owners and users. The short-term value is the output of the project, while the long-term value is the outcome. The study was based on a national questionnaire survey in Norway. The study population ( $\mathrm{N}=550)$ was professional practitioners, who have been involved in the planning and construction of buildings. Multivariate statistics were used to test 
nine hypotheses. Short-term project management priorities, such as early involvement of technical contractors and FM providers, contract strategy and involvement of owners and users, largely decide the qualities of the building, and thus the potential for long-term value creation. The most important factors for long-term value creation, i.e., buildings that facilitate the demand organisation's value creation, are the qualities of the completed building, project governance and involvement of owners and users during early-phase planning. Buildings are facilities managers' most costly resources. Thus, knowledge about how to obtain the most out of building or renovation projects, both in the short term and in the long term, are of great importance for facilities managers. The paper provides interesting insights into buildings' value for owners and users, which supplement the extensive research on the added value of FM.

Funding: This research received no external funding.

Institutional Review Board Statement: Not applicable.

Informed Consent Statement: Not applicable.

Conflicts of Interest: The author declares no conflict of interest.

\section{References}

1. Jensen, P.A. Facilities Management Models, Methods and Tools: Research Results for Practice; Routledge: London, UK, 2018.

2. Groen, B.; van Sprang, H. Perceptions of Hospitality and Safety Are Two Sides of the Same Coin. Buildings 2021, 11, 113. [CrossRef]

3. Echeverri, N.; Jylhä, T.; Koppels, P. Searching for Flexibility in Corporate Real Estate Portfolio: Six Co-Working Strategies for User Corporations. Buildings 2021, 11, 115. [CrossRef]

4. Lahti, M.; Nenonen, S. Design Science and Co-Designing of Hybrid Workplaces. Buildings 2021, 11, 129. [CrossRef]

5. Abisuga, A.; Wang, C.; Sunindijo, R. Organisational Justice Analysis of Facility Managers' Responses to User's Post-Occupancy Feedback. Buildings 2021, 11, 144. [CrossRef]

6. Boge, K.; Haddadi, A.; Klakegg, O.; Salaj, A. Facilitating Building Projects' Short-Term and Long-Term Value Creation. Buildings 2021, 11, 332. [CrossRef] 



\title{
Article \\ Perceptions of Hospitality and Safety Are Two Sides of the Same Coin
}

\author{
Brenda Groen * and Hester van Sprang
}

Citation: Groen, B.; van Sprang, H. Perceptions of Hospitality and Safety Are Two Sides of the Same Coin. Buildings 2021, 11, 113. https:// doi.org/10.3390/buildings11030113

Academic Editor: Per Anker Jensen

Received: 31 January 2021

Accepted: 9 March 2021

Published: 12 March 2021

Publisher's Note: MDPI stays neutral with regard to jurisdictional claims in published maps and institutional affiliations.

Copyright: (c) 2021 by the authors. Licensee MDPI, Basel, Switzerland. This article is an open access article distributed under the terms and conditions of the Creative Commons Attribution (CC BY) license (https:// creativecommons.org/licenses/by/ $4.0 /$ ).
Hospitality Business School, Saxion University of Applied Sciences, M. H. Tromplaan 28, 7513 AB Enschede, The Netherlands; h.vansprang@saxion.nl

* Correspondence: b.h.groen@saxion.nl

\begin{abstract}
Entering a building is a 'moment of truth' and may invoke feelings of hospitableness. Physical environments and staff behaviour deliver 'clues' that may result in the experience of hospitality. The focus in a reception area may be on mitigation of risks, or on a hospitable atmosphere, with either a host or a security officer at the entrance. However, the division of tasks to either the pleasing host or the controlling security officer to a certain extent disavows the overlap between perceptions of hospitality and safety. This exploratory qualitative study combines a group interview with three managers responsible for hospitality and security in reception areas and Critical Incidents by staff and visitors $(\mathrm{N}=51)$. Thematic coding was based on The Egg Aggregated Model and the Experience of Hospitality Scale. Results show that hospitality and safety are indeed two sides of the same coin. Usually people do accept security measures, provided that staff act in a hospitable way. A lack of security measures may seem 'inviting', but also decreases the perception of care for your visitor, and may cause uncertainty and therefore decrease comfort. A correct risk perception, flexible appliance of security measures, and a friendly approach connect aspects of 'safe' and 'hospitable' sentiments.
\end{abstract}

Keywords: perceived hospitality; perceived safety; risk perception; safety culture; reception; building entrance

\section{Introduction}

Hospitality is a broad concept that originates from the Latin 'hospes', meaning host, guest, and stranger [1]. The offer of hospitality recognises the mutual obligations of the host and guest [2]; hosts need to ensure the well-being of their guests, while guests need to respect the rules of the host and to reciprocate. Derrida and Dufourmantelle [3] point out that hospitality encompasses the impossible pairing of the necessary openness to the other and the equally essential exclusionary sovereignty.

Hospitality may be used to control strangers and outsiders [4]. This control perspective particularly applies to building entrances and receptions. The reception may invoke feelings of hospitableness in guests but may also be perceived as a barrier. Depending on an organisation's risk perception and risk aversion, or on a positive image of humankind, the focus of a receptionist is more on either the benign or the harmful aspects of guests, resulting in the use of either a host or a security officer at the entrance. This division of tasks to either the pleasing host or the controlling security officer to a certain extent disavows the overlap between the perception of hospitality and perception of safety. So, the question arises: when is a reception perceived as being hospitable and safe by both hosts and guests? In literature and (academic) models, hospitality and security are worlds apart, whereas in practice, they operate in the same area and mutually influence each other. This paper aims to develop a conceptual model that captures both domains as a starting point for better understanding of their interrelatedness. 


\section{Literature Review}

\subsection{Hospitality}

Defining hospitality is not easy, as different disciplines and sectors frame hospitality in quite distinct ways [5]. In its pure form, hospitality involves selfless giving; however, in practice, hospitality emerges through transactions and reciprocal arrangements of giving and receiving [3]. Hospitality is about gestures of welcoming and the creation of inclusive physical and symbolic spaces [6]. Burgess [7] describes hospitality as "the social relationship fostered by the warm, friendly, welcoming, courteous, open, generous behaviour of the host, creating the hospitable social environment". Aspects that contribute to a guest's feeling of being welcome are friendliness, being inviting, warmth, being home-like, openness, sincerity, and generosity [8-10].

Brotherton and Wood [8] identify two dominant perspectives on hospitality in social science: as a form of social and economic exchange and as a means of social control. Hospitality as a form of exchange is typically related to a business context, especially the hospitality industry. Lynch et al. [5] state that such a definition of hospitality reduces the interactions between hosts and guests to commercial exchanges and hospitality elements to commodities. Lugosi [11] argues that it is crucial to avoid conceptualising hospitality only in positive actions, as hospitality may also be used to ascribe status, reinforce hierarchies, and (re)construct relationships of power, fitting the perspective of hospitality as a means for social control.

According to Hemmington [9] and Brotherton and Wood [7], the guest's sense of safety is one of the most important responsibilities of a host. Pitt-Rivers highlights the mutual implication of power and a welcome: the guest is necessarily at the mercy of the host, on a knife-edge between suspicion and trust (cited in [4]). Many authors emphasise the reciprocity whereby the host strives to protect and keep the guest safe, and at the same time, the guest is 'obliged' to behave safely and not do any damage to the host $[3,5,12,13]$. Thus, hospitality is used as a mean of controlling "people who are essentially alien to a particular physical, economic and social environment" [8]. The act of giving and receiving offers a way to negotiate potentially harmful relationships between individuals and groups [4]. Transactions of hospitality may help create liminal spaces where transgressions are possible and alternative values, and norms can be created $[14,15]$. In this way, studies on hospitality highlight how hospitality acts as a powerful mediating social control mechanism [5]. In practice, facility management providers may deliver hospitality services and/or security services, which should lead to a hospitable and/or safe environment.

\subsection{Security}

Security services are focused on protection against danger or loss. This is achieved by the mitigation of adverse consequences through a broad spectrum of acceptable practices, procedures and principles [16,17]. In this context, a stable, relatively predictable environment is created in which an individual or group may pursue its goals without disruption, harm, and fear [18]. Security is a dynamic and versatile concept [19]. Two paradigms prevail: negative security versus positive security. Both paradigms are rooted in the Latin word 'securitas'. Securitas is made up of 'se' (sine, 'without'), 'cura' ('care'). 'Cura' has a double meaning. First of all, 'being without care' refers to living 'without restlessness' or 'without fear'. In line with the negative security paradigm, people are only safe when they know no 'pain' or 'danger'. However, 'cura' can also be interpreted positively in terms of 'vigilance' and 'zeal'. It is a form of 'care' that you spend on something or someone. This interpretation collides with the positive security paradigm [19]. This so-called positive security represents something that is positively valued, that is good or desired. It refers to security that is the result of a secure condition and refers to softer principles of 'connectedness', a 'safe-haven', 'care', and 'recovery' [20-22].

Security measures can be clustered according to organisational measures (i.e., policies, procedures, security staff), behavioural measures (i.e., creating awareness, training), technical measures (i.e., security cameras, metal detection gates), and physical measures (i.e., 
locked doors, entrance barriers). Other commonly used classifications are visible versus non-visible, and obtrusive versus non-obtrusive measures.

\subsection{Safety}

Differences between security and safety lie in nature of threats (security: deliberate external threads; safety: unintentional, occupational hazards); emotional (safety) versus physical (security) aspects; and coverage (security: narrow, safety: broad). The underlying concepts of safety and security are complementary [23]; safety cannot be achieved if security is not guaranteed.

Occupational Safety and Health (OSH) practices are defined as the science of the anticipation, recognition, evaluation, and control of hazards arising in or from the workplace that could impair workers' health and well-being or harm surrounding communities and the environment [24]. OSH management systems help companies accept and administer the building and maintenance of a culture of health and safety as their prime responsibility [24]. A safety climate is the degree to which employees perceive that safety is a priority in their company [25]. According to Cabrera et al. [26], the safety climate may be apparent in policies and practices, but the underlying schemata have far more impact than merely the willingness to follow policies. For example, Huang et al. [27] studied the effects of safety climate perceptions on lone working employees' job satisfaction, engagement, and turnover rate. They distinguish between an organisational level safety climate (OSC) and a group-level safety climate (GSC). Their study showed that safety climate perceptions occur at both OSC and GSC levels, and both directly and indirectly impact employee outcomes beyond those regarding the safety of the work environment. In line with positive and negative security, one could argue that negative safety is the absence of work-related accidents and injuries, whereas positive safety points at wider-ranging positive effects on organisations. Based on an extensive literature review, Guldenmund [26] concludes that safety climate can be interpreted as denoting attitudes to safety within an organisation, with safety culture being the (broader) convictions or dogma's underlying safety attitudes.

Schein and Schein [28] (p. 21) define culture as "the accumulated shared learning of that group as it solves its problems of external adaptation and internal integration. Accumulated learning is a system of beliefs, values, and behavioural norms that come to be taken for granted as basic assumptions and eventually drop out of awareness." They identify three layers of culture: an inner layer consisting of basic underlying assumptions (system of beliefs), a middle layer of ideals, goals, values, aspirations, ideologies, and rationalisations, and an outer layer of artefacts (visible and tangible structures and processes and observed behaviour) [28] (pp. 28-29)). Vierendeels et al. [29] apply Schein and Schein's layers of culture to define safety culture. Their 'The Egg Aggregated Model' (TEAM) of safety culture encompasses three related domains. The inner layer ('air') consists of underlying basic assumptions and values. The middle layer ('protein') encompasses both the organisational domain (leadership, trust in the organisation, management commitment, and communication-leading to a safety climate) and the human domain (individual attitudes, skills and ability, personal characteristics, and knowledge-leading to the intention for safe behaviour). The outer, easily visible domain ('yolk'), the artefacts, is called the technological domain (technology, procedures, training, and behaviour of people-leading to observable safety outcomes). Although this model stems from OSH, it is applicable in our study as it points out that safety not only depends on procedures, but also on people's perceptions and underlying paradigm of what safety means to them, as represented by the inner layer of 'The Egg Aggregated Model'.

\subsection{Perception}

So, safety is more than absence of harm. It also refers to the perception, the anticipation, of being in an environment where one will not be harmed. Consciously and subconsciously our senses provide us with information about the environment. These sensory clues are filtered and interpreted by our brains using prior experience, knowledge, and expectations. 
Perception is closely related to experience and satisfaction. Hospitality and security services take place in an environment with both physical and social dimensions [30,31]. Following Berry et al. [31], the experience of a service is based on three types of clues: functional clues (e.g., performance of the reception and security services); mechanical clues (sensory perception, e.g., of the physical environment of the entrance); and human clues (behaviour and appearance of employees and other guests). The mechanical and humanic clues may be interpreted as the middle layer, and the functional clues as the outer layer in Schein and Schein [28] or the TEAM model [29]. The resulting individual experience of hospitality and safety is internalised and therefore not easy to investigate [32]. Though on the level of artifacts in Schein and Schein, or the 'yolk' in the TEAM model, these experiences are intangible. Experience can, however, be measured.

Another important model that explains human-environment interaction in services processes is Bitner's servicescape [33]. The servicescape refers to the non-human elements of the environment in which service encounters occur. It is the complex mix of a service's environmental features (inputs or stimuli) that exert influence on people's responses and behaviours (output). Environmental inputs are sensory (ambient conditions), spatial (space and function) and symbolic (signs, symbols and artefacts). According to Maslow, the perception of safety is a basic need that people are highly motivated to achieve, surpassed only by the desire to meet first meet physiological needs. Nonetheless, safety has been regularly omitted from servicescape studies [34].

\subsection{Perception of Hospitality}

Both the design of the physical environment and staff behaviour deliver 'clues' that together conjure an image of hospitality. Experience is the interaction between the individual and its environment, containing functional, mechanical, and human clues, and the inner responses to this interaction [35]. From a host perspective, frequently mentioned concepts associated with hospitality-experience are: 'desire to please' [36-38]; 'understanding needs' [12,36,37,39]; 'welcoming' [7,8,36]; 'friendly' [7,8,40]; 'security' [7,9,39]. Amongst others, the offer of hospitality leads to 'comfort ' $[7,8,36,37]$ and 'pleasure/being happy' $[8,12,37,40]$.

Research into the guest's hospitality experience is scarce [35-37,40]. Pijls et al. [35] have developed a holistic scale for measuring a guest's hospitality experience. Its underlying dimensions are 'inviting', 'care', and 'comfort'. Inviting relates to openness and experience of freedom during a visit. Care is associated with providing support, taking care of a person, relieving him/her of tasks or worries, and taking an interest in them. Comfort is associated with feeling at ease, relaxed, and comfortable. In two previous qualitative studies exploring the meaning of hospitality experience from the viewpoint of professionals offering hospitality and from a customer's perspective, safety and security were both found to be attributes of the experiential dimension 'feeling at ease'. Likewise, Groen [41] concluded that the value of facility management in hospitals might concern realising a functional, pleasant, and comfortable environment, and behaviour that makes patients feel at ease and valued as an individual. This will reinforce the feeling of safety, an important aspect of hospitality in a hospital.

\subsection{Perception of Safety, Feeling Safe}

Comfort, connection, knowledge and control, interaction, as well as feeling at home and in a trusted environment, contribute to a positive feeling of safety $[19,42,43]$. Based on participant-led photography, Pijls et al. [44] identified eight experiential dimensions of hospitality out of 438 images, among which 'safety' was included. Images of safety include access gates, security personnel/equipment, remaining waiting time, a well-organised entrance, and open architecture.

But what are the effects of visible security measures on the perception of feeling safe? Could it be that these evoke fear by making people aware of security risks? Research on fear of crime in the school setting related to environmental characteristics helps us to 
better understand the mechanisms through which fear is created and maintained. Multiple studies into safety in schools in the USA show that visible security measures harm students' feeling of safety, although the type of security measure matters. For example, Schreck and Miller [45] found that metal detectors, locked doors, supervised hallways, and drug education were predictive of increased worry about being a victim of school crime, but they found no significant effect for security guards, visitor sign-in, locker checks and passes. Perumean-Chaney and Sutton [46] performed a secondary data analysis using the National Longitudinal Study of Adolescent Health (NLSAH; 5785 students, 112 schools). Their study suggests that metal detectors and the use of at least two physical security measures may decrease students' perception of being safe. However, environmental factors and previous experiences mediate the effect. Male, white students with higher Grade Point Averages that feel safe in their neighbourhood were more likely to report feeling safe at school. At the same time, those who experienced prior victimisations had larger class sizes, and those who attended schools that had disorder problems were more likely to report not feeling safe at school. This finding aligns with the social constitution of fear approach, which suggests that fear experiences should be seen in relation to wider social and geographical context, social relations, and power structures [47].

\subsection{The Experience of Hospitality and Feeling Safe Combined}

As the first point of contact, the building's entrance is considered important in providing hospitality to end-users and external clients. It is also a crucial element in keeping a building safe and secure. Reception services and entrance security potentially belong to bespoke products according to Katchamart's product-process matrix, as they directly influence the end user's perceptions and experience [48]. These products require a strategic approach to add value to the client company, yet these services are often perceived as commodities and are commonly outsourced.

Services, like hospitality and security services, are performed and consumed simultaneously, and they are intangible. In choosing and evaluating the provision of these services, it is therefore common for guests to use tangible clues to judge their quality [49]. Functional clues from a provider-perspective are related to services offered, procedures, scripted behaviour, and physical measures. The host (receptionist) provides for the guest's security, psychological, and physiological comfort [50] and is part of the security management system that protects an organisation and its assets against external threats. According to Schuilenburg and Van Steden [20], Bigo [42], and Akalin et al. [43], comfort, interaction, and feeling at home contribute to a positive feeling of safety. These attributes of positive security relate to the experiential dimensions of hospitality 'care' and 'comfort' [51]. The common denominator is the absence of stress. On the other hand, the presence of visible and intrusive security measures to ensure negative security may cause stress in a person, triggered by his/her expectations and previous experiences, which harms feelings of being safe and at ease, that are also part of the perception of hospitality $[45,46]$.

Because security and safety are not explicitly considered to be part of hospitality, nor part of the servicescape in the literature [34], it is worthwhile to explore to what extent the constructs 'safe' and 'hospitality' can be recognised in people's perception of (entrance) areas in utility buildings.

\section{Methods}

This exploratory qualitative study aims to deliver a conceptual model that captures both the experience of hospitality and safety. The starting point was a 2-h pilot group interview with three client managers working for one of the major facility management suppliers in the Netherlands (December 2019). Together, these managers are responsible for entrance management services in a large number of properties. The pilot interview aimed to investigate how professionals envision the interrelatedness of the perceptions of safety and hospitality. Next, the critical incident technique (CIT) was used to explore underlying experiential factors further. Front-line staff, managers of front-line staff, and 
visitors/workers were interviewed by telephone regarding their experiences with entrance management in buildings and their perceptions of safety and hospitality; 51 descriptions of situations were collected between January-February 2020. Respondents were asked to describe a situation that was both hospitable and safe, hospitable but not safe, safe but not hospitable, and neither hospitable nor safe. A number of situations described did not fulfil the criteria for a 'critical incident'; these were all observations by front-line staff managers. But because these observations provided useful information on the perception of hospitality and safety, they were included in the analysis as narratives. In total, 46 situations could be labelled as Critical Incidents, and five were narratives. Tables 1 and 2 show an overview of critical incidents and narratives.

Table 1. Characterisation of the critical incidents and narratives.

\begin{tabular}{ccccc}
\hline Characteristics & Hospitable and Safe & Hospitable & Safe & $\begin{array}{c}\text { Not Hospitable, } \\
\text { Not Safe }\end{array}$ \\
\hline Critical incident, host perspective & 8 & 6 & 9 & 9 \\
Narrative, host perspective & 4 & 1 & 0 & 0 \\
Critical incident, guest perspective & 3 & 2 & 5 & 4 \\
Total & 15 & 9 & 14 & 13 \\
\hline
\end{tabular}

Table 2. Initial coding into themes, based on The Egg Aggregated Model and Experience of Hospitality Scale.

\begin{tabular}{|c|c|c|}
\hline Theme & Description & In-Text Code \\
\hline Air * & Beliefs, basic assumptions, values & Air \\
\hline Protein-Human Domain *. & $\begin{array}{c}\text { Personal Psychological Factors that influence } \\
\text { individual intention to behave (skills and ability, } \\
\text { individual attitudes towards the behaviour, personal } \\
\text { characteristics) }\end{array}$ & Human \\
\hline Protein-Organisational domain * & $\begin{array}{c}\text { Perceptual factors that lead to shared perceptions on } \\
\text { safety, safety climate (leadership, trust in the } \\
\text { organisation, transparancy of communication, } \\
\text { management commitment) }\end{array}$ & Org \\
\hline Yolk-Technological domain * & $\begin{array}{l}\text { Observable safety outcomes (technology, training, } \\
\text { procedures, behaviour of people) }\end{array}$ & Tech \\
\hline Perception of Safety & & PSaf \\
\hline Perception of Hospitality ${ }^{* *}$ & $\begin{array}{c}\text { Inviting (openness, freedom, feeling invited), } \\
\text { Care (experiencing involvement, effort, interest, } \\
\text { relief, and support) } \\
\text { Comfort (feeling at ease, relaxed and comfortable) }\end{array}$ & $\begin{array}{c}\text { PInv } \\
\text { PCare } \\
\text { PComfort }\end{array}$ \\
\hline
\end{tabular}

The pilot interview was coded using open coding, amongst others, using the themes presented in Table 2. Coding of the CITS and narratives was based on The Egg Aggregated Model (air, protein-organisational domain, protein-human domain, yolk-technical domain) [2] that is based on the work of Schein and Schein [28]. To this model, we have added the perception of safety (2B). Next, the situations were coded using and the Experience of Hospitality Scale (inviting, comfort, care) [3]. Table 2 represents the initial coding on themes. 


\section{Results}

First, the cases were briefly described in four categories: hospitable and safe; hospitable; safe; neither hospitable nor safe (see Table 3). Next, the cases were labelled using the in-text reference codes presented in Table 2.

Table 3. Critical Incidents (CIT) and Narratives (Nar).

\begin{tabular}{|c|c|c|c|}
\hline Cluster & Case & $\begin{array}{l}\text { Host/ } \\
\text { Guest }\end{array}$ & Description \\
\hline \multirow{3}{*}{$\begin{array}{l}\text { Hospitable } \\
\text { and safe }\end{array}$} & CIT $(\mathrm{n}=8)$ & Host & $\begin{array}{l}\text { A hospitable response by the receptionist to unauthorised parking. } \\
\text { A positive experience of entrance management during a visit of } \\
\text { team members in a multitenant building. } \\
\text { Strict but kind sticking to access protocol when a known worker } \\
\text { forgets their badge. } \\
\text { Taking care of a visitor (coffee) while at the same time responding } \\
\text { to an urgent situation. } \\
\text { Hospitable alternative for visitor access without ID. } \\
\text { Receptionist taking time to calm-down a stressed-out student over } \\
\text { a cup of tea. } \\
\text { Bending aggressive client behaviour to warm customer } \\
\text { relationship. } \\
\text { Ensuring that the restrooms are included in security-inspection in } \\
\text { preparation of a VIP-visit. }\end{array}$ \\
\hline & $\operatorname{Nar}(\mathrm{n}=4)$ & Host & $\begin{array}{l}\text { Exclusive and at the same time high-security entrance at a } \\
\text { private bank. } \\
\text { A combined security/receptionist function at a large wholesaler. } \\
\text { Rigorous but respectful access control at the Central Bank. } \\
\text { Altering staff-dress codes at the unemployment office to make } \\
\text { visitors more comfortable. }\end{array}$ \\
\hline & CIT $(n=3)$ & Guest & $\begin{array}{l}\text { Taking off your shoes and belt upon entering a maximum-security } \\
\text { facility; patient and respectful guards soften discomfort. } \\
\text { A group visit to a company's headquarters, with a personalised } \\
\text { welcome sign and smooth check-in procedures. } \\
\text { A visit to the Hermitage in Russia, with free WIFI and apps in the } \\
\text { waiting room before a security check, followed by the security } \\
\text { check, and a welcome by classical music in the monumental hall } \\
\text { upon the entrance. }\end{array}$ \\
\hline \multirow[t]{3}{*}{$\begin{array}{c}\text { Hospitable, } \\
\text { not safe }\end{array}$} & CIT $(\mathrm{n}=6)$ & Host & $\begin{array}{l}\text { A mystery visitor using an obviously fake name that was warmly } \\
\text { welcomed without any identity check. } \\
\text { A receptionist that has to wait a long time for back-up while } \\
\text { dealing with a confused and aggressive person, but in the } \\
\text { meantime, she tries to comfort and calm the person trying not to } \\
\text { show that she is very scared. } \\
\text { A visitor greets the receptionist but walks past her to meet a } \\
\text { welcoming host, ignoring standard registration procedures. } \\
\text { In a multitenant building, a company occupies the 5th-10th floors, } \\
\text { with no security check at the ground level and the reception area } \\
\text { on the fifth floor doubling as a company restaurant. } \\
\text { Due to understaffing, a receptionist regularly is the only person to } \\
\text { welcome guests, which causes her to feel unsafe. } \\
\text { An agitated, aggressive person that does not speak a shared } \\
\text { language is calmed down and helped out. }\end{array}$ \\
\hline & $\operatorname{Nar}(\mathrm{n}=1)$ & Host & $\begin{array}{l}\text { At the reception desk visitors receive a beeper that will notify the } \\
\text { guest when the host arrives, so they can relax and enjoy a coffee } \\
\text { while waiting. }\end{array}$ \\
\hline & CIT $(n=2)$ & Guest & $\begin{array}{l}\text { Three students were locked-in after the departure of a group-visit, } \\
\text { as they attended the restrooms unnoticed. } \\
\text { A person is allowed to wander around in a hotel unsupervised } \\
\text { and talk to any member of staff she encounters. }\end{array}$ \\
\hline
\end{tabular}


Table 3. Cont.

\begin{tabular}{|c|c|c|c|}
\hline Cluster & Case & $\begin{array}{l}\text { Host/ } \\
\text { Guest }\end{array}$ & Description \\
\hline \multirow[t]{2}{*}{$\begin{array}{c}\text { Safe, not } \\
\text { hospitable }\end{array}$} & CIT $(\mathrm{n}=9)$ & Host & $\begin{array}{l}\text { Too strict enforcement of procedures occurs, causing a massive } \\
\text { traffic jam in the garage and stress in the visitor. } \\
\text { An unstaffed reception desk in a multitenant building while } \\
\text { security staff is instructed not to guide visitors. } \\
\text { High-security environment, all visitors are approached and } \\
\text { questioned about their reason for being there. } \\
\text { A safety drill that involves external visitors with OHS-officers } \\
\text { responding irritated to their questions. } \\
\text { High-security facility with security staff acting repressively, } \\
\text { intimidating visitors. } \\
\text { A non-registered visitor and a security guard refuses entry } \\
\text { without offering any further help. } \\
\text { A terrorist attack in the neighbouring area, the manager finds safe } \\
\text { space for the employee to stay for a few hours but forgot to check } \\
\text { if the employee could use the bathroom and for the availability } \\
\text { of F\&B. } \\
\text { Blood bank with so many safety protocols that hospitality is no } \\
\text { longer the focal point for the receptionists. } \\
\text { Surveillance to prevent vandalism with the aim to make people } \\
\text { feel noticed, not to feel welcome at a campus. }\end{array}$ \\
\hline & CIT $(\mathrm{n}=5)$ & Guest & $\begin{array}{l}\text { A reception desk positioned at } 14 \text { th floor (the first floor they } \\
\text { occupied), whereas they rent from } 2 \text { nd floor onwards. } \\
\text { A visit to a coworking space with a doorbell nobody answers, } \\
\text { reception desk visibly unstaffed. } \\
\text { Holidaymakers that do not know where to report and are forced } \\
\text { to stay in the hall until the landlord arrives. } \\
\text { A visit to the security unit of a national museum, the door opens, } \\
\text { but the tourniquet does not and no intercom is available. } \\
\text { A person arrives at a building to attend a meeting, the receptionist } \\
\text { asks her to wait but never comes back. }\end{array}$ \\
\hline \multirow[t]{2}{*}{$\begin{array}{c}\text { Not } \\
\text { hospitable, } \\
\text { not safe }\end{array}$} & CIT $(n=9)$ & Host & $\begin{array}{l}\text { In an asylum centre, a receptionist is left alone and cannot leave } \\
\text { her post, while at the same time a client becomes increasingly } \\
\text { angry as he cannot explain what he wants due to language } \\
\text { barriers. } \\
\text { A situation where the receptionist is distracted by her phone all } \\
\text { the time, not noticing visitors at all. } \\
\text { An employee that does not dare to leave work because of the } \\
\text { unsafe neighbourhood after-hours. } \\
\text { An employee that is stalked leading to unsafe work environment } \\
\text { for all reception staff, solved by safety glass barriers. } \\
\text { A panicking student that seemed like he was high on drugs that } \\
\text { later committed suicide. } \\
\text { An employee that opened safety doors and set off the alarms to } \\
\text { find out what would happen. } \\
\text { An employee that forgot badge demands access, but before the } \\
\text { receptionist has the opportunity to correct him, a colleague of this } \\
\text { person lets him slip through the gate. } \\
\text { Higher management not willing to participate in safety drills as } \\
\text { 'they are busy earning money'. } \\
\text { A private bank with mostly Turkish clients; some clients only } \\
\text { speak Turkish, but the receptionist does not speak Turkish }\end{array}$ \\
\hline & CIT $(\mathrm{n}=4)$ & Guest & $\begin{array}{l}\text { Shopper in supermarket is repeatedly unpleasantly approached by } \\
\text { a man, the security guard does not act upon her signals. } \\
\text { A person visiting an open office floor where employees are } \\
\text { supposed to welcome visitors, but everybody is so engaged in } \\
\text { their work that this person has to disturb people for obtain help. } \\
\text { Due to a visiting employee being denied access to the visitor } \\
\text { parking, multiple cars have to park on a steep slope in reverse. } \\
\text { A club-style banking concept without privacy is set up and people } \\
\text { can overhear private conversations there. } \\
\text { After office hours, hotel guests are requested to check-in at a pub. } \\
\text { The guests felt out of place and had to find their way around the } \\
\text { hotel by themselves. }\end{array}$ \\
\hline
\end{tabular}


The critical incident technique is a research method in which the research participant is asked to recall and describe a time when a behaviour, action, or occurrence impacted (either positively or negatively) a specified outcome. Thus, it is no wonder that all cases refer to the yolk-technical domain in The Egg Aggregated Model. This domain encompasses the observable factors: technology, procedures, and behaviour of people. The protein-human domain describes personal psychological factors that the drivers for the observable behaviour in the yolk-technical domain, as the following quote from the pilot-interview illustrates:

"Some of our clients are very hierarchical. We pay you; you just have to run and get it in order. It's friendly, but it's straightforward. Conversation? Why? We pay you, and it just has to be good. If you don't do it right, you have to work on it. A different way of thinking. You notice that towards the hosts, too. Those high-paid expatriates see our employees as their servants. That's nasty."

The majority of situations describe procedures, followed by the behaviour of people. Only some refer to technology and none to training. Underlying beliefs ('Air') were not mentioned. From the experiential dimensions of hospitality, the 'inviting' dimension applies most $(\mathrm{N}=9)$, followed by care $(\mathrm{N}=6)$, and comfort $(\mathrm{N}=5)$. This is not unexpected, considering the context of entrance management for the CITs.

Two visitors and two hosts described situations involving more-than-average security measures (Tech). These measures undoubtedly trigger the risk perception of visitors. One interviewee said:

"Focus on security brings focus on unsafety. Whether it is the presence or absence of danger, you become aware that there is danger in the world. You can't go in carefree." (PSaf)

"The funny thing is that if you want to increase safety by putting up security guards, people become aware of the risk, and they feel less safe because of the association with risk." (PSaf)

Even though visitors may understand that these measures are necessary, they may be considered unpleasant and especially uninviting (PInv) and uncaring (PCare), and they induce stress and thereby decrease comfort (PComfort). However, by compensating for the required procedures with hospitable humanic clues (a friendly, relaxed attitude), the visitor becomes forgiving towards the organisation and accepts the measures as being necessary for the organisation's safety (Human).

"When you enter the bank, they scan you, but in a friendly way; you feel you are being treated respectfully."

"When you're dressed up for the occasion, it's not very pleasant to have to take off your belt and shoes, but the friendly approach makes up for the inconvenience."

In situations with the usual entry procedures (Tech, procedures), frustrations may arise when people come unprepared, and the standard procedure cannot be completed as prescribed (10 critical incidents), e.g., because they did not bring an ID or the registration number of their car was not provided upfront, there is no parking space, or they try to park their car where they should not. These are awkward situations because the host has to refuse entry (Tech), which feels inhospitable (PInv). However, good communicative skills and understanding for the visitor may solve the problem without causing too much frustration (Human). The trick is to be flexible and think of alternative solutions (Tech), e.g., by letting the contact person identify the guest. Without this flexibility, the situation will escalate unnecessarily. The visitor/worker will sense (s)he is heard ('caring'), which will lessen their negative response (PCare).

"Then we explained to the employee that it's also about hospitality and that his way of dealing with the situation leads to unnecessary frustration".

Or, as a manager said in one of the narratives: 
"The guest perceives the situation as safe because of our clear protocols, but also because our people can apply these protocols without being too blue" [as in the Dominance-Influence-Steadiness-Conscientiousness (DISC) personality colours].

Quite another situation arises when there is no procedure for visitors entering a building. There is nobody to receive the visitor, especially when this is not what the visitor expected or when the staff has no overview over the area (13 critical incidents).

"I observed a visitor entering the building where there is no procedure to register visitors; you are free to go to your appointment. The receptionist hardly notices the visitor and does not take any action".

The visitor does not consider this 'inviting' (PInv), but rather not 'caring' (PCare), as the receptionist's attitude is interpreted as uninterested:

"Not hospitable as we felt lost".

Also, this is not a comfortable situation for receptionists, as they are quite aware that they may not notice unwanted visitors (Tech); this situation may be characterised as 'too inviting' (PInv).

This may lead to unwanted situations:

"A group of students on an international excursion visits a building site of a major contractor. Upon arrival, the contact person invites them into the building. No check, no registration. Just before the group leaves, three students need to go to the restroom without informing the host. Result: the incomplete group leaves the site, and the three remaining students are locked-in, and there is nobody to help."

The hospitable hassle-free welcome leads to a rather uncaring departure, and apparently nobody, neither the host nor visitors, saw any harm in not checking who entered and who left. The experience was possibly 'inviting' (PInv), but not safe (Tech).

In five situations, workers or visitors ignored or even sabotaged safety instructions (Tech, behaviour). In one case, a worker pushed the emergency button "to see what happens". A worker demanded to enter without showing an entry pass and thereby violating entry protocol in a second situation. This may indicate their underlying beliefs regarding safety and security (Air).

In two situations, people complained about an emergency drill or even refused to take part. In these cases, the worker lacks safety perception (Org) and deliberately violates safety protocol. Staff reciprocates by rebuking the visitor, showing a lack of 'care' (PCare). The workers claim that the visitor was asking for hospitality, especially 'inviting' (PInv), beyond what is considered safe (Tech). The worker's risk perception is low, whereas the host rebukes the worker because (s)he does feel responsible and is aware of the risks taken. In a fifth situation, a visitor ignores the receptionist and immediately approaches his host. The receptionist, somewhat flabbergasted, lets this happen but feels confused. Should she address the visitor about this behaviour? The visitor feels happy and 'invited' (PInv) and seems quite unaware of this breach of the protocol (Tech). What about a situation where somebody, when addressed in a friendly way by the receptionist (who wondered what this person was doing there), immediately leaves? Apparently, he thought he would not be noticed and, in the meanwhile, enjoyed the inviting factor of the hospitality of the organisation (PInv).

Fourteen situations are not primarily about procedures, but are focused on (strong) emotions of visitors (Human). Angry, frightened, or confused people trigger the risk perception of the host (PSaf):

"Because of prior experiences, the receptionist is worried about what the visitor might do."

"I had a very bad feeling about this situation." 
The hosts try to calm down the visitor by airing their anger or fear (PComfort). To do this, they need the skills and attitude to deescalate the situation while, at the same time, complying with procedures (Tech). In one situation, a mystery visitor deliberately used a fake name, which was not noted by the receptionist (Tech). In this case, it was the risk perception of the host that was too low.

During the pilot-interview, it was mentioned that:

"One of our customers has a security status as a fair percentage of clients show aggressive behaviour (Tech). In a successful pilot, we have deployed some hostesses to kindly welcome people (PInv), send them to the counter, give them a cup of coffee and to quieten them down" (PCare, PComfort).

If necessary, security will be called for:

"The confused person is restless, screams, and the hostess calls for help from security by walkie." (Tech)

While experiencing negative emotions themselves (fear, pity), they control their feelings (emotional labour [52]), but show typical 'caring' behaviour by supporting the visitor (PCare), making them feel heard, and relieving their worries (PComfort) [35]. Hochschild [52] has defined emotional labour as 'the management of feeling to create a publicly observable facial and bodily display'. It is a person's response to an emotionally stressful situation, where the employee's task requires that (s)he displays emotions different from this/her actual feelings. This so-called surface acting may be required, e.g., when handling incivility by clients or confused and angry visitors [53]. Communication is crucial; language barriers may decrease both safety and hospitality perceptions for employees and visitors. The dress code is also an issue: one of the interviewed hosts explains why they do not wear uniforms:

"When people approach the desk, and the security staff is in uniform, and the hostess is formally dressed, they feel even less at ease" (Tech, PComfort).

The last aspect that needs to be discussed is the balance between hospitality and safety. Quoting the group interview:

"The extent to which you are threatened as a person or organisation determines the emphasis on the visible security side of the visible hospitality side."

In five situations, the safety aspect prevailed, e.g., because there was an emergency call while the visitor approached the receptionist, or because surveillance cameras were deemed necessary. In these cases, hospitality perceptions decrease, but the question is whether this could have been avoided. The group interview revealed that visible security measures might trigger a feeling of unsafety in visitors, which has a negative impact on the comfort dimension of perceived hospitality, especially 'feeling at ease'. However, context and previous experiences seem to be important mediating factors. However, when a person feels unsafe on entering a premises, physical security measures may have a positive effect.

\section{Conclusion and Discussion}

A quote from one of the pilot-interviewees nicely describes what prompted this research, namely the situation where organisations employ both security staff and hospitality staff and consider them to have separate functions, instead of being two sides of the same coin:

"I've been to many clients, and what I'm really wondering is why there should be a certain level of security when in my experience it should have been hospitality much more often. First, you meet six security people, and then you come to a desk with two ladies and a queue of four people there. And then I ask myself, to what extent are all those security guards needed? They don't make me feel very comfortable, do you need that? I think it has to do with higher management wanting much security, and then there's a facility manager who thinks, it's also 
useful when people are offered a cup of coffee and so let's add a host. I think it would be much better to have receptionists there, and then we'd add security, or we'd solve that with technical measures."

The incidents and narratives presented in this research mostly concern situations where the visitor has no intention to harm the organisation. In these cases, as part of the entry protocol, there is no breach in hospitality for safety, as visitors often expect an entry procedure. Visitors understand that such procedures are necessary to avoid risks, and the procedures induce a perception of safety. These procedures, in fact, add to the perception of 'inviting'. Entry procedures also add to a feeling of 'care', as it means that the organisation pays attention to you, 'sees' you, and acknowledges your presence. Whether it was a host or security staff did not seem to matter in our results.

The perception of 'caring' even compensates for rather strict entry protocols: a hospitable human approach softens the impact of rigid procedures, and safety and hospitality complement each other.

However, strict enforcement of protocols that ensure safety, without an understanding attitude, not only creates annoyance - so no feeling of inviting and caring-but also causes stress-no perceived comfort-and lack of understanding from the visitor and stimulates evasive tactics. The host or security employee now has to enforce procedures on an unwilling visitor, whereas a more understanding approach might have induced compliance in the visitor. In these cases, safety may be ensured, but the lack of hospitality leads to unwanted behaviour and stress in both visitor and host, leading to a negative evaluation of both hospitality and positive security.

No entry protocol also does not lead to the desired effect. Although there will be visitors who do not mind (or even enjoy the lack of security measures), quite a number of visitors will start to feel insecure, and become quite aware of the risks the organisation might be taking. A lack of procedures diminishes the perception of safety, also there is no perception of care, and both inviting and comfort feelings are compromised. Based on these reflections, we may conclude that in cases where visitors pose no real threat to an organisation, security measures carried out by (hospitality or security) staff that has a hospitable attitude will not be perceived as decreasing the hospitality of an organisation as the visitor will feel safe as well as treated in a hospitable way. Also, that perception of safety (and possibly also hospitality) might be added to the TEAM model, at or beyond the yoke level.

In some cases, hospitality and/or security staff were confronted with emotional visitors, who were or became frightened, angry and/or confused. In these cases, employees will need to perform emotional labour; the staff looks for support and the protocols provide assistance, but staff also face emotional labour. To perform their tasks well, and be as hospitable as possible given the circumstances, they need to stay calm and not respond with anger, fear, or confusion. In those cases, it is beneficial to provide human support to the host, e.g., by having both two members of staff present, preferably hospitality as well as security staff, as this will alleviate the anxiety of the person confronting the emotional visitor. Language plays a crucial role in under these circumstances, as without a common language, it is hard for people to understand each other. Lack of understanding will increase the feeling of not being safe and being in an inhospitable environment. However, a strong safety climate is a means to directly and indirectly, increase job satisfaction and staff engagement, and to reduce staff turnover [26].

So far, the cases in this exploratory study have shown that perception of hospitality and safety go very well together, asking for alignment of measures to ensure each of the two. However, it remains to be seen whether this still is the case in other situations, e.g., when either risk perception is very high, people feel rather unsafe, or in situations where hospitality needs to be very prominent, not to forget situations where people's behaviour is extreme, or when hospitality and security staff need to deal with crowds instead of individuals. 
For now, we conclude that within the positive security paradigm, safety and hospitality do act like two sides of the same coin, where one needs the other.

Author Contributions: Conceptualization, H.v.S. and B.G.; methodology, H.v.S.; software, not applicable; validation, H.v.S. and B.G.; formalanalysis, H.v.S. and B.G.; investigation, H.v.S. and B.G.; resources, H.v.S.; data curation, B.G.; writing-original draft preparation, H.v.S. and B.G.; writing-review and editing, H.v.S. and B.G.; visualization, H.v.S. and B.G.; supervision, B.G.; project administration, H.v.S. and B.G.; All authors have read and agreed to the published version of the manuscript.

Funding: This research received no external funding.

Institutional Review Board Statement: Not applicable.

Informed Consent Statement: Not applicable.

Data Availability Statement: Data are available on request from the corresponding author.

Acknowledgments: The authors thank Facilicom and all respondents.

Conflicts of Interest: The authors declare no conflict of interest.

\section{References}

1. Benveniste, E. Le Vocabulaire des Institutions Indo-Européennes, 1. Economie, Parenté, Société; Editions de Minuit: Paris, France, 1969.

2. Lashley, C.; Morrison, A. In Search of Hospitality: Theoretical Perspectives and Debates; Routledge: New York, NY, USA, 2011; ISBN 9780750654319.

3. Derrida, J.; Dufourmantelle, A. Of Hospitality; Stanford University Press: Stanford, CA, USA, 2000; ISBN 9780804734066.

4. Candea, M.; Da Col, G. The return to hospitality. J. R. Anthropol. Inst. 2012, 18, 1-19. [CrossRef]

5. Lynch, P.; Molz, J.G.; Mcintosh, A.; Lugosi, P.; Lashley, C. Theorizing hospitality. Hosp. Soc. 2011, 1, 3-24. [CrossRef]

6. Dikeç, M. Pera peras poros: Longings for spaces of hospitality. Theoryculture Soc. 2002, 19, 227-247. [CrossRef]

7. Burgess, J. Perspectives on gift exchange and hospitable behaviour. Int. J. Hosp. Manag. 1982, 1, 49-57. [CrossRef]

8. Brotherton, B.; Wood, R.C. (Eds.) . The SAGE Handbook of Hospitality Management; Sage Publications Ltd.: London, UK, 2008; pp. 37-61. ISBN 1412900255.

9. Hemmington, N. From Service to Experience: Understanding and defining the hospitality business. Serv. Ind. J. 2007, 27, 747-755. [CrossRef]

10. Clapp, J.; Ridge, E. Security and Hospitality in Literature and Culture: Modern and Contemporary Perspectives; Rouledge: New York, NY, USA, 2016; ISBN 9780367873516.

11. Lugosi, P. Hospitality and organizations: Enchantment, entrenchment and reconfiguration. Hosp. Soc. 2014, 4, 75-92. [CrossRef]

12. King, C.A. What is hospitality? Int. J. Hosp. Manag. 1995, 14, 219-234. [CrossRef]

13. Morrison, A.; O'Gorman, K. Hospitality Studies: Liberating the Power of the Mind. In Proceedings of the Council for Australian University Tourism and Hospitality Education (CAUTHE) 15th Annual Conference, Footscray, Australia, 9-12 February 2006.

14. Lugosi, P. Hospitality spaces, hospitable moments: Consumer encounters and affective experiences in commercial settings. J. Foodserv. 2008, 19, 139-149. [CrossRef]

15. Lugosi, P. The production of hospitable space: Commercial propositions and consumer co-creation in a bar operation. Space Cult. 2009, 12, 396-411. [CrossRef]

16. Broder, J.F.; Tucker, E. Risk Analysis and the Security Survey, 4th ed.; Elsevier: Waltham, MA, USA, 2012 ; ISBN 9780123822338.

17. Talbot, J.; Jakeman, M. Security Risk Management: Body of Knowledge; John Wiley and Sons: Hoboken, NJ, USA, 2009; ISBN 978-0-470-45462-6.

18. Fischer, R.J.; Halibozek, E.P.; Walters, D.C. Introduction to Security; Elsevier: Waltham, MA, USA, 2013 ; ISBN 9780123850577.

19. Schuilenburg, M.; Van Steden, R. Positieve Veiligheid, een inleiding. Tijdschr. Over Cult. En Crim. 2016, 6, 3-18. [CrossRef]

20. Schuilenburg, M.; Van Steden, R. Positive Security: A Theoretical Framework. In Positive Criminology: Reflections on Care, Belonging and Security; Schuilenburg, M.B., Van Steden, R., Oude Breuil, B., Eds.; Eleven: London, UK, 2014; pp. 19-32. ISBN 9789462364448.

21. Van Steden, R.; Hoogland, J. (Eds.) In Vertrouwen Leven: Tegendraadse Beschouwingen Over Veiligheid; Buijten \& Schipperheijn: Amsterdam, The Netherlands, 2013; ISBN 9789058817051.

22. Hoogensen Gjorv, B. Security by another name: Negative security, positive security, and a multi-actor security approach. Rev. Int. Stud. 2012, 38, 835-859. [CrossRef]

23. Line, M.B.; Nordland, O.; Rostad, L.; Tondel, I.A. Safety vs. Security? In Proceedings of the 8th International Conference on Probabilistic Safety Assessment and Management, New Orleans, LN, USA, 14-18 May 2006.

24. Alli, B.O. Fundamental Principles of Occupational Health and Safety, 2nd ed.; International Labour Office: Geneva, Switzerland, 2008; ISBN 978-92-2-120454-1.

25. Zohar, D. Thirty years of safety climate research: Reflections and future directions. Accid. Anal. Prev. 2010, 42, 1517-1522. [CrossRef]

26. Guldenmund, F.W. The nature of safety culture: A review of theory and research. Saf. Sci. 2000, 34, 215-257. [CrossRef] 
27. Huang, Y.-H.; Lee, J.; McFadden, A.C.; Murhy, L.A.; Robertson, M.M.; Chueng, J.H.; Zohar, D. Beyond safety outcomes: An investigation of the impact of safety colimate on job satisfaction, employee engagement and turnover using social exchange theory as the theoretical framework. Appl. Ergon. 2015, 55, 248-257. [CrossRef] [PubMed]

28. Schein, E.; Schein, P. Organizational Culture and Leadership, 5th ed.; Wiley: Hoboken, NJ, USA, 2016; ISBN 9781119212041.

29. Vierendeels, G.; Reniers, G.; Van Nunen, K.; Ponnet, K. An integrative conceptual framework for safety culture: The Egg Aggregated Model (TEAM) of safety culture. Saf. Sci. 2018, 103, 323-339. [CrossRef]

30. Brunner-Sperdin, A.; Peters, M. What influences guests' emotions? The case of high-quality hotels. Int. J. Tour. Res. 2009, 11, 171-183. [CrossRef]

31. Berry, L.L.; Wall, E.A.; Carbone, L.P. Service clues and customer assessment of the service experience: Lessons from marketing. Acad. Manag. Perspect. 2006, 20, 43-57. [CrossRef]

32. Knutson, B.J.; Beck, J.A.; Kim, S.-H.; Cha, J. Identifying the dimensions of the experience construct. J. Hosp. Leis. Mark. 2007, 15, 31-48. [CrossRef]

33. Bitner, M.J. Servicescapes: The impact of physical surroundings on customers and employees. J. Mark. 1992, 56, 57-71. [CrossRef]

34. Siguaw, J.A.; Mai, E.; Wagner, J.A. Expanding Servicescape Dimensions with Safety: An Exploratory Study. Serv. Mark. Q. 2019. [CrossRef]

35. Pijls, R.; Groen, B.H.; Galetzka, M.; Pruyn, A.T.H. Measuring the experience of hospitality: Scale development and validation. Int. J. Hosp. Manag. 2017, 67, 125-133. [CrossRef]

36. Ariffin, A.A.M.; Maghzi, A. A preliminary study on customer expectations of hotel hospitality: Influences of personal and hotel factors. Int. J. Hosp. Manag. 2012, 31, 191-198. [CrossRef]

37. Blain, M.; Lashley, C. Hospitableness: The new service metaphor? Developing an instrument for measuring hosting. Res. Hosp. Manag. 2014, 4, 1-8. [CrossRef]

38. Telfer, E. The philosophy of hospitableness. In In Search of Hospitality: Theoretical Perspectives and Debates; Lashley, C., Morrison, A., Eds.; Butterworth-Heinemann: Oxford, UK, 2000; pp. 38-55. ISBN 9780750654319.

39. Sim, J.; Mak, B.; Jones, D. A model of customer satisfaction and retention for hotels. J. Qual. Assur. Hosp. Tour. 2006, 7, 1-23. [CrossRef]

40. Tasci, A.D.A.; Semrad, K.J. Developing a scale of hospitableness: A tale of two worlds. Int. J. Hosp. Manag. 2016, 53, 30-41. [CrossRef]

41. Groen, B.H. Contribution of facility to hospital(ity) issues. In Proceedings of the 13th EuroFM Research Symposium, Berlin, Germany, 4-6 June 2014; pp. 129-138.

42. Bigo, D. International Political Sociology. In Security Studies: An Introduction; Williams, P.D., Ed.; Routledge: Abingdon, UK, 2008; pp. 116-129. ISBN 0-203-92660-9.

43. Akalin, N.; Kristoffersson, A.; Loutfi, A. Evaluating the Sense of Safety and Security in Human-Robot I nteraction with Older People. In Social Robots: Technological, Societal and Ethical Aspects of Human-Robot Interaction; Korn, O., Ed.; Springer: Cham, Switzerland, 2019; pp. 237-264. ISBN 978-3-030-17107-0.

44. Pijls, R.; Groen, B.H.; Galetzka, M.; Pruyn, A.T.H. Images of hospitality: Validation of experiential dimensions. In Proceedings of the EuroCHRIE Conference 2016, Budapest, Hungary, 26-29 October 2016.

45. Schreck, C.J.; Miller, J.M. Sources of fear of crime at school: What is the relative contribution of disorder, individual characteristics, and school security? J. Sch. Violence 2003, 2, 57-79. [CrossRef]

46. Perumean-Chaney, S.E.; Sutton, L.M. Students and Perceived School Safety: The Impact of School Security Measures. Am. J. Crim. Justice 2013, 38, 570-588. [CrossRef]

47. Kyttä, M.; Kuoppa, J.; Hirvonen, J.; Ahmadi, E.; Tzoulas, T. Perceived safety of the retrofit neighborhood: A location-based approach. Urban Des. Int. 2013, 19, 311-328. [CrossRef]

48. Katchamart, A. Adaption between FM Product and Process. In Facilities Management Models, Methods and Tools; Jensen, P.A., Ed.; Routledge: New York, NY, USA, 2019; Chapter B26; ISBN 9780367028725.

49. Haywood, K.M. Assessing the quality of hospitality services. Int. J. Hosp. Manag. 1983, 2, 165-177. [CrossRef]

50. Hepple, J.; Kipps, M.; Thomson, J. The concept of hospitality and an evaluation of its applicability to the experience of hospital patients. Int. J. Hosp. Manag. 1990, 9, 305-318. [CrossRef]

51. Pijls-Hoekstra, R. Are You Feeling Served? The Embodied Experience of Hospitality in Service Environments. Ph.D. Thesis, Twente University, Enschede, The Netherlands, 2020. [CrossRef]

52. Hochschild, A. Emotion work, feeling rules, and social structure. Am. J. Sociol. 1979, 85, 551-575. [CrossRef]

53. Hur, W.M.; Moon, T.W.; Han, S.J. The effect of customer incivility on service employees' customer orientation through doublemediation of surface acting and emotional exhaustion. J. Serv. Theory Pract. 2015, 25, 394-413. [CrossRef] 


\title{
Searching for Flexibility in Corporate Real Estate Portfolio: Six Co-Working Strategies for User Corporations
}

\author{
Natalia Echeverri, Tuuli Jylhä * and Philip Koppels \\ Department of Management in the Built Environment, Delft University of Technology, 2628 CD Delft, \\ The Netherlands; nataliaecheverriag@gmail.com (N.E.); ph.w.koppels@gmail.com (P.K.) \\ * Correspondence: T.E.Jylha@tudelft.nl
}

check for updates

Citation: Echeverri, N.; Jylhä, T.; Koppels, P. Searching for Flexibility in Corporate Real Estate Portfolio: Six Co-Working Strategies for User Corporations. Buildings 2021, 11, 115. https://doi.org/10.3390/

buildings 11030115

Academic Editor: Per Anker Jensen

Received: 29 January 2021

Accepted: 8 March 2021

Published: 14 March 2021

Publisher's Note: MDPI stays neutral with regard to jurisdictional claims in published maps and institutional affiliations.

Copyright: (c) 2021 by the authors. Licensee MDPI, Basel, Switzerland. This article is an open access article distributed under the terms and conditions of the Creative Commons Attribution (CC BY) license (https:// creativecommons.org/licenses/by/ $4.0 /)$.

\begin{abstract}
The increasing competitive pressures and dynamic user preferences have resulted in a fast-paced and uncertain business environment. In the face of these circumstances, organizations are looking into alternatives to incorporate flexibility to become more adaptive and responsive to change. In this line, co-working, typically associated with freelancers, entrepreneurs, and startups, has become a particularly interesting alternative in the market that has caught the attention of corporate occupiers. Therefore, the aim of this paper is to identify co-working strategies that can be implemented as part of the corporate real estate portfolio, in alignment with the flexibility demands of the organization. This nascent research topic is studied through 5 qualitative case studies including in-depth, semistructured interviews with corporate real estate managers and related case documentation. The results evidence the different motivations that the organizations have when incorporating co-working in their property portfolio. As seen across the cases, organizations in different stages of maturity are implementing co-working as the main office location or as a temporary or complementary space solution, through six different strategies: (1) Swing Space, (2) Expansion Space, (3) Core and Flex, (4) Touchdown Space, (5) Testing Market, and (6) Temporary Projects and Staff. This research evidences that each strategy plays a specific role in the corporate real estate portfolio and implies different sources of flexibility that support the physical, functional, and financial flexibility demands of the organization.
\end{abstract}

Keywords: co-working; co-working strategy; flexibility; corporate real estate; case study

\section{Introduction}

Changes in society, technology, and economy have resulted in a dynamic and fastpaced business environment in which organizations operate. The increased competition and uncertainty in business operations have resulted in a growing demand for greater effectiveness and efficiency in the use of resources to support the overall business competitive strategy [1]. In the face of volatile conditions and external shocks that impact the capital markets-as seen in the COVID-19 pandemic-organizations are adopting different practices that overturn the rigidity of previous production systems to become more responsive and agile to change [2]. In this line, the far-seeing companies, that have realized the powerful strategic value of real estate (RE), are increasingly demanding flexibility in their portfolio as a means to embrace change and support the evolving needs of the organization under conditions of uncertainty, while remaining responsive and competitive [3].

Parallel to this, with the development of mobile technologies and improved network connections that have expanded the traditional boundaries of the workplace [4], today's knowledge workforce is increasingly demanding flexibility to choose when and where to work [3-5], this has been recognized by some authors as fundamental to support their work-life balance and increase their job satisfaction and engagement $[3,6]$.

As a result of these changing preferences and increased competitive pressures, the property market has responded with a growing array of property products that provide choice and flexibility to organizations and workers. Within this wide range of options, 
co-working spaces are of particular interest due to its exponential growth in the last years. With more than 22,000 spaces and 2,000,000 members worldwide, Deskmag [7] concludes that the number of co-working spaces around the world has almost doubled since 2016. Co-working has been seen as a workplace alternative, where the freedom and flexibility of independent working is combined with the structure and community aspects of traditional office environments [8-11]. Kyrö [12] suggests that the co-location of a variety of tenants and the resource sharing inherent to co-working is an important approach towards the circular economy in the context of the existing building stock; this contributes to maximizing the functional use of buildings and adapting the physical space to changing technological, organizational, and aesthetic priorities. Along the same lines, Brinkø [13] suggests that the shared use of space is a more efficient and sustainable method for the operation of buildings, which makes co-working an interesting real estate alternative for corporate users.

Co-working has recently become a widespread phenomenon, typically associated with freelancers, entrepreneurs, and independent workers [7,10]; but, as the concept of co-working has evolved and adapted throughout the years, the variety of services and workspace products offered, which range from shared desks, dedicated desks, private offices, meeting rooms, and open-plan areas [14], have caught the attention of corporate occupiers that have started to consider the possibilities offered by this service as part of a range of solutions for their corporate RE portfolio. However, despite the rapid growth and increasing popularity of co-working, research concerning the implementation of this model as part of corporate RE portfolio is still scarce.

As co-working continues to grow in the market and companies start incorporating it as part of a wide range of options in their RE portfolio, understanding what co-working provides in terms of flexibility and how it can be implemented to align with the requirements of the organization, becomes essential; this information is fundamental to create a more comprehensive view of this rather new phenomenon, and can assist the decision-makers of the organizations to take informed decisions about their real estate strategies. In this line, the aim of this paper is to identify the different motivations and approaches that organizations have towards implementing co-working within their corporate RE portfolio, and their alignment with the flexibility demands of the organization.

Accordingly, this paper is structured in six parts. After the introduction, the second section presents a review of the main concepts of the study, namely flexibility and coworking, according to theory. Consecutively, the third section is dedicated to explain the research methods, the fourth section presents the main results of the study, and the fifth section discusses the main findings and limitations of the research. Finally, the sixth section draws the final conclusions of the paper.

\section{Literature Review}

\subsection{Definition of the Co-Working Concept}

According to literature, co-working is defined as a type of multi-tenant office, with a high level of service, where a diverse group of individuals with more or less heterogeneous backgrounds share a "community work environment" on the basis of a membership that grants access to multiple services and facilities [11,15-17]. Although there are significant differences, both in terms of space and service offerings, across the different operators, Sankari, Peltokorpi, and Nenonen [18] defined five common characteristics, namely: Community, space-as-a-service, multipurpose office, high accessibility, and attractive workplace, which provide an idea of the core features that define the co-working concept.

As seen in literature, co-working is characterized by creating a sense of community that leverages the synergies of interaction, informal encounters, and knowledge sharing [16,19-24]; in this, the community managers play a fundamental role to build trust and facilitate the connections between the members [11]. According to Jakonen et al. [25], the value of co-working does not lie in the desk offered, but rather in the social aspects related to community, sharing, and collaboration. In this line, Capdevila $[8,26]$ has referred 
to co-working spaces as microclusters where the diversity and complementarity of the members creates synergies for value creation, innovation, and cross-pollination of different bodies of knowledge. In this perspective, the community attribute is a valuable asset from which learning and collaborations can emerge. Additionally, within the community environment, as suggested by Kyrö [12], the co-location of a variety of tenants and the resource sharing typical of co-working play a fundamental role in the efficient use of the space. As defined in the typology of sharing framework of Brinkø [13], the level of interaction and collaboration seen at the organizational level is related to the nature of the space sharing-determined by what, when, and how the space is shared —which in turn results in a more sustainable building operation.

In relation to the space-as-a-service characteristic, co-working is typically offered on a membership basis that grants access to a physical, social, and virtual work environment for a determined period of time on an hourly, weekly, monthly, or yearly basis [15-17,27-30]. The physical space offered is supplemented with additional user-centric value offerings, such as community events; personal programs; and work related services-that aim at delivering a high-quality workplace experience. This is aligned with what Danivska [31] referred to as the "servitization of the workplace": A concept that emphasizes the employeecentric bottom-up approach to workplace management, where users and organizations have the flexibility to pay for the use of different service packages on a short-term basis. According to Kyrö [12], this represents a paradigm shift in real estate where access over ownership is promoted and service-based systems combine tangible products-the physical space-with intangible services.

Co-working spaces are usually Activity-Based-Working (ABW) environments that offer a combination of spaces for shared, informal, quiet, concentrated, or confidential work [23], that aim at catering to a variety of user preferences [16,18,21,24,32]. As found by Palvalin, Van der Voordt, and Jylhä [33], workplaces that support concentration, communication, and self-management practices have an impact on individual and team productivity.

Multiple authors highlight the accessibility of co-working both in terms of location, usually in central urban areas or close to transportation hubs, and opening times, typically open $24 / 7$ [16,18,24,27,29,34,35]. As mentioned by Sankari [16] and Spreitzer et al. [23], flexible opening hours give members the freedom to choose the work schedules that best fit their agendas. Yu et al. [17] argue that the workplace accessibility offered in co-working has a significant impact on the environment, economy, and urban planning; by cutting commuting times and sharing facilities, co-working has the potential to reduce traffic congestion, pollution, and $\mathrm{CO}_{2}$ emissions.

According to the literature, co-working spaces aim at delivering attractive workplaces with high-level service packages that are increasingly focused on user experience; more and more value offerings are evolving towards the hospitality industry $[16,19,24,36]$. Operators are often incorporating personal services to attract users, which include wellness programs and transportation services, amongst others (dry-cleaning, florist, package handling, etc.) $[34,37,38]$. Kojo and Nenonen [21] stated that co-working is aligned with the workplace transformation, where the social aspects of work are increasingly more relevant than in the past.

Identifying these core characteristics of co-working provides a fundamental guide to understand the potential of this workplace model in corporate RE and define possible approaches that organizations can pursue according to their business requirements.

\subsection{Multiple Flexibility Demands in Corporate Real Estate}

Flexibility is a multifaceted concept that has different meanings for different actors. As evidenced by Shreidan and Conway [39], flexibility in the business context emphasizes an increase in efficiency and decrease in costs; while flexibility in the work practice context usually refers to arrangements that provide the workers autonomy and control to carry out their work and enable them to balance personal and work responsibilities. 
In this line, many authors have stated that, in the business context, flexibility refers to organizations becoming more agile and receptive to change as a response to the increasing pressures of the uncertain business environment of today $[2,3,25,40,41]$. As organizations seek a plethora of routes to become responsive to the changes in the external environment, the flexibility of the physical resources has become paramount. However, the challenge lies in the fact that real estate has typically been defined as an inherently inflexible asset [42] that is static, immovable, large, complex, and expensive [42,43].

Gibson and Lizieri [44] identified three flexibility demands in the corporate real estate portfolio, namely: Physical, functional, and financial that are required for the different parts of the RE portfolio-whether it is core facilities acquired in the long-term, or short-term arrangements for complementary or temporary spaces. In relation to physical flexibility, numerous authors have highlighted the increasing demand for spaces that have the capacity to accommodate changing organizational space requirements $[37,42,44,45]$, this includes the adaptability of the building's structural and technical systems [46] as well as the location of the office space to adjust to the employees' requirements and limit the time spent commuting to a central office.

In relation to functional flexibility, corporations have expressed their requirement for workplaces that can accommodate a more dynamic range of uses, first, in terms of the type of activities and second, in terms of the intensity of use of the space $[44,47,48]$. With this, organizations are looking for strategies that allow them to make a more efficient use of space according to their particular needs, by for instance introducing Activity-Based-Working (ABW) environments [49] to support multiple activities and workstyles of the different users $[21,50]$. In relation to financial flexibility, organizations are looking for methods to manage the financial risks and exposures associated with real estate decisions as a response to uncertainty [44,51]; this is mainly related to shortening the length of lease arrangements to match the fixed leased space with the needs of the organization [28,52,53]; and second, diversifying the portfolio with different options available in the market to spread the risk of real estate commitments [1,54-56].

In this same line, an extensive body of literature has acknowledged the increasing flexibility demands of the knowledge workers for having the freedom to choose when, where, and how to work [41,57-59]. Recent studies by Eurofound [58] have evidenced that although working time demands vary throughout the life course, the majority of the workers have a strong preference for having control over their working schedules, this often means variation in starting and finishing working hours (flexitime), the possibility of taking hours off work, and choosing when to dedicate time for personal or work-related activities [41,60]. Similarly, previous studies by Eurofound [57] have shown that, with the increasing accessibility to technological developments and ICT advancements that have made work more portable, workers are in favor of deciding where to work, as a way of reconciling activities of their professional and private life, and limiting the constant interruptions by colleagues. Additionally, researchers, organizations, and workers are recognizing the importance of diversity in workplace settings to cater to a variety of user preferences $[38,45,50,61]$; instead of being fixed to a desk for eight hours a day, employees want the freedom to choose, throughout the day, the type of setting that matches their tasks and work activities $[49,50]$. Literature suggests that catering to the flexibility demands of the workers is positively related to job satisfaction, labor productivity, and performance, and negatively related to turnover intent and job search behaviors $[62,63]$.

As seen in literature, the demand for flexibility examined from the lens of corporate real estate and the knowledge workers of the organization can be defined in three main categories: Physical, functional, and financial. These dimensions of flexibility are key on both levels, individual and corporate; Sheridan and Conway [39], Harris [3], and Ruhle and Süß [64] have highlighted the importance of recognizing and balancing the different flexibility demands in an effort to construct alternatives that are mutually satisfying and advantageous for individuals and organizations. 
Figure 1 summarizes the main concepts of this research; according to the co-working provider characteristics and sharing opportunities, and the organization's flexibility demands and property portfolio layers.

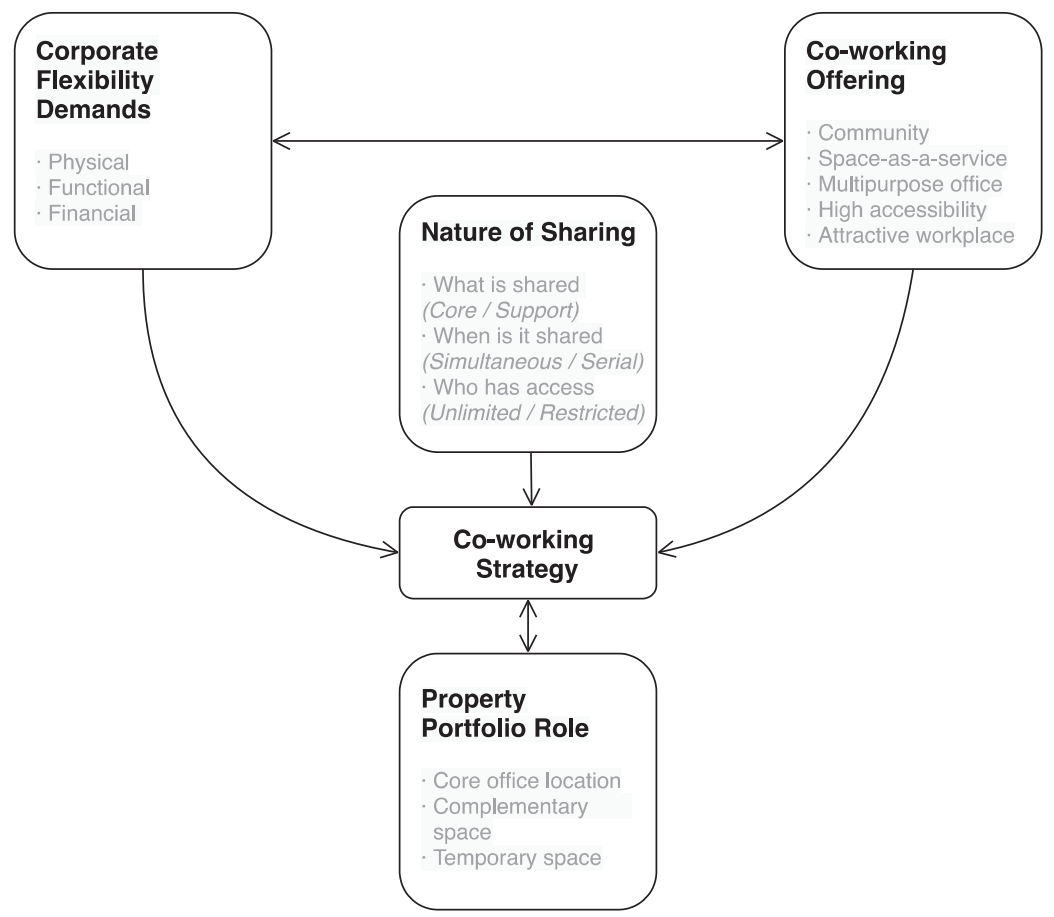

Figure 1. Summary of findings from literature.

\section{Research Methods}

Qualitative research offers a powerful approach to study management and business related topics; it provides an in-depth understanding and contributes in business performance improvements [65]. This research is exploratory by its nature, which implies, according to Edmondson and McManus [66], that rich and detailed data is needed to understand the relatively nascent research topic-the use of co-working services as part of the RE portfolio of larger user organization-and to contribute in theory building by presenting a new suggestive classification and invitation for further investigation.

This qualitative research follows the multiple-case study approach [67] with singleunit analysis. In each case, the motivations and approaches to use co-working as part of the corporate RE portfolio were studied through exploratory interviews ( 1 interview per case) and related documentation, such as plans, strategy reports, and corporate announcements. The in-depth, semi-structured interviews were conducted with corporate real estate managers including three themes: Co-working in general; co-working and its flexibility benefits for the corporation; and co-working as part of the corporate RE portfolio. Each interview lasted approximately $1 \mathrm{~h}$, and they were transcribed and afterwards analyzed and coded in Atlas.ti. A combination of theory- and data-driven analysis was followed, starting with the deduction from theory as proposed by Tuomi and Sarajärvi [68].

The multiple cases were not selected to predict similar results, but following Yin [67], to predict "contracting results but for anticipatable reasons". Therefore, a purposive selection of the cases covers a variety of motivations and approaches that organizations have towards implementing co-working within their corporate RE portfolio. The selection criteria are 
based on the concepts defined in the theoretical framework and divided into two: Required criteria, meaning all the cases must have it; and desired criteria, meaning that at least one of the cases has to meet this criterion. Table 1 provides an overview of the selected cases in relation to the 8 parameters defined.

Table 1. Case study selection criteria.

\begin{tabular}{|c|c|c|c|c|c|c|c|}
\hline & Selection Criteria & Motivation & A & B & $\mathrm{C}$ & D & $\mathbf{E}$ \\
\hline \multirow{4}{*}{ 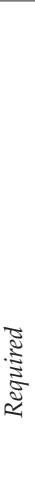 } & $\begin{array}{l}\text { 1. The organization is using } \\
\text { co-working as part of its } \\
\text { accommodation strategy }\end{array}$ & $\begin{array}{l}\text { Focusing on front-runner organizations that have adopted } \\
\text { co-working (either moderately or substantially), provides } \\
\text { significant insights into the main aspects of this research }\end{array}$ & $x$ & $x$ & $x$ & $x$ & $x$ \\
\hline & $\begin{array}{l}\text { 2. The users are knowledge } \\
\text { workers employed within the } \\
\text { company }\end{array}$ & $\begin{array}{l}\text { Ensuring that the co-working spaces are used by at least } \\
\text { part of the employees of the company, rather than only by } \\
\text { outsourced labor, enables a comprehensive understanding } \\
\text { of the effects of the program in the organization. }\end{array}$ & $x$ & $x$ & $x$ & $x$ & $x$ \\
\hline & $\begin{array}{l}\text { 3. The workers involved in } \\
\text { co-working belong to a } \\
\text { knowledge intensive fields }\end{array}$ & $\begin{array}{l}\text { Ensuring that the users involved in the program work in a } \\
\text { knowledge intensive field, enable the comparability of the } \\
\text { findings with the theoretical framework }\end{array}$ & $x$ & $x$ & $x$ & $X$ & $x$ \\
\hline & $\begin{array}{l}\text { 4. The organization is located in } \\
\text { the Netherlands }\end{array}$ & $\begin{array}{l}\text { Facilitating the process of data gathering and allowing the } \\
\text { comparability of the findings as they are embedded in the } \\
\text { political, economic and social characteristics of the Dutch } \\
\text { context. }\end{array}$ & $x$ & $x$ & $x$ & $x$ & $x$ \\
\hline \multirow{4}{*}{$\begin{array}{l}\overparen{\Xi} \\
\stackrel{\Xi}{\tilde{D}} \\
\stackrel{0}{0}\end{array}$} & $\begin{array}{l}\text { 5. Co-working space offers } \\
\text { multiple locations }\end{array}$ & $\begin{array}{l}\text { Ensuring that the organization is working with co-working } \\
\text { operators that have more than one location available, is } \\
\text { important as it covers the locational flexibility aspects } \\
\text { previously defined. }\end{array}$ & $x$ & $x$ & & $x$ & $x$ \\
\hline & $\begin{array}{l}\text { 6. Co-working space has an } \\
\text { extended opening schedule }\end{array}$ & $\begin{array}{l}\text { Ensuring that at least one organization is working with } \\
\text { co-working spaces that have an extended opening schedule } \\
\text { is important to cover the previously identified time } \\
\text { flexibility demand of the knowledge workers. }\end{array}$ & $x$ & $x$ & $x$ & $x$ & $x$ \\
\hline & $\begin{array}{l}\text { 7. Co-working space offers } \\
\text { varied working settings for } \\
\text { different activities }\end{array}$ & $\begin{array}{l}\text { Ensuring that at least one organization is using a } \\
\text { co-working space that offers different settings for varied } \\
\text { activities (concentration, informal conversation, individual } \\
\text { work, collaborative work, etc.) is important to cover the } \\
\text { previously identified functional flexibility demands of the } \\
\text { organization. }\end{array}$ & $x$ & $x$ & $x$ & $x$ & $x$ \\
\hline & $\begin{array}{l}\text { 8. Access to the co-working } \\
\text { space in a short-term basis }\end{array}$ & $\begin{array}{l}\text { Ensuring that at least one organization has short-term } \\
\text { commitments (less than one year) with the co-working } \\
\text { operator is important to cover the financial flexibility } \\
\text { demands of the organization. }\end{array}$ & $x$ & $x$ & $x$ & $x$ & $x$ \\
\hline
\end{tabular}

\section{Description of Case Studies}

Case A-Transportation Company: Innovative tech company from the transportation industry, currently undergoing one of the tech industry's fastest global expansions. Since establishing its operations in the Netherlands, the organization has been using co-working spaces in different ways to support the development of the company.

Case B-Communications Agency: Expanding creative firm from the PR and communications industry. The company started its operations in 2009, based at a co-working space in Amsterdam. After 10 years of being headquartered at a co-working space, the company has recently moved to its own office location.

Case C-Consumer Goods Company: Leading multinational company from the fastmoving consumer goods (FMCG) industry. With a presence in over 190 countries and about 150,000 employees around the globe, the company, one of the oldest in the industry, has been regarded as one of the top employers across the world. As a front-runner organization, the company has taken a first important move towards incorporating co-working as a 
complementary accommodation strategy in one of its locations, wherein about $30 \%$ of the workforce will be located at a co-working space.

Case D-Energy Company: Multinational company from the energy industry, listed as one of the top corporations in the Fortune Global 500 ranking of 2019 [69]. The energy company is a leading corporation with a large real estate portfolio composed of core facilities, owned by the organization, and supplementary facilities, typically leased in the mid and short-terms. As an innovative organization, the company has started to adopt coworking as part of the accommodation strategy in certain locations across the EMEA region to diversify the real estate portfolio and provide versatility to cope with the business needs.

Case E-Entertainment Company: Multinational media-services and production company, leader in the entertainment industry. The company is listed as one of the top regarded companies and world's best employers across the globe [70,71]. As a fast-paced and dynamic organization, the company has been expanding its operations in the EMEA region, in this process, the company has used co-working as a temporary solution to start the operation in some of the new markets.

\section{Results}

\subsection{Case Analysis}

This section presents briefly the approaches of each case organization towards implementing co-working across their property portfolio. Table 2 presents a summary of the case studies; each color bar represents the main reason that motivated the organization to make use of co-working spaces.

\subsubsection{Case A}

Since establishing operations in the Netherlands, in 2012, co-working has become a strategic partner throughout the different stages of development of the business operation. In the early phases, when the company started operating in the Dutch market, co-working provided an ideal head office space for a team of 50 employees; the low initial investments and short-term lease agreements allowed the company to set-up the operation in the face of uncertain conditions inherent to new markets. The company experienced a fast business expansion: Within two and a half years, the headcount increased eight times and co-working supported this process by allowing the company to grow up to 400 employees while minimizing the interruptions of the operation. Later on, in 2017, with the projected expansion plans of the core business, the company relocated to their own headquarters in Amsterdam Zuid, and established a partnership with a large co-working operator to co-locate in the same building complex and provide the flexibility to gradually take up complementary space as the operation expanded over time-allowing the company to expand up to 1,000 employees. As stated by interviewee A, "The headcount for this type of companies is always a black hole, [ . . ] in a matter of two weeks or a month it can be practically twice as many people. So, I think that for these types of companies where growth from a business point of view is tangible, but it is still very difficult for the company at that time to relate for sure how much that growth represents in a space, or in a number of people, that kind of flexible space gives that benefit of reacting quickly to continue supporting the business and without generating a disruption of the operations".

With the increasing business growth and the introduction of new lines of service, the case organization A signed a lease to relocate its headquarters to a new office complex of $30,000 \mathrm{~m}^{2}$, where the company will have the capacity to scale up to 3,000 employees; during this process, in the next couple of years, about 600 employees will be temporarily located at a co-working space while the office relocation takes place. Throughout these different phases, the organization occupied private office spaces operated by the co-working provider and shared only support facilities, such as meeting rooms, restaurant, etc., with the rest of the members. 
Table 2. Summary of motivations and approaches to implementing co-working in each case study.

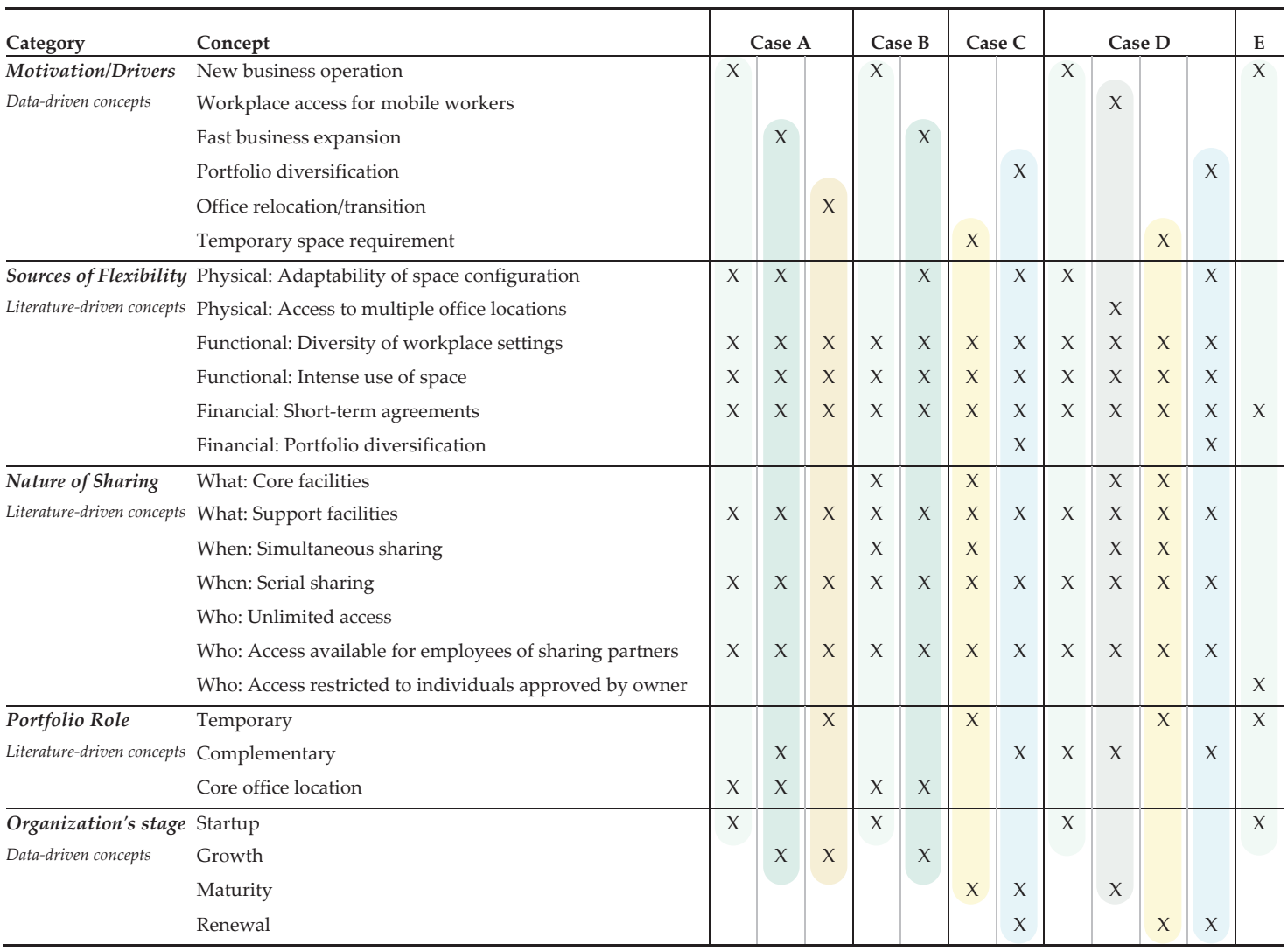

\subsubsection{Case B}

As an independent entrepreneurial project in 2009, initially, the organization started as a satellite desk at a co-working space with shared facilities; the low initial investments, the community environment with networking opportunities, as well as the centrality of the location, provided an optimal environment to start the business operation. As highlighted by interviewee B "Co-working spaces can really help small service businesses establish themselves to be able to operate and service clients, it is great for networking and being part of a community of like-minded individuals and teams where you can connect and bounce ideas off one another". Over time, as the case organization B grew and the team expanded, the firm relocated to a private office space offered by a co-working provider, and this allowed the organization to scale up without disrupting the core business. In 2019, the case organization was restructured and rebranded, and after 10 years of being headquartered at a co-working space, the company decided to relocate its team of 20 employees to their own office space in Amsterdam Oud-Zuid.

\subsubsection{Case C}

Over the years, the case organization $\mathrm{C}$ has sporadically used co-working as a temporary space solution for short-term projects or to accommodate temporary staff. However, in the last years, due to changes in the market that affected the business operation, one of the European branches of the organization was restructured; these changes implied the reduction of the headcount by over $40 \%$-from 1150 to about 700 employees. With the 
pressing need to exit the long-term commitment of the previous $24,000 \mathrm{~m}^{2}$ of office space occupied, the organization decided to diversify the real estate portfolio by relocating and downsizing the main office area to about $6500 \mathrm{~m}^{2}$ and complementing that space with a short-term lease agreement of two years with a co-working operator. In this strategy, the main office building has the capacity to house about 500 employees, while the co-working operator provides a private space with 200 desks and shared support facilities that include meeting rooms, lounges, reception, amongst others; with this, the employees have the possibility of choosing on a daily basis whether they prefer to work at the head office or at the co-working space, depending on their personal needs, activities, and schedules. This dual structure provides versatility to cope with changes in the headcount as experienced in the past by the company, and provides a more collaborative and dynamic business environment for the workforce. As mentioned by Interviewee C "The organization is in a constant state of transformation and the business finds it very hard to project beyond just the next three years, what the headcount will look like, or what the needs of the organization and employees will be. [ ... ] the nice thing is that it gives us this flexibility in the future, should we not need so much space, then we can simply terminate part or all of these serviced office desks. So, flexibility is really important in the company at the moment, and that's one of the things that you get with serviced offices that you cannot get with a traditional office".

\subsubsection{Case D}

The case organization $\mathrm{D}$ has been using co-working over the years as a temporary space solution for short-term projects, to support mobile workers outside the traditional corporate boundaries, or when starting business operations in new markets. However, recently, the company has started to consider co-working as a suitable strategy to diversify the real estate portfolio and provide versatility to cope with any future changes in the business operation. As mentioned by interviewee D, "One or two years ago we saw serviced offices really like a flexible layer for where we would enter a new country, for example, or we had a project which was very temporary and we just rented some spaces in a co-working space. But now, especially what we proved with some offices globally, is that it can also be seen as part of your leased portfolio." With this, in 2019, the company took an important step, wherein a team of about 200 employees was relocated to a co-working space for the next couple of years. This complementary strategy allows the organization to align the office space with the changes in the headcount according to the business requirements.

\subsubsection{Case E}

In 2015, the case organization E established its European headquarters in Amsterdam; with the continuous growth of the company, particularly in the EMEA region, the organization has started operations in five European cities over the course of the last year and a half. Through the on-going fast-paced expansion plans in new markets, the company has used co-working spaces as a temporary solution, for about three to six months, to start the operations in some of these new locations. The company mainly uses co-working due to the availability of short-term lease agreements. In this strategy, the company typically occupies a private office space and creates its own meeting rooms and amenities, which are not shared with the other tenants; in this case, the community aspect of co-working is not a relevant factor for the company as it only represents a temporary space solution. As reflected by interviewee E, "We use it (co-working) in an enterprise way, so we take out short-term leases with all the amenities, but we always take our own space. We are not working together in the same space as other companies [ ... ] we don't share the common areas, we even build our own meeting rooms and we also build our own café area. So, we mainly use them for the space and flexibility in the short-term, and then we do our fit-out." 


\subsection{Cross-Case Analysis}

Based on the case studies, it is possible to identify patterns and assess the similarities and differences across the cases. A summary of the cross-case analysis (presented in Table 3) identifies six co-working strategies that the case organizations in different stages of maturity have pursued to implement co-working within their property portfolio in alignment with their flexibility demands. Each strategy emerges from the six identified motivations that the organizations have to implement co-working, as seen in the table, each strategy plays a different role in the corporate RE portfolio, implying different sources of flexibility and involving varied advantages and implementation barriers that organizations have to consider.

Table 3. Summary of identified co-working strategies in corporate real estate.

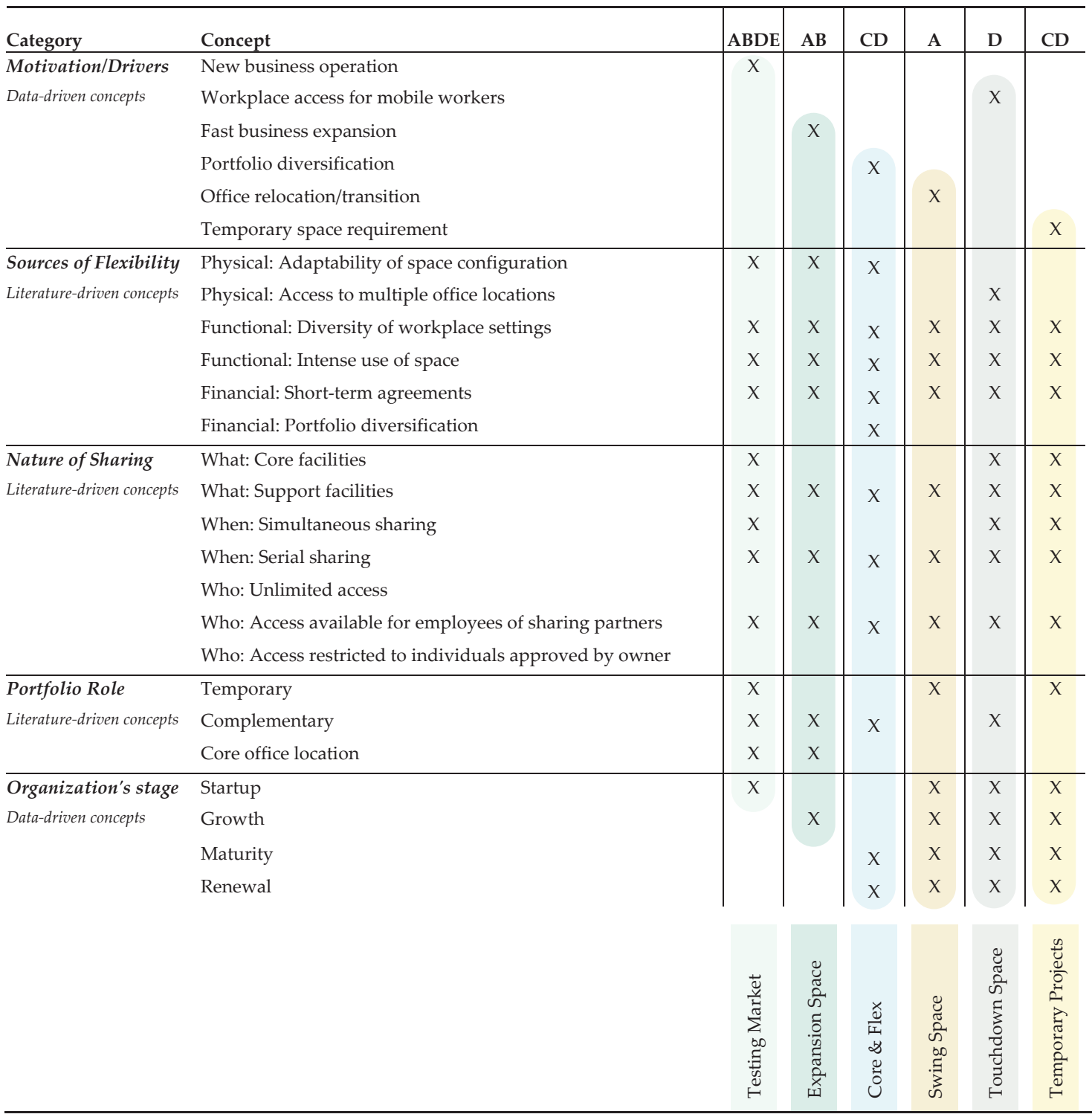




\subsubsection{Testing Market Strategy}

Initially, in the startup phase, with the high degree of uncertainty over the future of the business operation, co-working is mainly used as a strategy for testing the market. As seen in the cases A, B, and E, co-working is used by organizations starting operations or opening new business lines; the services and amenities provided, the adaptability of the space, the low entry-barriers, the speed-to-market and short-term commitments are particularly attractive to set up a business operation at a low risk. In this stage, the networking opportunities offered by co-working are fundamental to support the development of the company and open potential collaborations at the business-to-business level. As a Testing Market strategy co-working can play different roles in the real estate portfolio of the organization, either as the core office location, as a complementary solution, or as a temporary location, with core or support facilities shared, the main premise is that it emphasizes on providing the physical and financial flexibility that reduces the risks and uncertainties inherent to establishing new business operations.

\subsubsection{Expansion Space Strategy}

As companies move to the growth phase, accurate projections about the headcount and future space requirements of the organization become difficult to estimate, with this, as seen in the cases A and B, co-working is used by some organizations to support the fast business expansion. In this strategy, co-working can be used as the main office location, or as complementary space, the main premise is that it allows the company to take up space incrementally according to the needs of the core business; thus, providing physical flexibility in terms extending the office space. As an expansion space strategy co-working buffers the volatility of the headcount and the uncertainty over the space demands. With the pressing need to respond to the core business demands, co-working as an Expansion Space strategy provides the speed-to-market necessary to support the business growth, and the financial flexibility through short-term commitments that allow the organization to access space in a shorter period of time as compared to traditional leases. As seen in the cases A and B, this strategy is implemented by occupying private offices at the co-working space and limiting the interaction with the other members to shared support facilities.

\subsubsection{Core \& Flex Strategy}

During the maturity and renewal phases, as business projections become more accurate, organizations look for alternatives to diversify their property portfolio, and with this, co-working is mostly used in a core and flex strategy. As seen in cases C and D, co-working is used as a complementary space in combination with a core location; this dual strategy is composed by a long-term agreement for the core space and a short-term lease with a co-working operator. This strategy provides additional flexibility in the portfolio to buffer any changes in the business environment, and provides an alternative platform out of the traditional corporate setting to bring new ideas to the organization. As a core and flex strategy, co-working allows the case organizations $\mathrm{C}$ and $\mathrm{D}$ to reconfigure the real estate resources-by expanding or contracting the footprint-according to the needs of the company with minimum impact in the business operation; the adaptability of the space configuration, as well as the short-term commitments, cater to the physical and financial flexibility demands of the organization.

\subsubsection{Swing Space Strategy}

As seen in case A, co-working was used as a temporary space solution to relocate a team and continue the business operation while the renovation or construction of a new office space is being carried out. In this strategy, co-working mainly represents a bridge between the existing and the new work environment. The strategy facilitates the continuous operation of the business and provides a professional business environment for all types of knowledge workers by offering functional flexibility through a variety of workplace settings that cater to the different user preferences and financial flexibility in 
terms of short-term contractual agreements - that vary from a week, up to 6 months, or even a year in the most extreme cases-that offer a temporary solution to support the business operation.

\subsubsection{Touchdown Space Strategy}

As seen in case D, co-working was often used as a touchdown space that provides a professional work environment and a network of locations-locally and internationallythat are particularly relevant to support mobile workers that are constantly outside of the traditional corporate premises; for instance, managers, sales teams, employees travelling for business, etc. As a Touchdown Space strategy, co-working facilitates the work of satellite workers that require facilities and services to connect remotely to their digital workplaces and databases, in this, co-working plays an important role in offering physical flexibility through accessible locations that can potentially reduce the commuting time of the workers and indirectly contribute to productivity gains. In this strategy, the degree of sharing with the co-working community is the highest as the workers typically use flex-desks in combination with shared support facilities.

\subsubsection{Temporary Projects/Staff Strategy}

As in cases C and D, co-working is used as a temporary space solution to accommodate staff-internal or external to the organization-for a determined period of time, to work on particular projects or tasks. This strategy emphasizes the financial flexibility provided that allows the organization to make use of the co-working facilities and services for a short-period of time without significant initial investments.

As identified in the cross-case analysis, there is a connection between the motivation to implement co-working and the organization's lifecycle stage. On the one hand, three of the six strategies relate to the stage of maturity of the organization and the level of uncertainty over the business operation, in this, for example, the Testing Market strategy is mainly implemented during the startup phase, the Expansion Space strategy in the growth phase, and the Core and Flex strategy in the maturity and renewal phases. While on the other hand, the three other strategies are implemented sporadically, regardless of the stage of maturity of the company: As Swing Space, as Touchdown Space for mobile workers, or for Temporary Projects or Staff. These strategies mainly represent a temporary or complementary solution acquired for really short periods of time (less than one year) or even acquired under a pay-per-use scheme-charged per hour, day, week, or month.

In the same line, it is possible to identify specific characteristics that differentiate each of the strategies. While the Testing Market strategy focuses on the financial flexibility and low entry-barriers provided to new organizations, the Expansion Space strategy emphasizes on the flexibility (in physical and financial terms) to extend the space occupied by the organization as the core business grows. While the Core and Flex strategy and the Touchdown Space strategy are typically implemented as complementary strategies in combination with a main office location, the difference lies in the fact that the former focuses on diversifying the property portfolio through support facilities, and the latter emphasizes the membership agreements that provide access to flexible desks across the globe. Additionally, regarding the temporary space solutions, it is possible to prove that the aspect that sets them apart is that the Swing Space strategy mainly provides a bridging space between the former and the new office location; while the Temporary Projects/Staff strategy focuses on providing either core or support facilities for a determined group of employees for a specific period of time.

\subsection{Other Co-Working Advantages across the Case Studies}

Beyond the flexibility provided, from the cross-case analysis, three main advantages have been associated with co-working in corporate RE, namely, enhancing employee satisfaction, enabling networking opportunities, and supporting environmental sustainability. In the case studies, these three advantages are mainly leveraged by organizations that 
implement a co-working strategy either as a core or complementary location, rather than only as a temporary portfolio solution.

First, as highlighted in case studies A, B, C, and D, the variety of workplace settings, attractive facilities, and services, as well as the possibilities of social interaction offered within the co-working community, are some of the factors that have been associated with contributing to enhance employee wellbeing and satisfaction. Second, as found in the case studies A, B, and C, the co-location of a variety of tenants and the curated community environment offered at co-working enables networking opportunities for the company and the employees to create connections that can be relevant at the personal or business levels. For companies in the startup phase, for instance the case organization B, the networking opportunities offered are fundamental to support the development of the company and open potential collaborations at the business-to-business level; while for mature organizations, such as the case organization $\mathrm{C}$, the interactions with members outside of the corporate environment is used as a tool for innovation, to bring new ideas to the business. Particularly, the case organization A considers that the networking opportunities enabled by co-working are important at the employee level, but are not seen as potentially significant at the company level. Last, co-working is associated with supporting environmental sustainability. This aspect relates, on one hand, to lowering the carbon footprint in relation to the high accessibility of co-working and multitude of locations available, which can reduce commuting times; and on the other hand, to resource sharing, inherent to co-working, which results in more efficient consumption of resources and reduced slack space.

\subsection{Co-Working Implementation Barriers across the Cases Studies}

The cross-case analysis shows that the case organizations have faced three main barriers when implementing a co-working strategy as part of their corporate real estate portfolio. First, as shown in the cases A, B, C, and E, the costs of the space are considerably high as the flexibility and services provided come at a premium. Co-working seems to be a cost-effective solution, particularly in the stages of the organization and for the parts of the portfolio where uncertainty is high and flexibility is fundamental. In this line, the analysis of the requirements of the organization in relation to the uncertainty of the business operation is fundamental to determine whether a co-working strategy is a suitable solution for the company; as indicated in case D, taking a total cost of ownership (TCO) approach in the decision-making process is fundamental to estimate the conditions under which co-working is an optimal strategy for the organization.

Second, the management style is a significant barrier for implementing a co-working strategy, particularly companies with a management style based on presence and control face difficulties with flexible workplace solutions. Instead, as indicated in cases A, C, D, and $\mathrm{E}$, focusing on managing by results, trusting the employees and encouraging their autonomy to take decisions and carry out their tasks is a more suitable approach to ensure the success of implementing co-working in the corporate RE portfolio.

Third, cases A, D, and E, have referred to the barrier of reflecting the company's culture and image when locating at co-working spaces and ensuring a strong cohesion between the company and its employees. This barrier is particularly present in organizations that are starting operations in new markets as the workforce might not be embedded in the culture, values, and identity of the organization, such as in case E. Companies respond to this image barrier in two ways: On the one hand with change management and communication with the employees to maintain and strengthen a corporate culture; and on the other hand, through customizing and branding the private spaces occupied to reflect the corporate image.

\section{Discussion}

The findings of the research align with the findings from theory that indicate three main flexibility demands in corporate real estate, physical, functional, and financial. First, co-working offers the possibility of quickly expanding or decreasing the office footprint 
according to the business needs; as seen across the empirical research, this aligns with what Blakstad [46] referred to as the demand for "extendibility" of the building to adjust to changes in use, ownership, or environment. Second, as seen across the cases, co-working provides a variety of workplace settings that offer choice and cater to the different user preferences, and this aligns with the prepositions identified in theory in relation to the need for a variety of areas - from individual spaces and concentration areas, to teamwork rooms and communal spaces-to support different work tasks of the employees [16,21,32,46] Third, in line with the co-working business models [27,28], co-working presents an alternative to traditional leasing models that facilitates the responsiveness of the portfolio to match the assets with the business requirements in the face of changing circumstances; this presents an alternative to diversify the property portfolio and control the risks associated with real estate commitments.

This research contributes to the field of corporate real estate management and workplace strategy by providing knowledge about co-working from the perspective of corporate occupiers: It positions co-working as part of CRE strategy development to support the corporate business performance. The main contribution of this research relates to the identification of six strategies that organizations, in different stages of maturity, pursue to implement co-working as part of their real estate portfolio. In this line, the research evidences the relationship between motivations and flexibility sources in each of the coworking strategies. The research provides theoretical and practical information that can assist the decision-makers of the organizations in taking strategic decisions and leverage the attributes of co-working in relation to the requirements of the organization.

The results of the study are bound to certain limitations that provide an opportunity for future research. First, this research is limited to 5 purposively selected case studies to cover a variety of motivations and approaches to implement co-working. Due to the selected research strategy, more research is required to refine the findings: To validate and further develop the identified strategies and to determine more precisely the relation between co-working and the flexibility provided. This could be further used to compare co-working in relation to other alternatives available in the market.

Second, the case studies were carried out in the pre-COVID time, in the first quarter of 2020. The COVID-19 pandemic has fundamentally changed the common perspective of where to work. It has shown that it is possible for businesses to operate without using their offices at all. Which lessons can be learned from this unique situation, with a largely homebound workforce, is part of the ongoing debate in the corporate real estate domain. It might lead to a trend to reduce (fixed) office square meters as a cost-saving measure, and employees might also start to accept longer commuting times. The need for home office space might lead to more spatially dispersed working forces, as larger houses are often located at the periphery of cities. In the case of a more spatially distributed working force, co-working spaces can offer a way to fulfil the need for social interaction and personal proximity. In any of these scenarios, co-working has a potential role in the CRE strategy development. Therefore, research focusing on the effects of the COVID-19 pandemic, for example, through a follow-up of the cases presented here would provide a significant continuation to further study the research topic. Third, as the research is mainly based on information of organizations based in the Netherlands, future research could expand the study by developing an international comparability study to account for differences in context and provide additional information about how co-working is being implemented across regions in the post-COVID time.

\section{Conclusions}

In face of the competitive pressures of the business environment and changing user preferences, organizations are looking into alternatives to incorporate flexibility to adapt and respond to change. With this, co-working has been an alternative, typically associated with freelancers, entrepreneurs, and startups, that has recently caught the attention of 
corporate occupiers. However, literature focusing on the implementation of co-working in corporate RE is still limited.

In this line, with the aim of identifying different co-working strategies that can be implemented in the corporate real estate portfolio in alignment with the flexibility demands of the organization, this research has focused on a qualitative multiple case study of five companies that have implemented co-working across their RE portfolio.

The results suggest that companies in different stages of the organization's lifecycle can implement co-working as the main office location or as a temporary or complementary space solution, through six different strategies: As Swing Space to temporarily relocate a team while the main office space is under construction or renovation; as Expansion Space to support the headcount growth of the company; as Core and Flex in a dual strategy that combines co-working with a core space acquired in the long-term; as Touchdown Space to support mobile workers that need a professional environment to connect outside of the traditional corporate boundaries; as a Testing Market strategy to face the high uncertainties involved in starting operations or opening new business lines; and as a solution for Temporary Projects or Staff that require a space for a determined period of time to work on particular projects or tasks.

The study also evidenced that implementing co-working in the property portfolio involves three sources of flexibility that respond to the demands of the corporate real estate portfolio and the knowledge workers of the organization. These refer to physical flexibility in terms of space configuration and building location; functional flexibility in terms of variety of settings that offer choice to the different users, and intensity of use of space, which allows a more efficient use of space; and financial flexibility in terms of short-term lease agreements and portfolio diversification, which facilitate the responsiveness of the portfolio under changing circumstances and limit the risk of real estate commitments. Additionally, the research led to the identification of advantages and implementation barriers that organizations face when implementing a co-working strategy across the property portfolio.

The research provides a more comprehensive view on co-working and adds to the body of literature by shedding light on different approaches to implement this model in corporate real estate in relation to the flexibility demands of the organization.

Author Contributions: Conceptualization, N.E.; methodology, N.E. and T.J.; formal analysis, N.E.; data curation, N.E.; writing-original draft preparation, N.E., T.J. and P.K.; writing-review and editing, N.E., T.J. and P.K.; visualization, N.E.; supervision, T.J. and P.K. All authors have read and agreed to the published version of the manuscript.

Funding: This research received no external funding.

Institutional Review Board Statement: Not applicable.

Informed Consent Statement: Informed consent was obtained from all subjects involved in the study.

Data Availability Statement: The data presented in this study are available on request from the corresponding author. The data are not publicly available due to the nature of this research, where participants of this study did not agree for their data to be shared publicly.

Conflicts of Interest: The authors declare no conflict of interest.

\section{References}

1. Gibler, K.M.; Lindholm, A.-L. A test of corporate real estate strategies and operating decisions in support of core business strategies. J. Prop. Res. 2012, 29, 25-48. [CrossRef]

2. Cole, R.J.; Oliver, A.; Blaviesciunaite, A. The changing nature of workplace culture. Facilities 2014, 32, 786-800. [CrossRef]

3. Harris, R.H. The changing nature of the workplace and the future of office space. J. Prop. Invest. Financ. 2015, 33, 424-435. [CrossRef]

4. Ojala, S.; Pyöriä, P. Mobile knowledge workers and traditional mobile workers. Acta Sociol. 2018, 61, 402-418. [CrossRef] [PubMed]

5. Kojo, I.V.I.; Nenonen, S. Places for multi-locational work-Opportunities for facilities management. Facilities 2015, 33, 20-37. [CrossRef]

6. Duffy, F.; Laing, A.; Crisp, V.; DEGW London Limited; Building Research Establishment. The Responsible Workplace: The Redesign of Work and Offices; Butterworth Architecture in Association with Estates Gazette: Oxford, UK, 1993. 
7. Deskmag 2019 Global Coworking Survey. Available online: https://www.dropbox.com/s/jjor71mecwqbxdy/2019\%20Complete\%20 Coworking\%20Forecast.pdf?dl=0 (accessed on 20 September 2019).

8. Capdevila, I. Coworking Spaces and the Localized Dynamics of Innovation. The Case of Barcelona. SSRN Electron. J. 2014. [CrossRef]

9. Deskmag the History of Coworking in a Timeline. Available online: http://www.deskmag.com/en/thehistory-of-coworkingspaces-in-a-timeline (accessed on 5 December 2019).

10. Roth, K.; Mirchandani, N. The rise of co-working: A growing workplace movement. Corp. Real Estate J. $2016,5,314-328$.

11. Spinuzzi, C. Working Alone Together. J. Bus. Tech. Commun. 2012, 26, 399-441. [CrossRef]

12. Kyrö, R. How Can the Real Estate Sector Transition to Circular Economy? Approaches for Real Estate Management. In Proceedings of the 19th EuroFM Research Symposium, (EFMIC 2020), Online Conference, 3-4 June 2020; Jylhä, T., Ed.; Euro FM: The Hague, The Netherlands, 2020; pp. 15-24.

13. Brinkø, R. How to share space. In Facilities Management Models, Methods and Tools Research Results for Practice; Jensen, P.A., Ed.; Routledge: Abingdon, UK, 2019; pp. 115-121.

14. Savills. Flexible Office Space: A Flight to Flexibility. 2019. Available online: https://pdf.euro.savills.co.uk/the-netherlands/ commercial---dutch-other/spotlight---flexible-office-space---2019.pdf (accessed on 10 December 2019).

15. Garrett, L.E.; Spreitzer, G.M.; Bacevice, P.A. Co-constructing a Sense of Community at Work: The Emergence of Community in Coworking Spaces. Organ. Stud. 2017, 38, 821-842. [CrossRef]

16. Sankari, I. Co-Working Space as Workplace. Ph.D. Thesis, Aalto University, Helsinki, Finland, 2019.

17. Yu, R.; Burke, M.; Raad, N. Exploring impact of future flexible working model evolution on urban environment, economy and planning. J. Urban Manag. 2019, 8, 447-457. [CrossRef]

18. Sankari, I.; Peltokorpi, A.; Nenonen, S. A call for co-working-Users' expectations regarding learning spaces in higher education. J. Corp. Real Estate 2018, 20,117-137. [CrossRef]

19. Bouncken, R.B.; Laudien, S.M.; Fredrich, V.; Görmar, L. Coopetition in coworking-spaces: Value creation and appropriation tensions in an entrepreneurial space. Rev. Manag. Sci. 2017, 12, 385-410. [CrossRef]

20. Clifton, N.; Füzi, A.; Loudon, G. Coworking in the digital economy: Context, motivations, and outcomes. Futures 2019. [CrossRef]

21. Kojo, I.; Nenonen, S. Typologies for co-working spaces in Finland-What and how? Facilities 2016, 34, 302-313. [CrossRef]

22. Orel, M. Supporting work-life balance with the use of coworking spaces. Equal. Divers. Incl. Int. J. 2019, 39, 549-565. [CrossRef]

23. Spreitzer, G.M.; Garrett, L.; Bacevice, P. Should Your Company Embrace Coworking? MITSloan Manag. Rev. 2015, 57, 26-29.

24. Weijs-Perrée, M.; Van De Koevering, J.; Appel-Meulenbroek, R.; Arentze, T. Analysing user preferences for co-working space characteristics. Build. Res. Inf. 2018, 47, 534-548. [CrossRef]

25. Jakonen, M.; Kivinen, N.; Salovaara, P.; Hirkman, P. Towards an Economy of Encounters? A critical study of affectual assemblages in coworking. Scand. J. Manag. 2017, 33, 235-242. [CrossRef]

26. Capdevila, I. Knowledge Dynamics in Localized Communities: Coworking Spaces as Microclusters. SSRN Electron. J. 2013. [CrossRef]

27. Bouncken, R.B.; Reuschl, A.J. Coworking-spaces: How a phenomenon of the sharing economy builds a novel trend for the workplace and for entrepreneurship. Rev. Manag. Sci. 2016, 12, 317-334. [CrossRef]

28. Halvitigala, D.; Antoniades, H.; Eves, C. The rise of coworking and their implications on traditional leasing models. In Proceedings of the 25th Annual Pacific-RIM Real Estate Society Conference, Melbourne, Australia, 14-16 January 2019.

29. Hood, C. Building communities: Lessons in co-working for the enterprise world. Corp. Real Estate J. 2015, 4, 239-248.

30. Petrulaitiene, V.; Korba, P.; Nenonen, S.; Jylhä, T.; Junnila, S. From walls to experience-Servitization of workplaces. Facilities 2018, 36, 525-544. [CrossRef]

31. Danivska, V. From Walls to Experiences-Workplace Transformation from Physical Office Space to 'Workplace-as-a-Service' Model. Ph.D. Thesis, Aalto University, Helsinki, Finland, 2018.

32. Brown, J. Curating the "Third Place"? Coworking and the mediation of creativity. Geoforum 2017, 82, 112-126. [CrossRef]

33. Palvalin, M.; Van Der Voordt, T.; Jylhä, T. The impact of workplaces and self-management practices on the productivity of knowledge workers. J. Facil. Manag. 2017, 15, 423-438. [CrossRef]

34. Termaat, W.A.; Van Sprang, H.; Groen, B.H. Workspace 2020-Club, Hub and Cowork space: Business models for optimal FM support for office workers in the future. In Proceedings of the European Facility Management Conference (EFMC), Berlin, Germany, 4-6 June 2014.

35. Weinbrenn, J. Coming of age: Is demand for flexible workspace changing the office market? Corp. Real Estate J. 2016, 5, 248-260.

36. Orel, M.; Almeida, M.D.M.A. The ambience of collaboration in coworking environments. J. Corp. Real Estate 2019, 21, 273-289. [CrossRef]

37. CBRE. EMEA Occupier Survey 2019-Optimising Human Capital: Evolving Strategies for Skills, Space and Service. 2019. Available online: http:/ / cbre.vo.llnwd.net/grgservices / secure/EMEA_EOS_2019-FINAL.pdf?e=1574601947\&h=6548059750 d2f3873317f15112f3ad23 (accessed on 15 August 2019).

38. Gillen, N.; Cheshire, D. Innovation in fit-outs-Are Generation $\mathrm{Y}$ and technology firms heralding a new trend? J. Prop. Invest. Financ. 2015, 33, 465-473. [CrossRef]

39. Sheridan, A.; Conway, L. Workplace flexibility: Reconciling the needs of employers and employees. Women Manag. Rev. 2001, 16, 5-11. [CrossRef] 
40. Lindholm, A.L.; Gibler, K.M.; Leväinen, K.I. Modeling the Value-Adding Attributes of Real Estate to the Wealth Maximization of the Firm. J. Real Estate Res. 2006, 28, 445-475. [CrossRef]

41. Cañibano, A. Workplace flexibility as a paradoxical phenomenon: Exploring employee experiences. Hum. Relat. 2019, 72, 444-470. [CrossRef]

42. Gibson, V. In search of flexibility in corporate real estate portfolios. J. Corp. Real Estate 2001, 3, 38-45. [CrossRef]

43. Too, L.; Harvey, M.; Too, E. Globalisation and corporate real estate strategies. J. Corp. Real Estate 2010, 12, 234-248. [CrossRef]

44. Gibson, V.A.; Lizieri, C.M. New business practices and the corporate property portfolio: How responsive is the UK property market? J. Prop. Res. 1999, 16, 201-218. [CrossRef]

45. Knoll. Five Trends that Are Dramatically Changing Work and the Workplace. 2011. Available online: https://www.knoll.com/ document/1352940439324/WP_FiveTrends.pdf (accessed on 3 October 2019).

46. Blakstad, S.H. A Strategic Approach to Adaptability in Office Buildings. Ph.D. Thesis, Norwegian University of Science and Technology, Trondheim, Norway, 2001.

47. CBRE. EMEA Occupier Survey 2018-Optimising User Experience: The Personalised Workplace. 2018. Available online: http: / / cbre.vo.1lnwd.net/grgservices/secure/EMEA\%20Occupier\%20Survey\%202018_KWm6.pdf?e=1574681919 \&h=e8c68d6d9b1ebb598a72394b09e31db2 (accessed on 15 August 2019).

48. Lindholm, A.L. Identifying and Measuring the Success of Corporate Real Estate Management. Ph.D. Thesis, Helsinki University of Technology, Espoo, Finland, 2008.

49. Appel-Meulenbroek, R.; Groenen, P.P.; Janssen, I.I. An end-user's perspective on activity-based office concepts. J. Corp. Real Estate 2011, 13, 122-135. [CrossRef]

50. Haynes, B.P.; Suckley, L.; Nunnington, N. Workplace alignment. Facilities 2019, 73, 1082-1103. [CrossRef]

51. O'Mara, M.A. Strategies for demand forecasting in corporate real estate portfolio management. J. Corp. Real Estate 2000, 2, 123-137. [CrossRef]

52. CBRE. The Flexible Revolution: Insights into European Flexible Office Markets. 2017. Available online: http://cbre.vo.llnwd. net/grgservices / secure/The\%20Flex\%20Revolution.pdf?e=1574616870\&h=5ea10d6a68a9122368007387a13be1be (accessed on 15 August 2019).

53. Miller, N.G. Workplace trends in office space: Implications for future office demand. J. Corp. Real Estate 2014, 16, 159-181. [CrossRef]

54. Becker, F. Improving organisational performance by exploiting workplace flexibility. J. Facil. Manag. 2002, 1, 154-162. [CrossRef]

55. CBRE. The Agile Advantage. 2018. Available online: https://www.cbre.com/-/media/files/2018/cbre-the-agile-advantage2.pdf (accessed on 15 August 2019).

56. PwC. Future of Work 2030: A Wake-Up Call for Organisations, People and Government. 2018. Available online: https://www. pwc.nl/nl/dienstverlening/people-and-organisation/documents/pwc-future-of-work-2030.pdf (accessed on 20 August 2019).

57. Eurofound. Working Time Patterns for Sustainable Work; Publications Office of the European Union: Luxembourg, Luxembourg, 2017.

58. Eurofound. Striking a Balance: Reconciling Work and Life in the EU; Publications Office of the European Union: Luxembourg, Luxembourg, 2018.

59. Mitchell-Ketzes, S. Optimising business performance through innovative workplace strategies. J. Facil. Manag. 2003, 2, 258-275. [CrossRef]

60. Subramaniam, G.; Tan, P.-L.; Maniam, B.; Ali, E. Workplace Flexibility, Empowerment and Quality of Life. Procedia Soc. Behav. Sci. 2013, 105, 885-893. [CrossRef]

61. Greene, C.; Myerson, J. Space for thought: Designing for knowledge workers. Facilities 2011, 29, 19-30. [CrossRef]

62. Origo, F.; Pagani, L. Workplace flexibility and job satisfaction: Some evidence from Europe. Int. J. Manpow. 2008, 29, 539-566. [CrossRef]

63. Morganson, V.J.; Major, D.A.; Oborn, K.L.; Verive, J.M.; Heelan, M.P. Comparing telework locations and traditional work arrangements. J. Manag. Psychol. 2010, 25, 578-595. [CrossRef]

64. Ruhle, S.; Süß, S. Editorial: Workplace Flexibility. Manag. Rev. 2019, 30, 1-4. [CrossRef]

65. Gummesson, E. Qualitative Methods in Management Research, 2nd ed.; Sage Publications: Thousand Oaks, CA, USA, 1999 ; pp. 1-23.

66. Edmondson, A.C.; McManus, S.E. Methodological fit in management field research. Acad. Manag. Rev. 2007, 32, 1246-1264. [CrossRef]

67. Yin, R. Case Study Research, Design and Methods, 5th ed.; Sage: Thousand Oaks, CA, USA, 2014; pp. 27-69.

68. Tuomi, J.; Sarajärvi, A. Laadullinen Tutkimus ja Sisältöanalyys, 9th ed.; Kustannusosakeyhtiö Tammi: Helsinki, Finland, 2009; pp. 91-124.

69. Fortune Fortune Global 500. Available online: https://fortune.com/global500/2019/search/ (accessed on 17 April 2020).

70. Forbes the World's Best Regarded Companies. Available online: https://www.forbes.com/lists/best-regarded-companies/ (accessed on 17 April 2020).

71. Forbes Global 2000: The World's Best Employers. Available online: https://www.forbes.com/lists/worlds-best-employers/ (accessed on 17 April 2020). 



\title{
Design Science and Co-Designing of Hybrid Workplaces
}

\author{
${\text { Marko Lahti }{ }^{1, *} \text { and Suvi Nenonen }}^{2}$ \\ 1 Department of Computer Science, Faculty of Technology, University of Turku, 20500 Turku, Finland \\ 2 Department of Civil Engineering, Faculty of Built Environment, Tampere University, 33720 Tampere, Finland; \\ suvi.nenonen@tuni.fi \\ * Correspondence: mklahti@utu.fi
}

\section{check for} updates

Citation: Lahti, M.; Nenonen, S. Design Science and Co-Designing of Hybrid Workplaces. Buildings 2021, 11, 129. https://doi.org/10.3390/ buildings11030129

Academic Editor: Per Anker Jensen

Received: 30 January 2021

Accepted: 17 March 2021

Published: 20 March 2021

Publisher's Note: MDPI stays neutral with regard to jurisdictional claims in published maps and institutional affiliations.

Copyright: (C) 2021 by the authors. Licensee MDPI, Basel, Switzerland. This article is an open access article distributed under the terms and conditions of the Creative Commons Attribution (CC BY) license (https:// creativecommons.org/licenses/by/ $4.0 /)$.

\begin{abstract}
Background: Future places for learning and working are digitally and physically integrated hybrid environments. The archetypical context of learning is the classroom, and context of working is the office; especially in knowledge work. New information and communication technologies enable the spatial reconfiguration of work opening possibilities for work to take place across multiple locations. This paper aims to explore how the conceptual framework of design-science research in Information Systems can be applied when the design object is a hybrid working environment. Methods: The case study method as a qualitative approach was chosen; because it involves an empirical investigation of a particular contemporary phenomenon within its real life context using multiple sources of evidence. The empirical analysis of two hybrid working environments is based on Action Design Research (ADR)-entry points; where one analyzes two case studies stage by stage. By analyzing various stages in both case studies; one can identify co-designing challenges of hybrid working environments. Results: The results present four recommendations for co-designing of hybrid working environments. The use of hybrid working environment; the design of spatial solution; the identification of iterative processes; and the user experiences of presence and distance are significant. The Entry Point Analysis-tool can be used and further developed in analyzing and developing hybrid working environments. Conclusion: The results contribute to the tradition of usability studies. The usability briefing approach can be further developed by identifying the iterative processes inside the linear project management models. Additionally, design science research can find new insights from identification of the large stakeholder iterations more precisely.
\end{abstract}

Keywords: action design research; entry point analysis; project management; usability briefing; hybrid working environment; co-design; co-working

\section{Introduction}

Future places to learn and work are a digitally and physically integrated hybrid environment. The aim of this paper is to investigate the co-design processes of physical and digital solutions. Usability of built environment relies on the different service design methods. More of them can be found from the Information Systems field. Digital solutions are developed by applying the Action Design Research (ADR) process model by Mullarkey and Hevner [1]. The aim is to explore how the conceptual framework of design-science research in Information Systems can be applied when the design object is a hybrid working environment.

Instead of existing work and learning environments there is a shift towards more hybrid work and learning environments. This has been influenced by a number of different benefits [2,3]. Constraints have been the technology available and the courage for radical reform. Hybrid learning environments make it possible to combine physical, digital, and social learning in a novel way [4]. In this study, a process model for co-designing the hybrid work environment is presented to combine a physical space and digitalization in the design phase. More specifically, to solve the iterative process challenge for co-designing with users and co-designing with digital and physical design stakeholders. For the design 
of physical environments, Fronczek-Munter [5] has introduced a usability briefing model that describes the development cycles of space, whereas Mullarkey and Hevner [1] have introduced an ADR process model based on the Information System field. The former model is based on the long-term conceptual research of usability of workplaces, while the latter focuses on usability of digital solutions. The Entry Point Analysis-tool is developed for the framework.

The paper consists of four main sections. The introduction presents the background of the study, the goal of the research, and then usability approaches. The hybrid environments for learning and working are discussed. The co-creation processes of usability briefing and action design research are presented and compared. Section 2 continues with methods, the research process, and case study descriptions. Additionally, the Entry Point Analysis-tool is presented. In Section 3, we present analysis of two case studies and results. Finally, Section 4 concludes the research by evaluating the limitations and proposing future research topics.

\subsection{Hybrid Learning and Working Environments}

The archetypical context of learning is the classroom, and context of working is the office, especially in knowledge work. Novel technologies enable the spatial reconfiguration of work giving possibilities to work in multiple locations [6]. One way to implement this is to have a live 3D constructed feed from a chosen space, where remote users can participate with local users in a virtual environment. Changes in educational practice are driving the emergence of hybrid learning environments [3]. Established educational methods change, expand, and replace established roles, resources, and locations. Moreover, the working environments need to follow the learning environments and provide more integrated solutions for efficient use of both digital and physical working environments.

What do we mean by hybrid in the context of learning and working environment? Tynjälä, et al. [7] described modes of learning, which can generally divide between learning that is situated in a working environment and an educational environment. The first one is mostly informal learning, whereas the last one is more formal. Moreover, Tynjälä et al. [7] identified a hybrid form of learning when learners worked collaboratively while using project-based learning. Herrington and Herrington [8] introduced authentic learning, which is a similar concept to project-based learning, where the idea is how knowledge is used in real life and providing activities reminiscent of activities in practice. In addition to this, Van Merriënboer, et al. [9] have noted a similar concept called authentic learning, where real life tasks are the driving force of the learning. One of the trends was to integrate Information and Communication Technology (ICT) in real life tasks or projects according to van Weert and Pilot [10], which has continued to this day. Goodyear et al. [11] pointed out how ICT can also promote a socio-cultural aspect, since it enables learners and teachers to collaborate and learn together from a distance. Zitter et al. [12] introduced a descriptive model of learning environment. Moreover, Zitter et al. [13] positioned the learning tasks mentioned by Van Merriënboer et al. [14] to the previous model. Zitter et al. [13] also points out that learning environment is formed by these concrete learning tasks. To describe the learning task, four different perspectives are distinguished, which are:

1. Agency perspective, to describe the roles of the participants;

2. spatial perspective, to study learning tasks on the physical and digital space;

3. temporal perspective, describing the needed time for the learning tasks;

4. instrumental perspective, important boundary objects to deliver intermediary and final results of the learning tasks.

The Organization for Economic Co-operation and Development (OECD) [15] presented Education Working Papers in 2012, where they applied the same model for different cases like technology, hospitality, and sports.

Chen and Chiou [16] studied results which indicated that students of hybrid learning environments felt a stronger sense of community than students in traditional environments. Besides that, the students had significantly higher learning results. Sonntag et al. [4] study 
highlighted that augmented reality provides an opportunity to integrate physical, digital, and social learning in hybrid learning environments, thus enhancing learning interaction, motivation, and collaboration. Ibáñez et al.'s [17] study was aimed at system architecture and usability of a proof-of-concept for hybrid learning environments. It pointed out that usability had positive engagement effects on participants while participating in a 3D virtual mirror of the real space.

Halford [18] argued in his study that spatial hybridity changes the nature of the work, organization, and management across domestic, organizational, and digital space. The paper explored the implications of hybrid workspace. Halford [18] studied a financial service company that allowed part-time homeworking. The results were positive and changed, for instance, how people work, and finally Halford [18] concluded that previous studies have indicated that full-time home-working causes negative experiences and consequences, but material gathered in her study suggest that a combination of work spaces gave positive feedback. Later, co-working was defined as creative cities or districts, where two interlinked tendencies are embedded together [19]. Marchegiani and Arcese [20] addressed collaborative spaces and co-working as hybrid workspace in their work and concluded it to be effective in the context of a collaborative and sharing economy. The conclusion was based on Gandini [21] and Bostman and Rogers's [22] earlier work. Marchegiani and Arcese [20] continued to say that the co-working space seems to give workers an area that supports the physical and the digital interaction simultaneously, which eventually leads to innovative outcome.

While the concept of hybrid learning and working environment can be defined in different ways, Hilli et al. [23] presented five designing, developing, and implementing principles for it in a higher education context. These principles are one way to divide and structure the design processes and practices while designing the hybrid learning space. All the five principles are further discussed by Hilli et al. [23]. Both Stommel [24] and Hilli et al. [23] present a hybrid pedagogy as a methodological approach for interlinked practices and processes. The challenge in both working and learning environments is to ensure that their usability is considered in the interaction of people, building, and technology.

\subsection{The Goal of the Research}

The aim is to explore how the conceptual framework of action design research (ADR) in Information Systems can be applied when the design object is a hybrid working environment. The research question asked is: How can the action design research paradigm be applied in understanding the usability challenges in hybrid working environments? The case study method was chosen as a qualitative approach, since it involves empirical research on a particular contemporary phenomenon in its real life using multiple sources of evidence [25]. The data used in the study is collected through interviews, participant workshops, and retrospective analysis of documents. This paper will enlarge the discussion in terms of hybrid working environments integrating people, organizations, technology, and buildings.

\subsection{Usability Approaches in the Context of Physical and Digital Environments}

\subsubsection{Usability Briefing Approach}

Based on a series of studies on usability in the built environment conducted in Europe, which propose that management or governance of use-centric processes is seen as crucial to ensure not only functional, but also usable, outcome of co-designed built environments [26].

Incorporating the users' knowledge and preferences in the architectural, engineering, and construction (AEC) project is important [27]. Based on these studies, several process descriptions have been developed further. They emphasize the significance of user participation in different phases of the process, indicating many simultaneous processes.

A usability briefing model provides an overview of the activities in the usability briefing process. Its meaning as a continuous and dynamic process of capturing user 
perspectives throughout all the phases of building projects is captured. The model is generic and simple to use, and it is meant to be used in the planning of new complex building projects [5]. Figure 1 illustrates how Fronczek-Munter [5] has introduced the usability briefing.

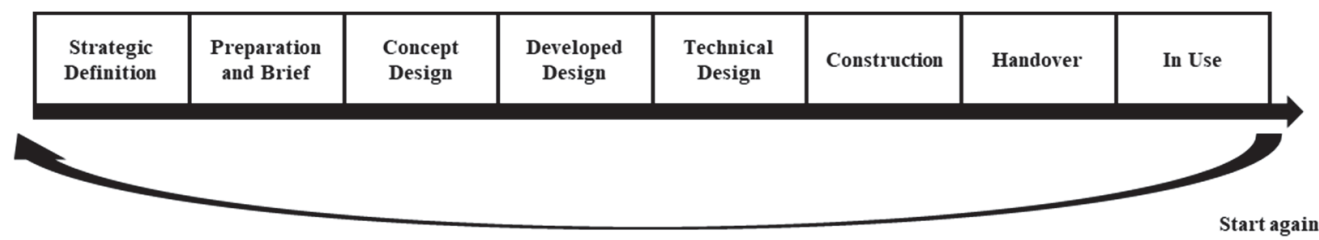

Figure 1. Usability briefing process modified from Fronczek-Munter [5].

The usability briefing's first two phases are preliminary to the project. At these stages, decision-makers create a shared vision. It takes into account, e.g., strategy objectives, data collection, organization, and order of priority of decisions. The next four phases are about design and construction. More specifically, it includes, e.g., an architectural vision, usability, innovation, usability, co-learning, co-designing, layout, functionality of design proposals, and maintaining usability. The last two phases are about moving in successfully, learning to use the facility, evaluations, requirement tests, and improvements [5]. During these phases, the user involvement, design, evaluations, and briefing activities ratio varies. These activities should interact with each other.

While the usability briefing model unites the different activities, it is a straightforward process. It is recommended that topics of all activities are well formalized, which make them easy to discuss in the meetings. When using the model, the focus should always be on usability in every phase. After the final phase, one can start the process again based on the evaluation and user experience.

\subsubsection{Action Design Research Approach}

Usability research in man-machine interaction has a long tradition. In comparison to the usability of a built environment, the usability of a digital environment has differences in scales of the object. Traditionally, in the development of information systems, two paradigms characterize much of the research in the field of information systems research: Behavioral science and design science [28]. To predict or explain human or organizational behavior, one can seek to develop and verify theories by using a behavioral-science paradigm. The paradigm of action design research tries to expand the boundaries of human and organizational features by creating new and innovative objects. Similarities can be found from the usability of the workplaces studies: One needs to understand the humanbuilding relationship [29]. Hevner et al. [28] states that two paradigms, the behavioral and design science, are based on Information System (IS) science, which is at the intersection of people, organizations, and technology. Co-designing hybrid environments has multiple stages, which differ from each other (see Figure 2).

The entry points of each stage are described as follows [1]:

1. Problem-centered, to describe the research problem and specify where the solution is aimed for.

2. Objective-centered, to study design possibilities and in that way increase the data for the solution area.

3. Development-centered, aims to implement a designed solution that solves the research problem.

4. Observation-center, studies implemented a design and evaluates its usage to enhance the implementation even further. 


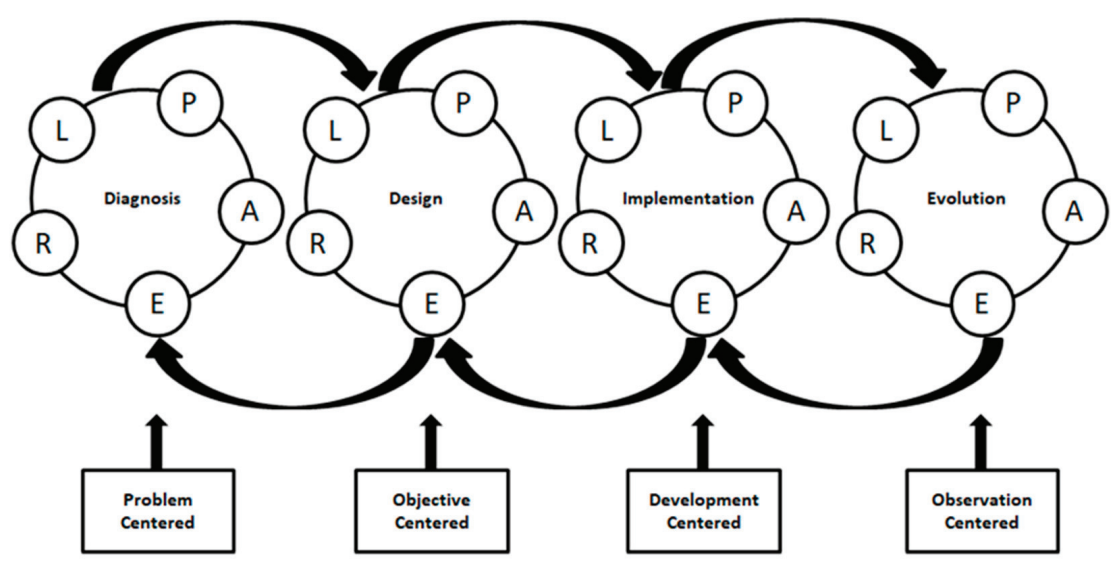

Figure 2. Action design research-process model with research entry points [1].

Mullarkey and Hevner [1] elaborated on ADR-entry points, which describe the starting point to use the ADR-study. Mullarkey and Hevner [1] even argued that the group of researchers had an obligation to recognize and present the entry point that motivates the ADR-study. The research entry point could occur at any one of the ADR-stages, as shown in Figure 2.

\subsubsection{Similarities and Differences of Usability Briefing and Design Science Approach}

To summarize, both models have similarities and differences (see Table 1).

Table 1. Comparison of the process models.

\begin{tabular}{lcc}
\hline Features & Usability Briefing & Action Design Research \\
\hline Process & Aligned with the construction process & Aligned with the design process \\
User involvement & Strongly emphasized & Strongly emphasized \\
Identified phases & Eight phases & Four phases with five sub-phases \\
Iteration Frequency & Feedback loop from use of the building to begin of the new usability brief & Each phase includes iterations \\
\hline
\end{tabular}

Both usability briefing and action design research approaches focus on the process. While usability briefing is aligned with the building lifecycle with different stake holders in the AEC-project, action design research focuses on process, which is an interaction with the external environment and research knowledge. User centricity can be seen at different stages in both models. Users are influencing to the matching of the physical or digital solution to the needs of the users.

The major differences between the approaches are in the length and rhythm of the process. The cycle of usability briefing is longer. There are no feedback loops within different phases, while in the ADR-model, it is visualized that iterations are taking place more frequently. This makes the ADR-model look more agile by the nature: Iteration steps are small and fast. The potential learning occurring among co-design stakeholders is visualized differently in models.

The co-design of hybrid learning and working environments needs to integrate the agile digital design sprints and more static progress of the built environment. In response to this need, this research tests the Entry Point Analysis-tool in two case studies of hybrid working environments. 


\section{Methods and Research Design}

\subsection{Case Study Approach}

This research follows exploratory study principles as it aims to gain more understanding on design processes of hybrid working environments. The case study method as a qualitative approach was chosen, because it involves an empirical investigation of a particular contemporary phenomenon within its real life context using multiple sources of evidence [25]. Case selection criteria were the following:

1. Work environments of about the same size;

2. work environment in an academic work context;

3. user participation in the co-design process;

4. hybrid work environment in a significant role.

Two cases were selected: Case 1 was Health Tech Hub at the University of Turku in Finland. The size of the hybrid work environment was 187 sqm space. The research group of health technology relocated from the faculty building to the building of medical faculty of the university. Additionally, the building was used by researchers from the local hospital district and the university of applied sciences. The vision was to conduct health technology research in the research surroundings of medical sciences. Additionally, the research group had a lack of office space in the existing faculty building.

The second case was from the same university. The Future Tech Lab is 200 sqm space for open innovation in software engineering education and research. It was set up by the Finnish University of Turku to the main campus of the University of Namibia. The expected users were the students of future software engineering study programs, researchers, and supervisors. The vision was to develop a platform for the new innovations, which have global impact, and support research, development, and learning in open innovation processes.

Both cases represented the need to co-design both technical and physical solutions in an integrated manner to achieve the hybrid solutions. Table 2 represents the cases at a glance.

Table 2. Summary of the cases.

\begin{tabular}{|c|c|c|}
\hline Features & Case 1: Health Tech Hub & Case 2: Future Tech Lab \\
\hline Size of the space & $187 \mathrm{sqm}$ & $200 \mathrm{sqm}$ \\
\hline Previous use of the space & Business premises & Storage and IT class room \\
\hline New use of the space & Research and collaboration & Co-work and co-learn \\
\hline Hybrid factors & Collaborative use of technology in $\mathrm{ABW}$ environments & $\begin{array}{l}\text { Novel technology for overseas } \\
\text { collaboration in flexible space }\end{array}$ \\
\hline The initiator of the process & Research group & Management of two universities \\
\hline Location & Turku, Finland & Windhoek, Namibia \\
\hline User groups & Research group and partners & $\begin{array}{c}\text { Research group and industry partners, } \\
\text { Finnish and Namibian students and staff } \\
\text { of universities }\end{array}$ \\
\hline Estimated number of users & $30-35$ & $40-50$ \\
\hline
\end{tabular}

The data gathering focused on two topics: The co-design process of the hybrid working environment and the user experience of the hybrid working environment. The aim of the study was to discover how to integrate the design of digital and physical to achieve a hybrid working environment that is usable. The qualitative approach to the problem seems most relevant because the co-design of either physical or digital environment is more typical than the integrated approach. The quantitative data is not easy to gather because the hybrid working environments are not yet the usual case in the context of working.

The data collection was performed in three steps.

The first step was based on literature review. It was a basis to the integrated Entry Point Analysis (EPA)-tool. The tool aims to identify the different phases of co-designing the hybrid working environments. 
The second step was dedicated to the analysis of the co-design processes. The data was gathered by participatory workshops and document analysis. Four participatory workshops (see Table 3) were conducted in case 1 during 2018-2019. In the first case study, the participants were the research group members as users, interior designer, digital designer, and facilitator with co-design expertise. The topics of the workshops were:

1. Vision;

2. user profiles and needs;

3. iteration of the digital and physical solution;

4. iteration 2 of the digital and physical solution.

Table 3. Participatory workshops.

\begin{tabular}{lcc}
\hline Features & Case 1: Health Tech Hub & Case 2: Future Tech Lab \\
\hline Amount of Participatory workshops & 4 & 5 \\
Participants & $\begin{array}{c}\text { Research group members as users, } \\
\text { interior designer, digital designer and } \\
\text { facilitator with co-design expertise }\end{array}$ & $\begin{array}{c}\text { Management from both universities, } \\
\text { architect, two digital designers, employees } \\
\text { from both universities and facilitator with } \\
\text { co-design expertise. }\end{array}$ \\
$\begin{array}{l}\text { Participants in average } \\
\text { Time schedule }\end{array}$ & $\begin{array}{c}25 \\
\text { 2018-2019 }\end{array}$ \\
Data & $\begin{array}{c}\text { Process descriptions, Layout plans, } \\
\text { minutes and other notes }\end{array}$ & $\begin{array}{c}\text { Process descriptions, Layout plans, minutes } \\
\text { and other notes }\end{array}$ \\
\hline
\end{tabular}

In case two, five participatory workshops followed similar themes during 2019-2020. Participants of the workshops included the management from both universities, an architect, two digital designers, employees from both universities, and a facilitator with co-design expertise.

In the third step of data gathering focused on user experiences, data was gathered by observations and experience mapping questionnaires. Observations were conducted in case 2 two times after the retrofitted environment was in use. The researcher used an observation sheet to gather data from the usability of the solutions. User-questionnaires were conducted in both cases (Table 4).

Table 4. Experience mapping questionnaires.

\begin{tabular}{lcc}
\hline Features & Case 1: Health Tech Hub & Case 2: Future Tech Lab \\
\hline Conducted questionnaires & 1 & 1 \\
Participants & Users of the hybrid working environment & $\begin{array}{c}\text { Event organizers of the hybrid } \\
\text { working environment }\end{array}$ \\
$\begin{array}{l}\text { Responses } \\
\text { Amount of questions }\end{array}$ & 8 & 6 \\
Structure of questionnaires & 26 & 32 \\
Topics & Semi-structured questionnaire with \\
open comments & Semi-structured questionnaire
\end{tabular}

In the first case study, user experiences were gathered from users of the hybrid working environment by a feedback questionnaire with 26 questions, and the responses were gained from eight participants. The feedback questionnaire focused on user experiences in previous and current workspace as well as on needs for improvement. The more detailed topics concerning hybrid working environments were the availability of facilities, the need for change, teamwork, technical implementation, and opportunities for cooperation between stakeholders.

In the second case study, a feedback questionnaire with 32 questions provided insights from six event organizers that used the hybrid working environment. The focus was more about usability of the hybrid working environment for different purposes. The topics 
were: How different spaces support collaboration and individual work and the factors that improve these, as well as how well hybrid environments have been implemented and what still needs to be taken account. Both Likert-scale questionnaires had similar statements, but the amount of open questions differed.

The intention of the questionnaires was not to produce generalized quantitative data, but serve as one sources of data next to the observations, participatory workshops, and document analysis. Triangulation [30] was used to complement the data and to find new information, in other words, to get additional pieces to the overall picture of hybrid working environments.

Because the response rate was small, some interviews were also conducted about the usability of the facilities for different purposes, benefits of the hybrid working environment, and the development ideas for the technical setup. The observations also provided data about the usability of the places.

\subsection{Data Analysis}

The data was organized in transcripts. To analyze the process more thoroughly, the Entry Point Analysis-tool based on Action Design Research approach was developed. The tool is applied from Hevner's theoretical model. The development was made in three co-design workshops among researchers who use the in digital context and researchers who are familiar with usability of the built environment.

Entry Point Analysis (EPA)-tool aims to identify the different phases of co-designing the hybrid working environments. It clarifies how to integrate the digital and physical environment to support user. It is also a tool to model the co-design hybrid learning environment. It is needed to improve the design processes of the digital and physical in a systematic way. The focus is on co-designing the artifact, which is a hybrid working environment. The EPA-tool maps four co-design stages with a five-step process in each stage (see Table 5) In this study, the data of two case studies was used in analysis.

Table 5. The Entry Point Analysis (EPA)-tool for co-design in the hybrid working environments

\begin{tabular}{|c|c|c|c|c|}
\hline Stage & Hybrid Vision & Hybrid Integration & Hybrid Fit & Hybrid Fix \\
\hline \multirow[t]{2}{*}{ Main questions } & \multirow[t]{2}{*}{$\begin{array}{l}\text { What is the vision of } \\
\text { the hybrid solution? } \\
\text { Who are involved? }\end{array}$} & $\begin{array}{l}\text { What are the functions } \\
\text { supported by digital } \\
\text { platform-what are the } \\
\text { requirements of this to } \\
\text { physical environments? }\end{array}$ & $\begin{array}{l}\text { How does the digital } \\
\text { and physical solution } \\
\text { fit together to } \\
\text { ensure usability? }\end{array}$ & $\begin{array}{l}\text { How is the hybrid } \\
\text { working environment } \\
\text { used and continuously } \\
\text { both evaluated } \\
\text { and developed? }\end{array}$ \\
\hline & & Who are involved? & Who are involved? & Who are involved? \\
\hline
\end{tabular}

In the hybrid vision stage, the hybrid working environment is seen as an integrated artifact which is supporting the collaboration and individual work tasks of the user. The main topic to co-design is the vision: For what purpose the hybrid working environment is developed. The artifact is developed in collaboration with different user groups and project stakeholders, and it leans on a diverse knowledge base. The questions asked in this stage are:

1. Why does one need to make or modify a hybrid environment?

2. What problems will the hybrid space solve-which functions it will support?

In the hybrid integration phase, the artifact is co-designed by finding solutions to the visions and functions which are identified in the first stage. The main topics on co-design are:

1. The requirements of individual and collaborative work for the digital environment;

2. the requirements of functions and digital environment to physical environment.

The knowledge base is formed by dialogue among users, digital experts, and built environment experts. The questions asked in this stage are: 
1. Which individual and collaborative functions need to be supported?

2. Which technology supports them?

3. What requirements are set for the physical environment based on functions and technology?

In the hybrid fit stage, the alignment of digital and physical environments is conducted, and the emphasis of co-design is on avoiding usability misfit. To co-design hybrid fit, one needs to ask:

1. How is the hybrid working environment implemented?

2. How is the solution evaluated?

In the hybrid fix stage, users can give feedback to develop the solution even further or if, for instance, the user's practice changes significantly, it might affect the current solution quite a bit. The questions asked in this stage are:

1. How to evaluate the user experience?

2. How should the hybrid working environment be developed further?

Entry point analysis indicated the different stages with key concepts and questions. The iterations in the different stages provide a more detailed description on how the process proceed. The co-design iterations in each stage follow the five steps. During the planningphase $(\mathrm{P})$ the exiting knowledge and ideas from co-designing participants creates a plan for hybrid vision: What kind of functions will be supported by hybrid solution. It includes gathering ideas, plans, and suggestions together to create the vision. The second phase is about Artifact creation (A), where a group of co-designers creates an example based on the vision by integrating functions, technology, and place. The Evaluation phase (E) has a group of co-designers evaluate the solution. The Reflection phase (R) includes classification of intermediate feedback. The last phase is Learning (L), pointing out the outcome of the iteration cycle: What is learned in terms of digital and physical environment, including the use of both of them. It is also possible to identify further development to the possible next iteration cycle. The participants in different co-design stages are important to identify and orchestrate the combination of different stakeholders.

\section{Results}

The results are analyzed by Entry Point Analysis-tool comparing them and finally identifying the hybrid working environment.

\subsection{Entry Point Analysis Stage 1: Hybrid Vision}

\subsubsection{Hybrid Vision Case 1}

The vision of the hybrid working environment was to provide a research and collaboration platform for development of health technology in the context of medical sciences. The digital environment was an essential part of the working culture as a tool, but also as a research object. However, the vision set was not co-designed with users, it was more given by management as a solution to an operational problem of the research group: Lack of space.

The first iteration was conducted among management and included following steps:

- Strategic meeting about development of technology research;

- identifying the need to disperse the development work closer to its context;

- discussing the ideas with different stakeholders;

- identifying the locations within the city;

- $\quad$ starting the negotiations with different stakeholders.

The vision was approached by focusing on location of the new solution. The iteration with users included the following steps:

- Participatory workshop;

- $\quad$ identifying the user groups and their needs;

- $\quad$ reflecting on the results and starting design dialogue; 
- clustering the different needs;

- identifying and mapping the requirements for digital and physical solutions.

\subsubsection{Hybrid Vision of Case 2}

In the second case study, the vision was a satellite campus in Namibia. It was possible to identify two iterations from this stage. The first iteration was conducted in an international group including Finnish and Namibian representatives from universities. It contained following steps:

- Participatory workshops;

- identifying the activities of the satellite campus;

- evaluating the current curricula;

- new requirements for the concept: The campus itself must be an innovative solution, not a copy from somewhere. More precisely, the ideas of novel technology supporting the presence while collaborating remotely;

- observations and new lead thoughts were listed.

This was constructing a common knowledge base. The second iteration was made in the campus of UNAM in Namibia. It contained following steps:

- Site visit;

- the identification of ICT-architecture and infrastructure requirements;

- assessment how the education can be organized;

- reflections on real infrastructure locally;

- identifying the differences of built infrastructure in the cultural context as well as better understanding the cultural differences in attitudes towards technology.

To sum up, the hybrid vision stage provided a hybrid vision in both cases. The location to realize the hybrid working environments was identified, and the collection of functional, digital and physical solutions were conducted. The vision stayed still in the abstract level. The interesting thing was that the attitudes and use of technology can play a role in the realization of future solutions.

\subsection{Entry Point Analysis Stage 2: Hybrid Integration}

3.2.1. Hybrid Integration in Case 1

This phase included iterations with users and an interior designer. Multi-functional solution and flexibility were the leading keywords in participatory workshops and in processing requirements. This was a key reason to divide the working environment for four zones and a private area. The artifact was an Activity based work environmentconcept. The iteration included designing layout and interior design options, evaluating design options, and choosing the suitable version and getting the feedback ideas in design dialogue with the research group and designer. Based on classified content of feedback, the design changes were conducted.

The concept is described here more precisely, especially representing the functional zones. The hub consists of four zones, Author-zone, Lab-zone, Neighbor-zone, Synergyzone, and two private areas that include typical technical setup. The hub has been codesigned with users and implemented for the purpose of the research group needs.

The Lab-zone provided four workstations and a possibility to test measurements with individual test persons. The Lab-zone also needed activated carbon filters and a sufficient air condition for soldering. In addition, they need flexible furniture for equipment and assembling and testing. The digital environment supported all these activities. The Authorzone was for senior researchers and group leaders with management tasks, whereas the Neighbor-zone was for younger researchers, also allowing more social interactions. The Synergy-zone mirrors the area, where researchers can meet other researchers from the building, e.g., from medical sciences. The Synergy-zone includes different kinds of conference rooms and labs that can be used as shared facilities. Figure 3 illustrates the drafts of the different zones and the final layout of the space. 


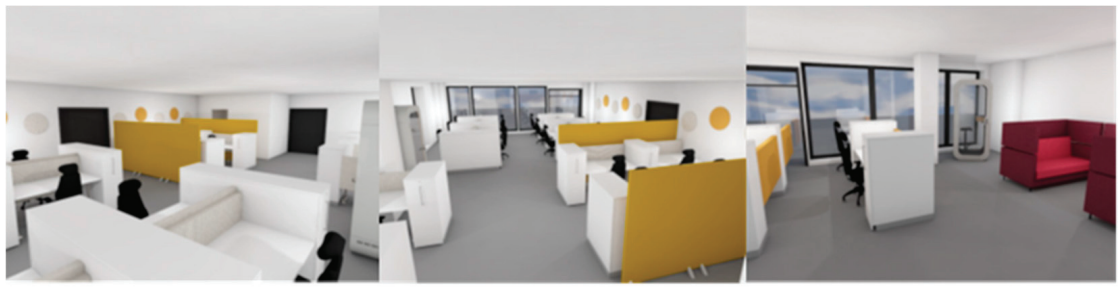

(a)

(b)

(c)

\section{Health Tech Hub}

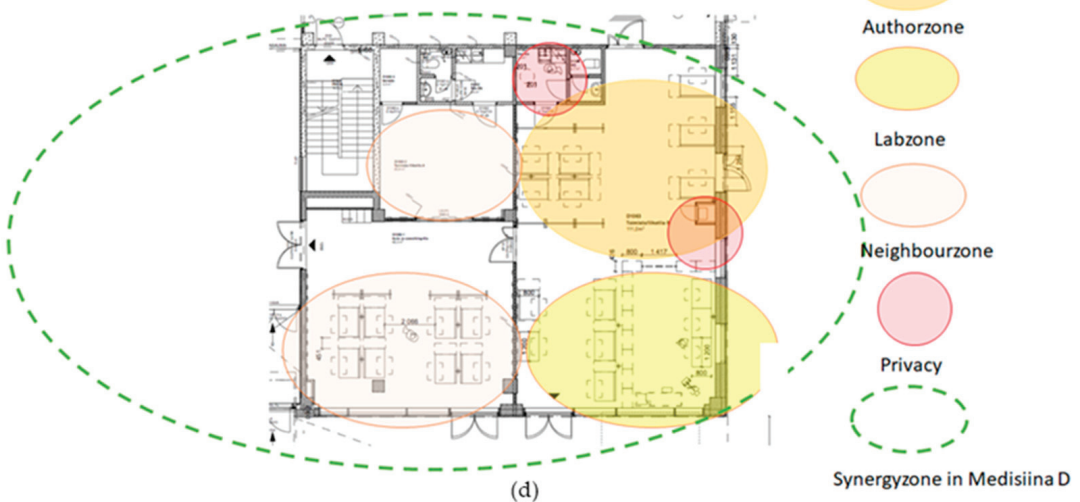

Figure 3. Case 1 working area divided into several zones with different activities. (a) Draft from the Lab-zone and Author-zone; (b) draft from the Author-zone to Lab-zone; (c) draft from the larger Neighbor-zone; (d) final floor plan.

\subsubsection{Hybrid Integration in Case 2}

Hybrid integration began in case 2 by identifying the novel technology and structural plans of the chosen space. Both technical and physical design teams initially worked separately. During the artifact creation's phase, the design team made the first drafts of the layout, dividing the space for three zones. Simultaneously, the technical team designed the novel technical setup for the place. While evaluating the drafts, multiple issues were raised. One of the issues was that technical setup would be too expensive to implement. Then some other issues were raised that needed to be taken into account. Then in the reflection phase, both physical and technical issues were specified. Good and new findings were recorded to the knowledge base in the formalization of the learning phase.

Another cycle was conducted to finalize the complete design. The technical team altered the way that technical innovation should be implemented. In the first iteration, the idea was to combine two physical spaces together with the technology by using highly expensive display walls in both university campuses. The intention was to continue the local space on the opposite space. While the technology aims to capture the physical space and everything in it, the idea changed to share any of the physical places that had the technical setup installed. So, compared to the first idea, this would be cheaper to implement and enables the possibility to share the environment for multiple locations, whereas previous was stuck to combine just two locations. In addition to this, it opened many other possibilities for learning and working. Finally, after several drafts, physical drawings were supporting the technical solution in a way that future implementation is possible after renovation.

The lab consist of three zones, the Collaborating and Co-working zone, the Welcoming zone, and the Co-learning and Connecting zone with a readiness of novel technology setup. The lab has been co-designed with stakeholders and implemented for the purpose of local 
and foreign students and lectures. Figure 4 illustrates floorplan in the starting point and pictures from each zone after renovation.

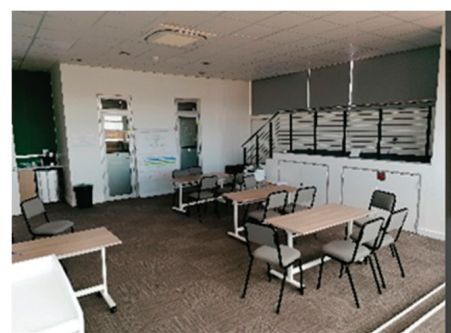

(a)

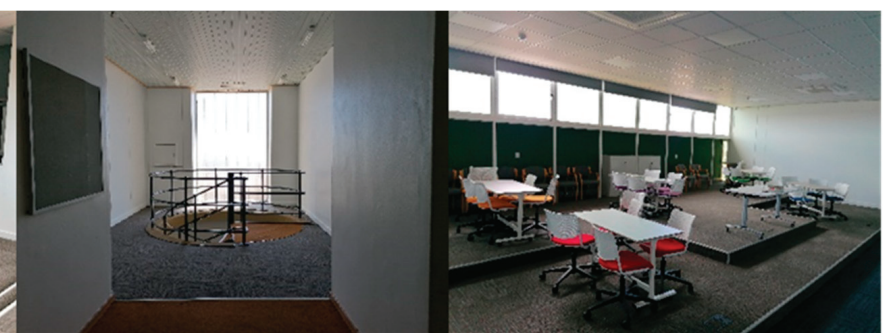

(b)

(c)

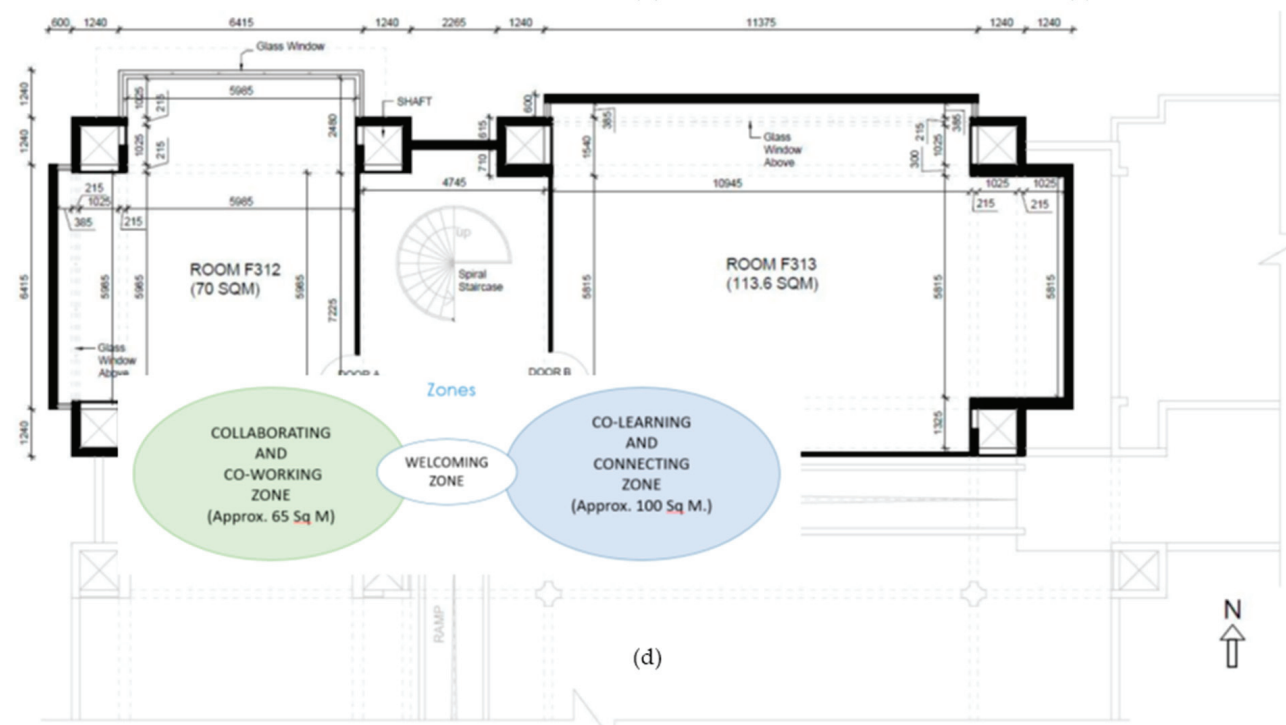

Figure 4. Case 2 working area divided into several zones with different activities. (a) Collaborating and Co-working zone; (b) Welcoming zone; (c) Co-learning and connecting zone; (d) floorplan in the starting point, where the unit of length is in millimeters.

The camera pair illustrated in the front of Figure 5 gives an example of the cameras used for the hybrid working environment. Fixed camera pairs will be installed on the wall around the space to be able to create a 3D constructed environment. 


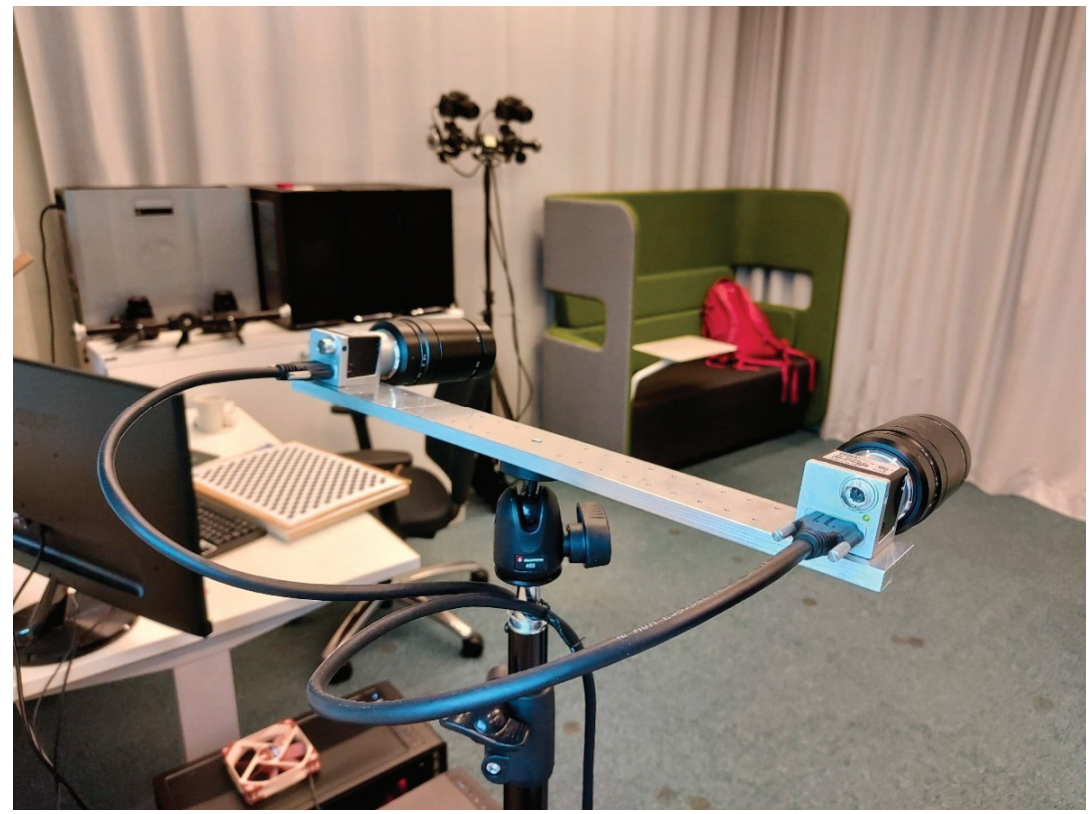

Figure 5. Testing setup with multiple camera pairs.

The hybrid integration stage indicated that instead of single workstations, the zoning perspective provided possibilities to discuss the digital solutions in a fluent way. The collaborative functions conducted by digital means especially bring in more requirements for physical solutions.

\subsection{Entry Point Analysis Stage 3: Hybrid Fit}

\subsubsection{Hybrid Fit in Case 1}

Hybrid fit in case 1 focused on the relocation process while the design of the layout was realized. The relocation plan and time schedule guided the user participation. However, the preliminary iteration was disrupted by the justification process, where users needed to ensure from different management levels if the relocation is really necessary. The focus was mostly on physical environment, and the potential of digital working environments was not considered. The relocation was hard to accept due the fact that the vision iterations and user need iteration were conducted with different stakeholders. However, the time schedule of removal was kept. The first impressions in settling to the new place included evaluation, and based on the instant reactions, some practical changes were made in order to improve digital and physical usability, planning scheduled with transport, furniture business, and research group, A, implementation by schedule, E, evaluating finalized workspace and getting feedback from users, R, classifying evaluation feedback and L, formalizing development suggestions.

Implementing the activity based work environment concept users to organize their work processes in the different way. The concept is based on three pillars of place (physical environment), users (behavioral environment), and technology (including knowledge sharing) where every user shares a communal workplace consisting of areas or zones that have their own purpose for certain office tasks [31]. The demand for digital collaboration increased due to the fact that the location of the physical place was different than earlier, especially in the connection with the faculty. 


\subsubsection{Hybrid Fit in Case 2}

In case 2, several iterations of this stage can be identified. First, the design brief was shared with local partners in Namibia. Then, a local planning team scheduled the renovation. The artifact creation phase started the renovation, and the requirements of the novel technology were included in the project brief. The renovation was followed and reported weekly. Data, pictures, and other feedback during the process provided material for evaluation and reflection.

However, the hybrid fit stage included many small iterations, even few iterations back to design stage. One reason was the topic of power consumption: The technology needed stronger infrastructure. The $3 \mathrm{D}$ feed to achieve fluent digital environment required computing power. It was uncertain if the power production of the old building would be sufficient. Figure 6 illustrates the example case, how the power consumption topic was dealt.

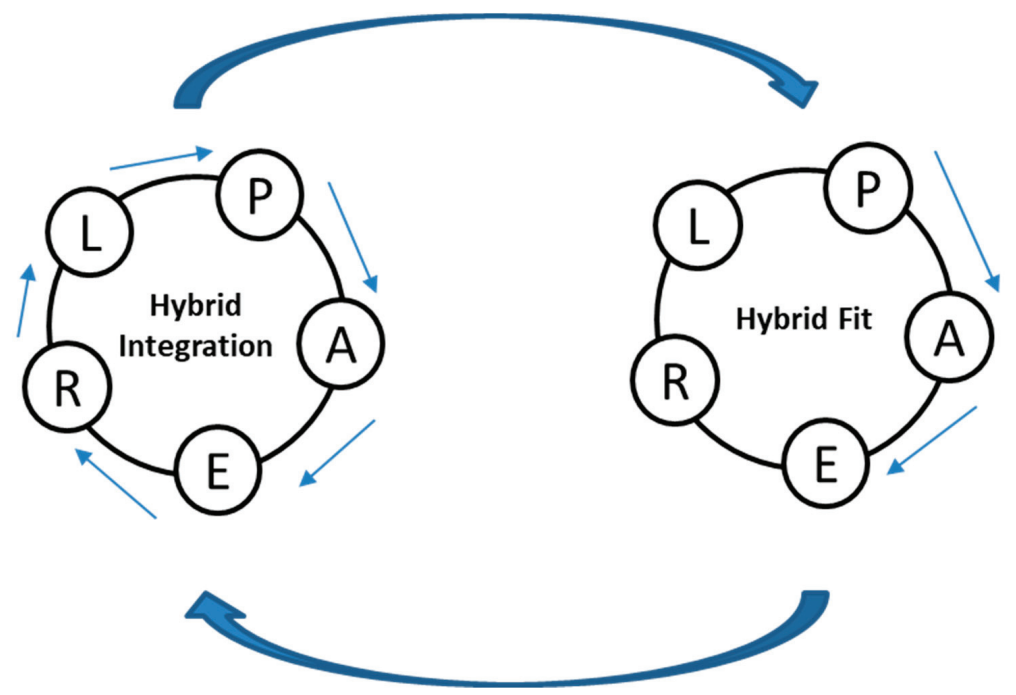

Figure 6. Case 2 iterations proceeded back and forth when solving the power production demanded by the digital environment.

The hybrid fit iteration was based on weekly schedules and plans. In that iteration, the possible lack in power consumption was identified. There was a need to check the layout designs, and the corrections were made accordingly—one iteration in design integration was conducted to update the structural changes to layout. The Hybrid fit iteration continued with the updated plans.

In both cases, one noticed that the iterations could happen simultaneously, either hindering or enabling the core iteration. In case 2, it was important to react on the requirement of power consumption and fix the problem before it began harming the users' daily life.

\subsection{Entry Point Analysis Stage 4: Hybrid Fix}

\subsubsection{Hybrid Fix in Case 1}

The hybrid fix stage in case 1 has been running for 18 months now. In that time, the Neighbor-zone has been enlarged. On top of this, the interior design has been slightly improved. The hybrid fix of new environment had the following steps in the iteration:

- Planning the evaluation and identification of possible changes to the usability of hybrid working environment;

- $\quad$ suggesting amendments for it; 
- evaluating the effect of improvements;

- classifying the benefits and possible consequences;

- formalizing needed changes for workspace.

The experience mapping was made by digital user questionnaire $(n=8)$. According to the results, the distance to the former location was a dissatisfying factor. The work practices were based on face-to-face tutoring and lecturing in the former location, while research processes were conducted in the new location. The physical dissatisfaction factors were taken care of according to the feedback, but the digital procedures in the work processes were not discussed. The expected enrichment for the previous working environment and its technology was not achieved properly.

\subsubsection{Hybrid Fix in Case 2}

In case 2, the hybrid fix stage started with the handover of physical place since the technology was not ready. The use with existing portable technology made it possible to use the current space.

Experience mapping was made by observing, interviewing, and conducting a userquestionnaire $(n=6)$. The feedback was gathered and reflected. Based on the results of the interviews and questionnaire, the atmosphere at Future Tech Lab is comfortable for co-learning and co-working. Renewed space is usable and functional for a wide variety of activities. Observation indicated that the acoustic is supporting remote presence-based collaboration as well as face to face collaboration. Now the gathered data has not yet been used to develop the environment further, because there have been some delays in production and installation of the novel technology.

The hybrid fix pointed out two clusters of experiences. Experiences of presence in the hybrid working environment are discussed both from the physical presence and the digital presence perspectives. The indoor environment can support both experiences, e.g., by good acoustics. The other cluster is experience of distance. The physical distance between different locations can be "shortened" by digital collaboration.

\subsubsection{Summary of the Results}

To sum up the results, the following recommendations for co-designing hybrid working environments can be proposed:

1. The hybrid vision of the future digital and physical solution needs to also consider the attitude and ability to use the digital solution.

2. The integration of digital environment is easier to realize in functional zones of the physical environments instead of smaller spatial units, e.g., workstations.

3. The iterations in the co-design process can happen simultaneously, and they can proceed back and forth. This may hinder or enable the improvement of the final solution. The awareness of the iterations makes it easier to manage the process.

4. The experience of hybrid working environment is not only an experience of digital platform or physical space: It is more an experience of presence and distance.

The Entry Point Analysis (EPA)-tool as a framework to analyze whether the co-design of the hybrid working environments is worth developing further. This trial indicated that hybrid vision, hybrid integration, hybrid fit, and hybrid fix provide concepts and process description which can be followed by the stakeholders of digital and physical working environments, as well by users. The Entry Point Analysis-tool made it possible to identify iterations around physical and digital objects stage by stage. It is important to visualize and follow the co-design process, not only the processes of design.

The entry point analysis indicated that the needs of the users for both physical and digital working environments need to be considered in a more integrated way than traditional usability briefing proposes. The user needs the work sets requirements for the digital solution. This technical layer sets requirements for the physical environment and elements. This was noticed, especially in the case 2 . The acoustic environment needed to be designed in the way that both digital and face to face collaboration have good quality for interaction. 
The entry point analysis applied from the Action Design Research approach also provides an agile perspective to the development of a more static physical working environment. This means that the usability challenges can be captured early enough to avoid usability challenges. However, if the digital and physical solutions are not integrated, one can still fail with the process. The use of a digital working environment for experiencing the physical location and distance differently would have made the user experience more satisfying. The factors for sense of presence are essential when designing a hybrid working environment.

The iteration frequency is committing the users. However, the tradition of ADRmodel itself does not point out as clearly the different stakeholders as the usability briefing model does. A process which distributed the co-design process appeared in case 1 . The disruption occurred due to the fact that the shared vision was too weak, and one needed to check different policies before continuing the process. In addition to the ADR process, there occurred a justification process seeking reasons to disrupt the ongoing co-design. This influenced the ADR process, especially in the design and implication stages. The process gave new ideas to the above stages that have not been mentioned previously in any workshop. The user-centered approach does not guarantee the successful outcome if the stakeholder representation is too limited.

Based on the literature review and case analysis, we state that to develop hybrid working environments, one needs to combine the ADR process model and usability process model. The entry point analysis-framework provides four key concepts for that: Hybrid vision, hybrid integration, hybrid fit, and hybrid fix.

\section{Conclusions}

This study explored the co-design challenges of hybrid working environments with an attempt to understand if there is a way to integrate two co-design approaches: The co-design of a usable built environment and the co-design of a digital environment. Both approaches focus on the process and user involvement. They differ in the length and rhythm of the process, as well as in feedback loops. The aim of the research was to explore how the conceptual framework of action design research (ADR) in Information Systems can be applied when the design object is a hybrid working environment. The exploration was made by integrating the agile digital design sprints and more static progress of built environments to the Entry Point Analysis-tool to analyze the co-design processes in two case studies of hybrid working environments.

The research question of how the action design research paradigm can be applied in understanding the usability challenges in a hybrid working environment is answered by developing and testing the Entry Point Analysis (EPA)-tool as a framework to analyze the co-design of the hybrid working environment. The hybrid vision provides a starting point for co-design to understand functions of the users conducted in digital and physical environments. The hybrid integration aims to seek both digital and physical solutions simultaneously, while hybrid fit aligns the solutions to one entity. Hybrid fix is a phase for feedback. Additionally, the EPA-tool identified iterations around physical and digital objects stage by stage, and it provided more insights into challenges of co-designing both physical and digital working environments simultaneously.

The article offers an explorative approach to understand the co-design of hybrid working environments, which are increasing. It points out the need of multidisciplinary approach to capture the design tradition of both digital and physical entities. Identification of integrated approach requires conceptual and contextual research, which is crossing the boarders of traditional design approaches.

Practical contribution is based on the result, which provided input to the co-design of hybrid working environments. It is not a question only of the hybrid solutions, but also the ability and skills to use it. The hybrid working environment is easier to understand as functional zones in the physical environment than only places which are enriched with technology. The co-design of hybrid working environments is a complex process where 
one need to identify the steps taken forward and backward, as the process is not a linear path. All in all, a hybrid working environment is an experience. By co-designing the digital and physical working environment, one is co-designing the experience of presence and distance. The hybrid working environment requires learning from users and designers to identify not only the needs of the users for hybrid working environments, but also the competences to use the digital and physical solutions for different functions and purposes.

The findings of this study must be seen in the light of some limitations. The first is the number of cases. The second limitation concerns the size of cases. Both limitations effect the generalization of the results. Nonetheless, these results must be interpreted with caution of the limitations. Additionally, the more objective approach to process analysis increases the reliability. The analysis was made by researchers representing both a real estate approach and an information technology approach. More interdisciplinary backgrounds could have brought more insights to the analysis. The EPA-tool requires more validation.

The future studies focusing on the success of the hybrid working environment are needed. The impact of co-design and use of the EPA-tool as a tool to guide the process is an interesting topic for both case studies and for a longitudinal research approach. The amount of hybrid working environments are increasing, the experts of built environments and digital environments will work more closely in the future, both in practice and research. The provision of healthy and sustainable hybrid working environments requires new insights. This exploration is one step in that direction.

Author Contributions: Conceptualization, M.L. and S.N.; methodology, M.L. and S.N.; validation, M.L.; data analysis, M.L.; writing, M.L.; review and editing, S.N.; visualization, M.L.; supervision, S.N.; All authors have read and agreed to the published version of the manuscript.

Funding: This research received no external funding.

Institutional Review Board Statement: Not applicable.

Informed Consent Statement: Not applicable.

Data Availability Statement: Data sharing not applicable.

Conflicts of Interest: The authors declare no conflict of interest.

\section{References}

1. Mullarkey, M.T.; Hevner, A.R. An elaborated action design research process model. Eur. J. Inf. Syst. 2019, 28, 6-20. [CrossRef]

2. Ninnemann, K.; Liedtke, B.; den Heijer, A.; Gothe, K.; Loidl-Reisch, C.; Nenonen, S.; Nestler, J.; Tieva, Å.; Wallenborg, C. Hybrid Environments for Universities; Waxmann Verlag: Münster, Germany, 2020. [CrossRef]

3. Raes, A.; Detienne, L.; Windey, I.; Depaepe, F. A systematic literature review on synchronous hybrid learning: Gaps identified. Learn. Environ. Res. 2020, 23, 269-290. [CrossRef]

4. Sonntag, D.; Albuquerque, G.; Magnor, M.; Bodensiek, O. Hybrid learning environments by data-driven Augmented Reality. Procedia Manuf. 2019, 31, 32-37. [CrossRef]

5. Fronczek-Munter, A. Usability Briefing-A Process Model for Healthcare Facilities, Proceedings of CIB Facilities Management Conference 2014: Joint CIB W070, W111 and W118 Conference, Copenhagen, Denmark, 21 May 2014; Polyteknisk Boghandel og Forlag: Lyngby, Denmark, 2014; pp. 266-279.

6. Pope, N.; Apiola, M.-V.; Salmento, H.; Islam, N.; Lahti, M.; Sutinen, E. The Latest in Immersive Telepresence to Support Shared Engineering Education. In Proceedings of the 2020 IEEE Frontiers in Education Conference (FIE), Uppsala, Sweden, 21-24 October 2020; IEEE: New York, NY, USA, 2020; pp. 1-5. [CrossRef]

7. Tynjälä, P.; Välimaa, J.; Sarja, A. Pedagogical perspectives on the relationships between higher education and working life. High Educ. 2003, 46, 147-166. [CrossRef]

8. Herrington, A.; Herrington, J. Authentic Learning Environments in Higher Education; IGI Global: London, UK, 2005. [CrossRef]

9. Van Merriënboer, J.J.; Kirschner, P.A.; Kester, L. Taking the load off a learner's mind: Instructional design for complex learning. Educ. Psychol. 2003, 38, 5-13. [CrossRef]

10. van Weert, T.J.; Pilot, A. Task-based team learning with ICT, design and development of new learning. Educ. Inf. Technol. 2003, 8, 195-214. [CrossRef]

11. Goodyear, P.; Jones, C.; Asensio, M.; Hodgson, V.; Steeples, C. Effective networked learning in higher education: Notes and guidelines. Retrieved May 2001, 17, 2006.

12. Zitter, I.; Kinkhorst, G.; Simons, R.J.; ten Cate, O. In search of common ground: A task conceptualization to facilitate the design of (e) learning environments with design patterns. Comput. Hum. Behav. 2009, 25, 999-1009. [CrossRef] 
13. Zitter, I.; De Bruijn, E.; Simons, R.-J.; Ten Cate, O. The role of professional objects in technology-enhanced learning environments in higher education. Interact. Learn. Environ. 2012, 20, 119-140. [CrossRef]

14. Van Merriënboer, J.J.; Clark, R.E.; De Croock, M.B. Blueprints for complex learning: The 4C/ID-model. Educ. Technol. Res. Dev. 2002, 50, 39-61. [CrossRef]

15. Zitter, I.; Hoeve, A. Hybrid learning environments: Merging learning and work processes to facilitate knowledge integration and transitions. OECD Educ. Work. Pap. 2012, 81. [CrossRef]

16. Chen, B.H.; Chiou, H.-H. Learning style, sense of community and learning effectiveness in hybrid learning environment. Interact. Learn. Environ. 2014, 22, 485-496. [CrossRef]

17. Ibáñez, M.B.; Maroto, D.; García Rueda, J.; Leony, D.; Delgado Kloos, C. Architecture for collaborative learning activities in hybrid learning environments. J. Univers. Comput. Sci. 2012, 18, 2187-2202. [CrossRef]

18. Halford, S. Hybrid workspace: Re-spatialisations of work, organisation and management. New Technol. Work Employ. 2005, 20, 19-33. [CrossRef]

19. Moriset, B.; Malecki, E.J. Organization versus space: The paradoxical geographies of the digital economy. Geogr. Compass 2009, 3 , 256-274. [CrossRef]

20. Marchegiani, L.; Arcese, G. Collaborative spaces and coworking as hybrid workspaces: Friends or foes of learning and innovation? In Learning and Innovation in Hybrid Organizations; Palgrave Macmillan: Cham, Switzerland, 2018; pp. 51-71.

21. Gandini, A. The Rise of Coworking Spaces: A Literature Review, Ephemera: Theory and Politics in Organization. 2015, 15, 1, 193-205. Available online: https://air.unimi.it/retrieve/handle/2434/618721/1152525/Ephemera_ASN.pdf (accessed on 19 March 2021).

22. Bostman, R.; Rogers, R. What's Mine Is Yours: How Collaborative Consumption Is Changing the Way We Live; Collins: London, UK, 2011.

23. Hilli, C.; Nørgård, R.T.; Aaen, J.H. Designing hybrid learning spaces in higher education. Dan. Univ. Tidsskr. 2019, 15, 66-82.

24. Stommel, J. Hybridity, pt. 2: What is hybrid pedagogy? Hybrid. Pedagog. 2020. Available online: https://hybridpedagogy.org/ hybridity-pt-2-what-is-hybrid-pedagogy (accessed on 1 March 2021).

25. Yin, R.K. Case Study Research: Design and Methods 4th Edition, United States: Library of Congress Cataloguing-in-Publication Data; Sage Publications: Thousand Oaks, CA, USA, 2009. [CrossRef]

26. Lindahl, G.; Blakstad, S.; Hansen, G.K.; Nenonen, S. USEframe-A framework to understand and map usability research. In Proceedings of the 6th Nordic Conference on Construction Economics and Organisation-Shaping the Construction/Society Nexus, Copenhagen, Denmark, 13 April 2011; pp. 83-95.

27. Jensen, P.A.; Alexander, K.; Fronczek-Munter, A. Towards an Agenda for User Oriented Research in the Built Environment. In Nordic Conference on Construction Economics and Organisation: Shaping the Construction/Siciety Nexus; Danish Building Research Institute, Aalborg University: Aalborg, Denmark, 2011; pp. 55-56.

28. Hevner, A.R.; March, S.T.; Park, J.; Ram, S. Design science in information systems research. Mis Q. 2004, 75-105. [CrossRef]

29. Alexander, K.; Blakstad, S.; Hansen, G.; Jensen, P.A.; Lindahl, G.; Nenonen, S. Usability: Managing facilities for social outcomes. Facil. Manag. Maint. 2013, 136. [CrossRef]

30. Breitmayer, B.J. Triangulation in qualitative research: Issues of conceptual clarity and purpose. Qual. Nurs. Res. Contemp. Dialogue 1991, 19, 226-239.

31. Hoendervanger, J.G.; De Been, I.; Van Yperen, N.W.; Mobach, M.P.; Albers, C.J. Flexibility in use. J. Corp. Real Estate 2016. [CrossRef] 


\title{
Organisational Justice Analysis of Facility Managers' Responses to User's Post-Occupancy Feedback
}

\author{
Abiodun Olatunji Abisuga *, Cynthia Changxin Wang and Riza Yosia Sunindijo \\ School of Built Environment, The University of New South Wales, Sydney, NSW 2052, Australia; \\ cynthia.wang@unsw.edu.au (C.C.W.); r.sunindijo@unsw.edu.au (R.Y.S.) \\ * Correspondence: o.abisuga@unsw.edu.au
}

Citation: Abisuga, A.O.; Wang, C.C.; Sunindijo, R.Y. Organisational Justice Analysis of Facility Managers' Responses to User's Post-Occupancy Feedback. Buildings 2021, 11, 144. https://doi.org/10.3390/

buildings 11040144

Academic Editor: Per Anker Jensen

Received: 28 December 2020

Accepted: 25 March 2021

Published: 1 April 2021

Publisher's Note: MDPI stays neutral with regard to jurisdictional claims in published maps and institutional affiliations.

Copyright: (C) 2021 by the authors Licensee MDPI, Basel, Switzerland. This article is an open access article distributed under the terms and conditions of the Creative Commons Attribution (CC BY) license (https:// creativecommons.org/licenses/by/ $4.0 /)$.
Abstract: There has been growing interest in how to foster collaborative relationships between facility managers and end-users to obtain user-centred post-occupancy data for improving design and user satisfaction. Despite this attempt, there is little understanding on how facility managers respond to user feedback and its impact on user post-feedback behaviours. Drawing from theoretical insights from organisational justice, organisational response, and service quality studies and using a case study of higher education facilities in Australia, how facility managers manage user feedback to drive collaboration between facility managers and users during occupancy is explored. Various methods were used in this case study research, including document analysis, interviews, and observations. The research findings indicate that facilitation, timeliness, redress, apology and explanation, and attentiveness and efforts are applicable to facilities management (FM) services and could influence user post-feedback behaviour. Current responses to user feedback are not satisfactory, resulting in a poor relationship between facility managers and users that negates service acceptance and the engagement in a positive word-of-mouth. To foster more facility manager-user collaborative relationships in post-occupancy evaluation, and position FM as a service organisation, there is a need for improvements in current FM responses to user feedback and the effective management of user post-feedback behaviours.

Keywords: facilities management; facility managers; organisational justice; post-occupancy evaluation; user feedback

\section{Introduction}

Post-occupancy evaluation (POE) is a systematic approach used to collect user feedback on facilities performance [1]. Questionnaire, interview, and focus group are common techniques used to collect POE data from end-users. It was argued that POE could be used as a process to facilitate communication between facility managers and users [2,3]. However, these formal POE data collection techniques may not effectively support the day-to-day interactions between facility managers and users [4]. The evaluation of facilities in this research extends to include the day-to-day process of data collection on the facilities' performance from the end-users. This is a less formal process for collecting data more frequently than the traditional POE, and it is important to continuously support, enhance and examine the performance of facilities [5,6]. User post-occupancy feedback refers to the facilities' performance information collected from end-users and it is in the form of compliments and complaints [7]. User post-occupancy feedback can be gathered via both formal and informal channels, such as social media, internal memos, e-mail, face-to-face reporting and phone calls $[6,8,9]$. User post-occupancy feedback reflects users' needs and their level of satisfaction on the facilities in use [10].

End-users have been identified as one of the most relevant key stakeholders within facilities management (FM) relationships [11]. Coenen et al. [11] stated that strong relationships in FM can be achieved through the co-creation of services, integration of resources and effective communication. The co-creation of services between facility managers and 
end-users could only be possible through cooperation and collaboration. There is a need for an equal dialogue and exchange of ideas between the facility managers and end-users [11]. However, the tendency of facility managers to neglect users in the daily management of facilities has been criticised $[2,3,12]$. The inadequate two-way communication between facility managers and users negates the effectiveness of user feedback collection $[2,3]$. It was also argued that the value of FM services provided can only be defined by all the stakeholders and not just the facility managers [11]. Besides, it was found that facility manager responses to feedback contribute to different levels of user satisfaction [13]. Indeed, in FM, while there has been some research into user satisfaction with the performance of facilities [14], there is little research into FM responses to feedback and the post-feedback behaviour of users after their feedback has been handled [7].

There is a need to improve facility manager-user relationship in the day-to-day evaluation of facilities performance via effective communication [3]. The relationship between the facility manager and users can be influenced by the level of openness and trust in resolving user complaints $[15,16]$. Facility managers need to improve their level of fairness in responding to users' requests [7]. Organisational justice means the fairness with which a service organisation responds to customer or employee issues. Campbell and Finch [17] claimed that the application of organisational justice can enhance two-way communication in the FM industry. It is inevitable for facilities users to make demands and how their demands are resolved is crucial. Davidow [18] pointed out that the service providers' effort should be appraised and assessed from the viewpoint of feedback response. Organisational justice principles could enhance customer experience and remodel FM services as a service organisation [17], and an appropriate feedback response could facilitate continuous commissioning where services target customer requirements [6]. Remodelling FM services as a service organisation would involve the use of innovative business models to inform FM practices. However, organisational justice and response research is argued to be undeveloped and under-theorised, particularly in the field of FM [7,17] and empirical research into facility manager-user relationship in the evaluation of facilities performance remains scant and largely anecdotal $[2,7,19]$. Furthermore, while the theme of organisational justice and response to customer complaints has been on the retail and service organisational research agenda for many years $[18,20,21]$, research into how this operates in the evaluation of facilities performance is rare [6,7]. To overcome this research gap, the purpose of this research is to explore the value of organisational justice and response theory in answering the following research questions.

1. How do facility managers respond to user post-occupancy feedback?

2. How do facility managers' responses to user post-occupancy feedback influence user behaviours?

\subsection{Organisational Justice and Response Perspective in Post-Occupancy Feedback}

For this research, organisational justice refers to the degree to which users view themselves as being fairly treated by the facility managers in relation to the facilities they are using and responses to their feedback. Prior post-occupancy evaluation (POE) studies show some degree of users' dissatisfaction with the performance of some facilities provided [22], whereas there is a need to improve user satisfaction [23]. Users tend to express dissatisfaction when the facilities do not adequately support their activities [7], and when such dissatisfaction extends beyond a certain level of tolerance, they may lodge formal complaints [24]. The way organisations respond to complaints is critical [25] because it determines the customer service encounter, which represents interactions between the service provider and the customer regarding the service rendered [26]. The relationships and interactions between the users and facility managers determine the service encounter experience during the post-occupancy phase of facilities. The use of the organisational justice theory to evaluate service encounter and recovery procedures has been rarely explored in FM studies [7,17]. 
The organisational justice theory is an extract of the social exchange theory and equity theory and is based on social psychology [27]. Previous studies on service organisations research have applied a three-dimensional approach, when studying organisational justice, that is, distributive, procedural and interactive justice $[28,29]$ as shown in Figure 1. Distributive justice is the fairness of the complaint and the final recovery outcome based on customer perception [28,30]. Procedural justice, regarding the provision of feedback, is the perceived equity of policies, processes and the mechanisms available to support feedback reporting and responsiveness [18]. Customer perceptions of procedural justice can be improved if customers are given the chance to provide information and voice their concerns before decisions are taken [29]. The opportunity for customers to present information and voice their complaints that require appropriate actions by an organisation are the voice and choice effects in procedural justice (see Figure 1). Interactional justice deals with interpersonal interactions during the process of service delivery [31]. Some researchers classify interactional justice into interpersonal and informational justice [32]. Interpersonal justice refers to the equity of the action towards the customers during the service encounter [33], while informational justice is the perceived equity of the suitability and rightfulness of clarifications [32]. The interactional justice focuses on the service provider's effort, empathy and politeness towards the customers [30].

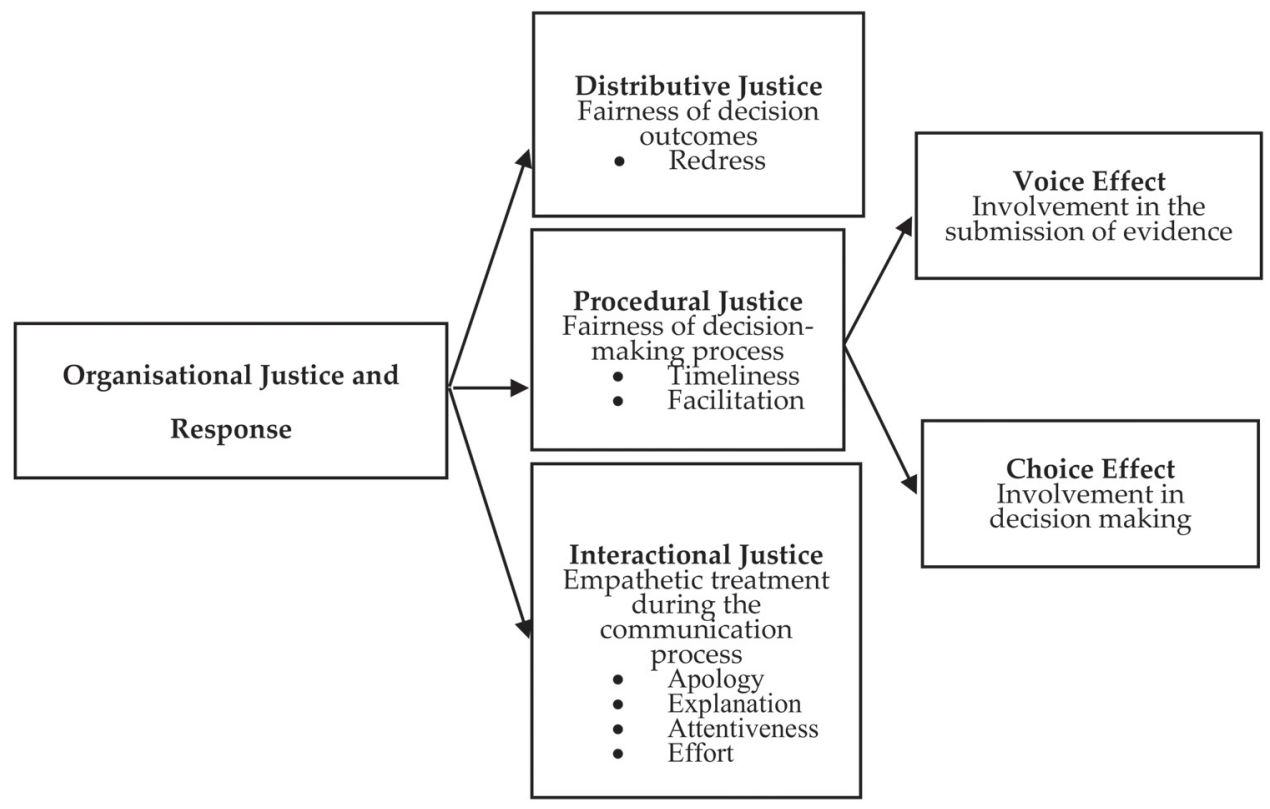

Figure 1. Dimensions of organisational justice and response theory. Adapted from Abisuga et al. [7].

Different commentators have examined the links between the three organisational justice dimensions in regard to customer satisfaction and post-complaint behaviours [31,34]. However, Davidow [18] argued that organisational justice dimensions cannot give an appropriate measure of the equity in the actions taken by the organisations, and the organisational action should be examined based on organisational responses to feedback. Davidow [18] contented that the justice dimensions required to be re-classified to extend a relational framework which can evaluate the attribute of handling customer feedback. Davidow $[18,20]$ proposed six response dimensions which are attentiveness, apology, timeliness, redress, facilitation, and explanation, whereas Karatepe [33] and Cai and Chi [35] believed that effort is another response dimension, because of the amount of effort involved in resolving a feedback is paramount. Further, Karatepe's [33] study relates redress with 
distributive justice; facilitation and timeliness with procedural justice; and attentiveness, apology, effort and explanation with interactional justice (See Figure 1).

As mentioned above, there is a scanty discourse in the literature on what accounts for an appropriate response procedure to user feedback in the FM context. A synthesis of previous studies has indicated the dimensions of an appropriate response to feedback based on organisational responses and justice theory. These dimensions are facilitation, timeliness, redress, apology, explanation, attentiveness, and effort (see Table 1). Table 1 indicates the description of the organisational responses dimensions and the operationalised items, that is, the measurable variables. The idealised FM operational items of dimensions are derived from variables used in previous studies on organisational justice and responses $[18,33,36]$.

Table 1. Core responses dimensions to user feedback.

\begin{tabular}{|c|c|c|}
\hline Dimensions & Definition of Dimensions & Idealised FM Operational Items of Dimensions \\
\hline Facilitation & $\begin{array}{l}\text { "The policies, procedures, and structure that } \\
\text { a company has in place to support customers } \\
\text { engaging in complaints and } \\
\text { communications" [18] (p. 232). }\end{array}$ & $\begin{array}{l}\text { It was easy to determine where to lodge my complaints. } \\
\text { The facilities management (FM) unit policies made it clear } \\
\text { how to lodge complaints. } \\
\text { The FM unit should develop a policy guideline for } \\
\text { complaints reporting. } \\
\text { Too much paperwork was required during the process. }\end{array}$ \\
\hline Timeliness & $\begin{array}{l}\text { "The perceived speed with which an } \\
\text { organisation responds to or handles a } \\
\text { complaint" [18] (p. 232). }\end{array}$ & $\begin{array}{l}\text { The facility managers reacted to my complaint very fast and } \\
\text { resolved it. } \\
\text { The facility managers' response to my complaints was very } \\
\text { slow. } \\
\text { The facility managers were not fast in dealing with issues. }\end{array}$ \\
\hline Redress & $\begin{array}{l}\text { "The benefits or response outcome that a } \\
\text { customer receives from the organization in } \\
\text { response to the complaint" [18] (p. 232). }\end{array}$ & $\begin{array}{l}\text { The facility I complained about was properly fixed. } \\
\text { The way my complaint was handled had no impact on the } \\
\text { condition of the facility I complained about. } \\
\text { The way my complaint was handled further worsens the } \\
\text { state of the facility I complained about. }\end{array}$ \\
\hline Apology & $\begin{array}{l}\text { "An acknowledgement by the organization } \\
\text { of the complainant's distress" [18] (p. 232). }\end{array}$ & $\begin{array}{l}\text { I did not receive any form of apology from the facility } \\
\text { managers. } \\
\text { The facility managers gave me a genuine apology. } \\
\text { I received a sincere "I'm sorry" from the FM unit. }\end{array}$ \\
\hline Explanation & $\begin{array}{l}\text { "This is the ability or willingness of the } \\
\text { service provider to explain the reason for the } \\
\text { problem or failure that caused user } \\
\text { complaints" [7] (p. 8). }\end{array}$ & $\begin{array}{l}\text { The facility manager did not give me any explanation at all } \\
\text { I did not believe the facility manager's explanation of why } \\
\text { the problem occurred. } \\
\text { The facility manager's explanation of the problem was not } \\
\text { comprehensive enough for me to address future occurrence. }\end{array}$ \\
\hline Attentiveness & $\begin{array}{l}\text { "The interpersonal communication and } \\
\text { interaction between the organizational } \\
\text { representative and the customer" [18] (p. } \\
\text { 232). }\end{array}$ & $\begin{array}{l}\text { The facility managers were quite pleasant to deal with. } \\
\text { The facility manager appreciates me making a complaint. } \\
\text { The facility manager paid attention to my concerns. }\end{array}$ \\
\hline Effort & $\begin{array}{l}\text { Effort is the amount of time and energy spent } \\
\text { by the service provider representative to } \\
\text { accomplish a task [7] (p.8). }\end{array}$ & $\begin{array}{l}\text { The facility manager worked at his/her full capacity to } \\
\text { resolve my complaint. } \\
\text { The facility manager strived as hard as possible to be } \\
\text { successful in resolving my complaint. } \\
\text { The facility manager devoted himself/herself to resolving } \\
\text { my complaint. }\end{array}$ \\
\hline
\end{tabular}

Thus, the service quality (SERVQUAL) model is often applied to FM research to measure customer satisfaction with FM service quality $[37,38]$. However, the model has been criticised to lack the potential to measure service encounter outcomes [38,39]. It is important that facility managers provide appropriate and satisfactory responses to users' requests and complaints during service delivery. Campbell and Finch [17] attested that a productive two-way communication between facility managers and users can lead to 
collaborative decision making in FM. Therefore, for FM organisations to competitively position themselves as service providers [40], and effectively manage customer satisfaction and post-feedback behaviour, facility managers need to be conscious of how customers are treated during service encounters $[41,42]$.

\subsection{Impacts of Organisational Response on Customer Post-Feedback Behaviour}

Previous studies in service research have investigated the interrelationships between the response dimensions and post-complaint behaviours, such as satisfaction, intention to repurchase and word-of-mouth (WOM) $[18,35]$ as shown in Table 2. Table 2 indicates the descriptions of the user post-feedback behaviour dimensions and the operationalised items, that is, the measurable variables. The idealised FM operational items of dimensions are derived from variables used in previous studies on organisational justice and responses impacts on post-complaint customer behaviour $[18,33,36]$.

Table 2. Core user post-feedback behaviour dimensions.

\begin{tabular}{cll}
\hline Dimensions & \multicolumn{1}{c}{ Definition of Dimensions } & \multicolumn{1}{c}{ Idealised FM Operational Items of Dimensions } \\
\hline $\begin{array}{c}\text { Relationship } \\
\text { satisfaction }\end{array}$ & $\begin{array}{l}\text { "Relationship satisfaction is the users' overall } \\
\text { feeling with the way a service provider has } \\
\text { handled their feedback" [7] (p.10). }\end{array}$ & $\begin{array}{l}\text { I am satisfied with the channel of communication and } \\
\text { interaction with the facility managers. } \\
\text { I am satisfied with the facility managers" responses to my } \\
\text { feedback and will collaborate. } \\
\text { I now have a more positive attitude towards the FM units. }\end{array}$ \\
\hline $\begin{array}{l}\text { Word-of-mouth } \\
\text { FM services } \\
\text { (Intention to } \\
\text { repurchase) }\end{array}$ & $\begin{array}{l}\text { It is the information that people tell each } \\
\text { other rather than it being in written form. }\end{array}$ & $\begin{array}{l}\text { I will say positive things about the FM services to other } \\
\text { people. } \\
\text { I am likely to tell as many people as possible about my } \\
\text { negative experience. }\end{array}$ \\
\hline $\begin{array}{l}\text { This is the willingness of a customer to } \\
\text { service provider. In relation to FM, it is the } \\
\text { willingness of a user to continuously utilise } \\
\text { the facilities provided [7] }\end{array}$ & $\begin{array}{l}\text { I will probably prefer to move to another better space due to } \\
\text { how my complaint was handled. } \\
\text { I prefer not to use the facility due to poor services. } \\
\text { Encourage friends and colleagues to utilise and accept the } \\
\text { facilities. } \\
\text { Recommend the facilities to someone who seeks your } \\
\text { advice. }\end{array}$ \\
\hline
\end{tabular}

For instance, Stevens et al. [43] confirmed that timeliness of service delivery helps to prevent the customer from engaging in negative word-of-mouth; whereas Estelami [44] confirmed that promptness positively influences the level of satisfaction with the complaint handling procedure. Einwiller and Steilen [45] argued that redress is the most critical part of the response to feedback which has a significant impact on satisfaction. In addition, [45] stated that just apologising does not have a significant influence on customer satisfaction, but apologies are anticipated responses to complaints. Additionally, Ali et al. [46] found that an apology has no significant influence on customer intention to repurchase the products. Karatepe [33] found that an explanation impacts interactional justice, because an explanation supports interactions between the customers and the service provider, while Saad and Zaki [34] stated that it is essential for a service provider to provide an explanation of the situation and effort taken to resolve the complaints. Davidow [20] stated that attentiveness has a positive significant impact on satisfaction and repurchase behaviour. In relation to effort dimension, Karatepe [33] stated that effort has a more significant impact on interactional justice than apologies and explanations. In another study, Davidow [20] established that there is a positive significant relationship between satisfaction, repurchase intention and word-of-mouth. Additionally, user satisfaction fosters engaging in positive word-of-mouth that inspires other users to utilise the facilities provided $[47,48]$. Cai and Chi [35] attested that service organisations with written feedback handling procedures and policies, facilitates customer feedback, and supports continuous service improvements. 
As mentioned above, there are interrelationships between organisational responses dimensions and post-complaint customer behaviours. Therefore, it is important to measure the relationships between organisational responses dimensions and post-complaint customer behaviours. This is because it enables organisations to appraise customers' attitude after their complaints are resolved. Few studies have used the SERVQUAL model to appraise how end-users feel about facility managers' action when responding to users' requests, whereas no study has adopted organisational responses dimensions to analyse facility manager-user relationships in the day-to-day evaluation of facilities performance. Abisuga et al. [7,19] proposed a conceptual framework for facility managers' responses to user post-occupancy feedback and their impact on user post-feedback behaviours as indicated in Figure 2, which shows the framework for hypothetical relationships among the response dimensions and user post-feedback behaviours. However, there is no comparable research into facility managers' responses to user feedback and user post-feedback behaviour in the context of organisational justice and responses dimensions. As such, this research addresses this gap by conducting an in-depth case study.

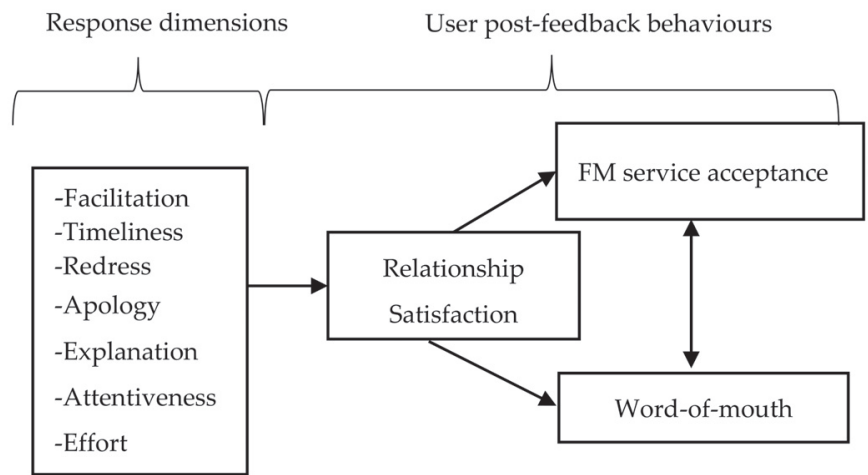

Figure 2. Hypothetical framework for facility managers responses to user post-occupancy feedback and behaviour. Adapted from Abisuga et al. [7].

\section{Methods}

\subsection{Case Study Selection}

The purpose of this research is to examine the value of organisational justice and response in understanding how facility managers handle user feedback, and the resulting user post-feedback behaviours. To achieve this, two research questions and a hypothetical framework was established based on previous studies. To seek answers to the questions, a case study approach was adopted. Noor [49] (p. 1603) stated that a case study is useful in "capturing the emergent and immanent properties of life in organizations and the ebb and flow of organization activity, especially where it is changing very fast". To select an appropriate case study organisation, it was paramount to target an organisation that needs continuous day-to-day capturing of facilities performance, and where it is essential to sustain a good relationship between facility managers and the users. Reviews of POE studies indicated that higher educational facilities were one of the most targeted building types subjected to performance evaluation [50]. Higher educational institutions (HEIs) were considered for this purpose due to their large building stocks with building services required to support daily operations and the need for daily users' feedback.

Buildings in HEIs have a wide range of spaces with different functions to support the daily activities of a variety of users, including students, staff, and public visitors. As pointed out by Price et al. [51], user requirements of these spaces change over time, and this can influence users' perceptions, and therefore it is a very challenging task to ensure these spaces meet end-users' needs [10]. Facility managers in HEIs have a responsibility to ensure the provision of functional facilities to support the daily activities of all the 
users. It has been argued that the identification of user needs is one of the challenges facing facility managers in HEIs [52], and it is essential for facility managers to be more conversant with diverse user needs to improve user satisfaction [13]. In this case study, an HEI building accommodating Built Environment disciplines in an Australian University was selected. This institution was selected for this research because of the availability of access $[53,54]$, allowing the researchers to observe the building users and occupants for an extended period of time [54]. This provides a better understanding of a real-life user's post-occupancy experience within the selected institution.

The selected faculty building was designed in 1997 with a passive design system that governs the indoor environment quality of the facility. The building has 8 floors (ground, mezzanine, and level 1-6) and a basement. The building comprises of staff offices, teaching and learning spaces, studios, computer labs, lecture hall, toilets, elevators, staircases, and open spaces (see Figure 3a-d). The users of this building, i.e., the students and staff, were considered as prospective research participants, while the staff in charge of the management of the building were considered as the FM personnel. Some of the major components of the facility and methods for controlling the indoor environment includes air conditioning, cross ventilation (comprises of manual louvres), daylighting control (provision of clerestory windows, internal voids, and large facing glazing), exposed thermal mass, heating devices (provision of a mobile personal heater, convertor heaters and gas heater) and the manual operation of the passive system.

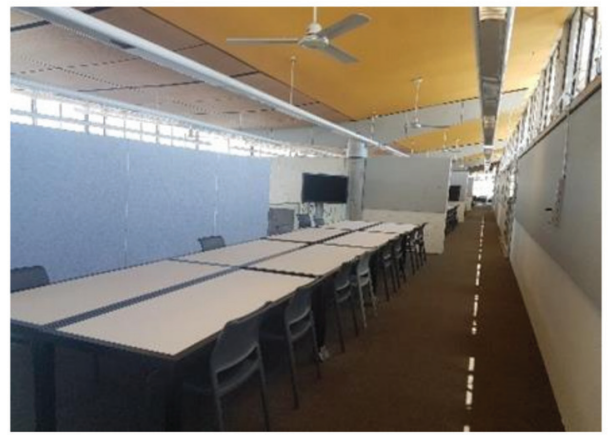

(a)

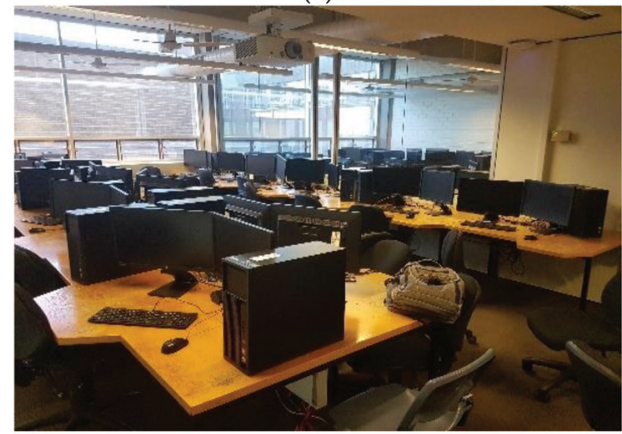

(c)

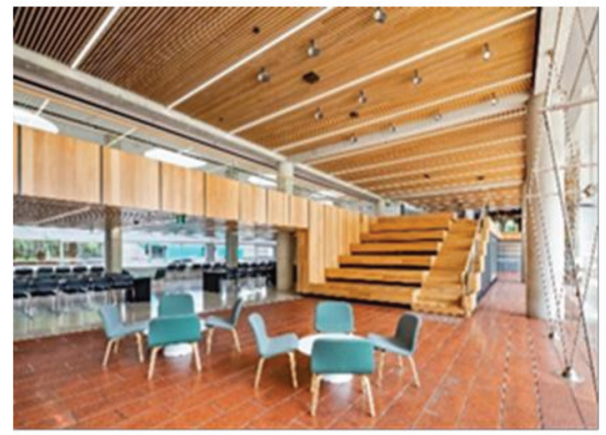

(b)

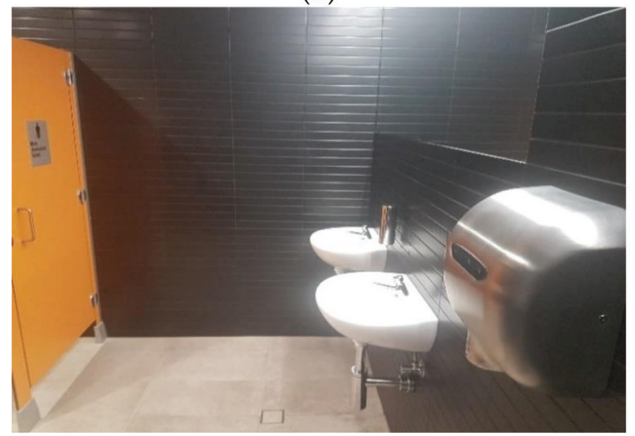

(d)

Figure 3. (a) Study spaces and classroom level 6; (b) newly renovated learning spaces; (c) computer lab at level 3; (d) toilet at basement. 


\subsection{Data Collection and Analysis}

The study adopts a qualitative method based on the process of interpretivism (constructivism) epistemology and subjectivism ontology. Constructivism recognises that many different stakeholders in an HEI would have different post-occupancy experiences of the performance of facilities in use and on that account individually fashion their own subjective understanding and interpretation of their FM services encounter [54,55]. Interpretivist epistemology, which consists of qualitative methods of data collection and analysis, is an in-depth interaction with the respondents in the natural setting of an educational institutions [56,57]. This research has obtained the required ethics approval (HC180574) before the commencement of data collection. This approval covers the participant selection process, data collection and analysis procedure, data storage, participant confidentiality and dissemination of results. All the necessary terms of the ethics approval were adhered to during the conduct of the research, and individual participants, including facility manager, students and staff, are not identifiable.

To carry out the case study investigation, semi-structured interviews were conducted. This involved targeting various students and members of staff within the selected building to gain a balance perception. Figure 4 shows the process of conducting the data collection and analysis. First, participants were randomly invited to take part in the interviews through email and face-to-face, in which the aim of the research was explained. Those who were interested gave their consent to participate in the interview process. Second, among the participants who indicated their interest to participate in the interview, the interviewed participants were purposefully selected from those who have interacted, provided feedback to, or have had any encounter with, the facility management unit.

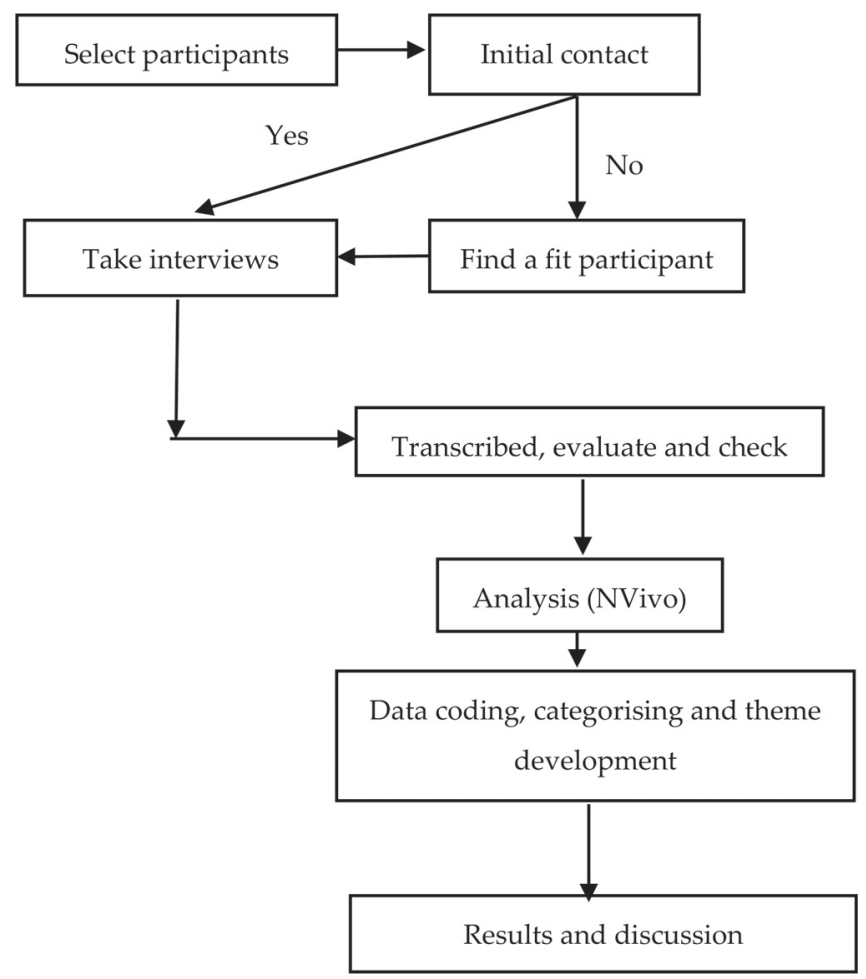

Figure 4. Data collection and analysis process. 
Semi-structured interviews were conducted with the intention to corroborate the ideas obtained from previous studies and verify the hypothetical framework in relation to the research questions, using an HEI as a case study. The interview sessions were targeted to collect opinions and to extract new ideas from participants who were experienced in the post-occupancy feedback process. A total of 29 participants were interviewed as users of the facilities and their profile is presented in Table 3. According to Bazeley [58], the adequacy of the sample size of ten is tenable because saturation could occur with any number greater than six. As pointed out by some previous researchers, the size of the sample in qualitative research becomes irrelevant when the population considered is a small group with experience of a specified topic $[59,60]$. The participants were classified into three groups: academic staff, administrative staff, and students. According to Table 3, 17 students, 5 academic staff and 7 administrative staff participated in the interview. Additionally, the participants have been occupying the building between 1-12 years. A total of 14 males and 15 females were interviewed.

Table 3. Demographic of participants.

\begin{tabular}{cccc}
\hline Participants Code & Role & Gender & Years of Occupancy \\
\hline SE01 & Student & Male & 2.5 years \\
SE02 & Student & Male & 2 years \\
SE03 & Student & Female & 2.5 years \\
SE04 & Student & Female & 2 years \\
SE05 & Student & Female & 1 year \\
SE06 & Student & Male & 3.5 years \\
SE07 & Student & Female & 2 years \\
SE08 & Student & Male & 3 years \\
SE09 & Student & Male & 3 years \\
SE10 & Student & Female & 4 years \\
SE11 & Student & Male & 4 years \\
SE12 & Student & Female & 3.5 years \\
SE13 & Student & Female & 2 years \\
SE14 & Student & Male & 5 years \\
SE15 & Student & Male & 4 years \\
SE16 & Student & Female & 5 years \\
SE17 & Student & Male & 4 years \\
AS18 & Academic staff & Male & 2 years \\
AS19 & Academic staff & Female & 10 years \\
AS20 & Academic staff & Male & 6 years \\
AS21 & Academic staff & Female & 12 years \\
AS22 & Academic staff & Male & 11 years \\
PS23 & Administrative staff & Female & 8 years \\
PS24 & Administrative staff & Female & 6 years \\
PS25 & Administrative staff & Female & 10 years \\
PS26 & Administrative staff & Male & 8 years \\
PS27 & Administrative staff & Female & 5 years \\
PS28 & Administrative staff & Male & 6 years \\
PS29 & Administrative staff & Female & 6 years \\
\hline & & & \\
\hline
\end{tabular}

The interview questions were based on the idealised FM operational items of dimensions, as highlighted in Tables 1 and 2. The participants were asked questions on how facility managers handled their day-to-day complaints or requests about the performance of the facilities provided. The day-to-day user post-occupancy feedback reported to the facility managers' focus on indoor air quality, thermal comfort, acoustic comfort, visual comfort, cleanliness, accessibility, maintenance and management, and safety and security. The most common feedback channels used by the participants to report their complaints and requests are through email and face-to-face.

The semi-structured interviews were conducted face to face and by telephone. The participants were interviewed from October 2018 to April 2019. Each interview lasted ap- 
proximately 40-90 min and were recorded after receiving the participants' permissions. All recorded interviews were transcribed with all participants' information being anonymised. NVivo software can facilitate the analysis of large text used in qualitative research, construct code, themes and categories, and generate data visualisation [61]. The data collected were analysed with a thematic approach using NVivo Pro. NVivo Pro was used to code and generate sub-themes from the participants' narratives, which were categorised under the FM response dimensions (main themes). Further, NVivo Pro was employed to establish visualisation with word cloud and cluster analysis to establish a word similarity metric within nodes with Pearson's correlation coefficient. Cluster analysis is an exploratory technique that can be used to visualise pattens within nodes that share similar words, whereas a similarity metric is a statistical method utilised to calculate the correlation between items. The visualisation with the word cloud reflects the degree to which participants referenced a particular theme, whereas the cluster analysis indicates possible links and interrelationships between the participants' referencing of the themes.

The transcripts were then analysed, coded, and compared against the findings of previous studies on whether FM responses conform with the organisational response dimensions, as operationalised in Tables 1 and 2. The thematic analysis conducted using NVivo Pro enables the generation of sub-themes categorised under the main themes. A total of 194 references were generated, which were categorised into 22 sub-themes and 8 main themes (see Table 4). The findings of the research are presented in the narrative form buttressed by selected quotes from the interviews. Additionally, supporting information from POE records, such as indoor air quality, thermal comfort, temperature condition, equipment provided, lighting, cleanliness, flexibility of layout and toilet were considered.

Table 4. Number of nodes and reference found in NVivo analysis.

\begin{tabular}{|c|c|c|c|c|c|}
\hline Research Focus & $\begin{array}{l}\text { Main Themes } \\
\text { (Nodes) }\end{array}$ & $\begin{array}{l}\text { No. of Sub- } \\
\text { themes } \\
\text { (Nodes) }\end{array}$ & Sub-Themes & Source & References \\
\hline \multirow{5}{*}{$\begin{array}{l}\text { FM response } \\
\text { dimensions }\end{array}$} & FM Facilitation & 3 & $\begin{array}{l}\text { Unclear modes of communication } \\
\text { Lack of FM policy for feedback reporting } \\
\text { Difficulty in accessing FM personnel }\end{array}$ & 25 & 40 \\
\hline & FM timeliness & 3 & $\begin{array}{l}\text { Reactive nature of FM } \\
\text { Lack of promptness in FM services } \\
\text { provision } \\
\text { FM services provided at designated time }\end{array}$ & 19 & 27 \\
\hline & FM redress & 3 & $\begin{array}{l}\text { Inappropriate FM services and repairs } \\
\text { rendered } \\
\text { Neglect of user feedback on the } \\
\text { performance of repaired facilities } \\
\text { Uncertainty of the standard of FM } \\
\text { services and repairs rendered }\end{array}$ & 27 & 32 \\
\hline & $\begin{array}{l}\text { FM apology and } \\
\text { explanation }\end{array}$ & 3 & $\begin{array}{l}\text { Need for FM politeness and respect in } \\
\text { handling feedback } \\
\text { Unconvincing FM apology } \\
\text { Unacceptable FM explanation }\end{array}$ & 12 & 13 \\
\hline & $\begin{array}{l}\text { FM attentiveness } \\
\text { and effort }\end{array}$ & 3 & $\begin{array}{l}\text { Lack of FM personnel willingness to help } \\
\text { users } \\
\text { Lack of FM personnel effort to } \\
\text { understand user needs } \\
\text { Lack of FM personnel attention to user } \\
\text { requests }\end{array}$ & 5 & 10 \\
\hline
\end{tabular}


Table 4. Cont.

\begin{tabular}{|c|c|c|c|c|c|}
\hline Research Focus & $\begin{array}{l}\text { Main Themes } \\
\text { (Nodes) }\end{array}$ & $\begin{array}{l}\text { No. of Sub- } \\
\text { themes } \\
\text { (Nodes) }\end{array}$ & Sub-Themes & Source & References \\
\hline \multirow{5}{*}{$\begin{array}{c}\text { User } \\
\text { post-occupancy } \\
\text { feedback } \\
\text { behaviour } \\
\text { dimensions }\end{array}$} & $\begin{array}{l}\text { FM relationship } \\
\text { satisfaction }\end{array}$ & 3 & User dissatisfaction with FM relationship & 26 & 34 \\
\hline & & & $\begin{array}{l}\text { Lack of facility manager-user } \\
\text { collaborative relationship } \\
\text { Neglect of user participation in FM } \\
\text { decision making }\end{array}$ & & \\
\hline & $\begin{array}{l}\text { FM service } \\
\text { acceptance }\end{array}$ & 2 & $\begin{array}{l}\text { Need for provisions to improve FM } \\
\text { services } \\
\text { Utilisation of facilities due to lack of } \\
\text { alternatives }\end{array}$ & 14 & 23 \\
\hline & Word-of-mouth & 2 & $\begin{array}{l}\text { Engaging in negative word-of-mouth } \\
\text { Engaging in positive word-of-mouth }\end{array}$ & 12 & 15 \\
\hline & Total & 22 & & 140 & 194 \\
\hline
\end{tabular}

The majority of the participants indicated that they have not had opportunities to participate in a comprehensive POE exercise. The last comprehensive POE result of the building in record was conducted in 2011. It is important to note that some of the POE issues complained about in the outcome of the POE conducted in 2011 are similar to the current user post-occupancy feedback. Post-occupancy issues, such as acoustics between offices and classrooms, temperature conditions, sizes of staff offices, and cleanliness of the toilets, are still lingering issues raised in the user post-occupancy feedback. This research has considered user post-occupancy feedback provided to the facility managers through email and face-to-face, and the user perceptions on how facility managers handled the feedback. These user perceptions could be influenced by some factors, such as age, climate, season, language, gender, and roles [62-64]. The impacts of these factors were not investigated in this research.

\section{Results and Discussion}

This section is divided into two parts to address research questions one and two, and the hypothetical framework. The first part discusses the findings relating to research question one on how facility managers handle user post-occupancy feedback, in accordance with the seven response dimensions from the organisational response criteria, including facilitation, timeliness, redress, apology and explanation, and attentiveness and effort, as shown in Figure 2. The second section deals with the findings of the impact of facility managers' responses to user feedback on user post-feedback behaviours, that is, FM relationship satisfaction, FM service acceptance and word-of-mouth as in the hypothetical framework (see Figure 2).

\subsection{FM Responses to User Feedback}

\subsubsection{FM Facilitation}

FM facilitation is the policies, procedures, and structure that facility managers need to put in place to support user feedback reporting. Facilitation is classified under the procedural justice dimension (see Figure 1). The findings of the research showed that FM facilitation was principally depicted by participants in the case study as dissatisfactory. Some of the participants believed that FM still lacks an appropriate communication structure and policy that could support facility manager-user collaboration in the day-to-day evaluation of educational facilities. This means that the current FM practice, to some extent, does not encourage user participation in day-to-day post-occupancy feedback or does not consider the importance of user feedback in decision making. 
“Ignorance is not an excuse. Maybe there is a policy in place that I don't have access to. For me definitely it will be good to have a policy in place which should be implemented to get FM response, and feedback from users". (AS18)

The research findings also indicated that poor FM facilitation could result in time wasted, frustration, and discouragement because it is difficult for users to know how, who and where to report facilities performance.

"I guess it is not clear whom to contact. I don't know whom to give feedback to, so it takes a lot of time, is frustrating and does not encourage me to give feedback". (SE02)

Another issue raised by the majority of participants is that they felt that they have limited access to report their complaints directly to facility managers for prompt attention. Participants believed that the responses to their requests were always delayed due to the bureaucratic structure puts in place so that users must report to a third party instead.

“Unfortunately, we didn't even know where to complain to. But honestly, nothing was complained to the FM, but we complain to the support service assistance. But of course, we will get results as quickly as possible if we all have the channels to report. Because it's just like one party to another party which ends up with another party". (SE01)

In contrast, some of the participants believed it is appropriate to lodge their complaints with FM representatives within their faculty building. This approach of direct communication with a third party was appraised to be an effective procedure of providing information to the facility managers.

"Yes, very easy since we have an operation manager within the faculty". (AS22)

Some participants also indicated that reporting to the third party may delay the FM response. Our findings revealed that email is the primary communication link between the users and FM representatives.

"If we have issues in our facilities or office, we send an e-mail to the FM representative so they can help us". (SE 05)

The importance for the provision of a clearly defined FM policy for the feedback process was discussed, and it was revealed that the implementation of a clearly defined FM policy will ease complaints procedure and standardise the feedback process.

"The school should come up with a policy to enhance the synergy on how the users are meant to respond. It will enhance the process of users complaining on time and the FM responding on time. And maybe collaborating". (SE04)

The findings revealed that the current FM policies and structure is inadequate and does not support effective communication between the users and facility managers. This research finding supports Kamaruzzaman et al. [65] and Odediran et al. [66] who found that FM organisations still lack policy implementation. Therefore, the current FM practice needs to be improved to foster user collaboration tendency as succinctly stated by participant SE02, "I mean the interaction is too low currently". Cai and Chi [35] found that service organisations with established written feedback handling procedures and policies inspire customer feedback and continuous improvements. Therefore, encouraging user postoccupancy feedback necessitates facility managers to be explicit and provide open access for all users to report and review the feedback process. This suggestion aligns with Stevens et al. [43] who said that openness and clarity are essential in managing customer feedback. The inadequate support of FM facilitation within the case area is an indication that the practice of procedural justice is inappropriate. Additionally, this may negate end-users' perceived fairness of FM decision making regarding the day-to-day evaluation of facilities performance. 


\subsubsection{FM Timeliness}

FM timeliness is the speed with which facility managers respond to a complaint, and timeliness is categorised with procedure justice. The findings showed that some of the participants were satisfied, whereas some were not with the responsiveness of facility managers to their feedback.

"I think it is fair enough. They respond on time". (SE03)

"No, it's very slow. Mostly one week, I think. They are not efficient". (SE05)

This finding reveals that the facility managers in charge of the building are slow in responding to user post-occupancy feedback. The results support the argument of Eley [67] and Odediran et al. [66], who stated that facility managers are reactive in responding to feedback, and in managing and maintaining facilities.

"No, we are not satisfied, the communication is poor, the response is slow. Sometimes it takes like 3 months before the facility problems are rectified". (AS19)

It was also confirmed that FM timeliness could influence user satisfaction, word-ofmouth, and collaboration. Davidow [20] and Estelami [44] established that timeliness has a significant impact on satisfaction and word-of-mouth. Improving FM service quality dimensions such as responsiveness to feedback will increase FM performance [68].

"Anyways we always discuss the facility managers issues because their activities and facilities provided are not encouraging" (SE10)

"Of course. Since I am the user of the system, I will do that with pleasure; to collaborate and give timely response if the facility managers too will respond promptly". (AS22)

\subsubsection{FM Redress}

FM redress is the outcome(s) the users receive from the facility managers responding to their complaints. Redress deals with the distributive justice, which is a measure to ascertain the fairness of the decision outcome. Most of the participants expressed their dissatisfaction with FM redress to their post-occupancy feedback. They complained that the facility managers' redress has not met their expectations. The observation and interviews revealed that according to users, most of the facilities' problems that they had complained about have not been corrected. Additionally, they opined that when facility managers address facilities problems, sometimes the situation remains the same or is worsened. The participants believed they should be involved in the day-to-day evaluation of the facilities, and their inputs should be considered during FM decision making. This aligns with Hua [2] who argued that users should be integrated in the POE decision making. Further, participants indicated that the quality of FM redress may depend on providing feedback directly to the facility managers.

"So yes, when you are not involved in the decision making, you cannot say something has improved or the other way around". (SE05)

"Of course, that aspect may also be worrying your productivity and it becomes a problem, or you end up reporting to the wrong person who may not have the chance to do anything about what's happening". (SE01)

The result shows the need for effective interactions between facility managers and users in addressing post-occupancy issues. As stated by Abisuga et al. [69], there is a need for a collaborative FM approach in the evaluation of facilities performance such as POE.

\subsubsection{FM Apology and Explanation}

An FM apology refers to the facility managers' acknowledgement of users' distress, whereas an FM explanation is the willingness of the facility managers to explain the reason behind the problem that caused the user complaints. Apology and explanation are grouped under interactional justice, which is the empathetic treatment during the communication 
process. The findings revealed that facility managers should provide a convincing apology and explanation when FM services fail to meet user expectations. This is to show that facility managers are genuinely concerned with user needs and acknowledge the limitation of the FM in meeting such needs in a timely manner. This gesture could positively affect the facility manager-user relationship satisfaction.

"Subsequently if people are complaining and they don't really know if those things are addressed, then FM should be able to let people know why they can't address them. Like bear with us if it is in terms of finance, there should be motivation, good communication with clients". (PS26)

Further, few participants agreed that facility managers sometimes give an apology and explanation, and even when they did, participants were dissatisfied with such an apology and explanation. The participants complained that facility managers are not always sincere in fulfilling their promise to resolve some facilities problems reported.

“They don't usually give reasons or apology. They will say they haven't approved the budget. The only reason they usually give is that they don't have the adequate fund to carry out all maintenance". (SE11)

"Yes, they would explain and sometime apologise, with no solution". (SE04)

The above findings indicate that some of the basic constraints that influence FM performance reflect in the way facility managers respond to feedback, and the gap between facility manager-user communication negates shared understanding that results in dissatisfaction. Facility managers need to further improve their relationships with the users to foster collaboration by apologising and providing credible explanations. This suggestion conforms with Karatepe [33] who said that a proper explanation can actually foster productive interactions between the customers and service providers. This research indicates the need to improve interaction justice within the case area. That means the facility managers in charge of the faculty building should be more empathetic in interacting with end-users.

\subsubsection{FM Attentiveness and Effort}

FM attentiveness is the interpersonal communication between the facility manager and the user, whereas FM effort is the amount of time and energy spent by the facility manager to resolve a complaint. Attentiveness and effort are also grouped under interactional justice. The research findings indicate that facility managers do not usually give adequate attention and efforts in resolving user feedback.

"Most of them just do things without considering users' feelings or thoughts". (SE03)

"We have so many reports on this, but they have not responded. We still expect the management to act on them, it is discouraging". (PS25)

Importantly, the findings point to the fact that a lack of FM attention and efforts in resolving user feedback can negate facility manager-user collaboration. As stated by Davidow [20], attentiveness has a positive significant relationship with customer satisfaction and repurchase behaviour. The finding implies that facility managers need to give adequate attention and efforts to address user post-occupancy feedback to encourage user participation in the evaluation of facilities performance.

"If someone complains about something and less than one week it is done, ...

people can see that if I talk, someone is listening, then we can collaborate with them". (PS27)

To explain the FM response further, a word cloud was generated based on the number of references indicated under the FM response dimensions extracted from the interview using NVivo Pro (refer to Table 4). As shown in Figure 5, facilitation, redress, timeliness, apology and explanation are important FM responses. Facilitation is the most frequent 
matter raised by the participants, implying that FM facilitation has a strong potential to influence the relationship between facility managers and users. Our findings reveal that FM facilitation is poor due to unclear modes of communication, lack of FM policy and guidelines for feedback reporting and difficulty in accessing FM personnel. These findings support Schoenefeldt [3] and Odediran et al. [66] that FM organisation lacks policy implementation and effective communication with stakeholders. As mentioned earlier, service providers, who have established written customer feedback handling policies and procedures, encourage customer feedback and can make improvements from it [35]. Therefore, it is important that facility managers in charge improve the procedure of communicating the day-to-day facilities performance.

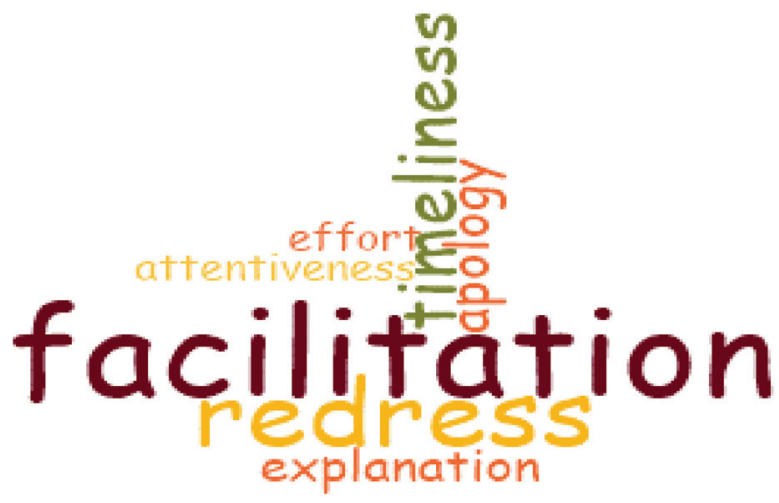

Figure 5. Word cloud for FM response dimensions.

Another key point is to understand how facility managers are redressing feedback. FM redress is mainly achieved by corrective or preventive actions, such as repairs and replacement. The findings indicate that FM redress is essential to foster user satisfaction, thus, appropriate redress should follow user post-occupancy feedback in a timely manner. Most of the participants indicated that they were dissatisfied with the current mode of FM redress. This is because most time user inputs are not considered in the redress process, and most FM decisions are not user-centred. We also observed that there are some user requirements that maybe difficult to be redressed by the facility manager. According to the previous POE results of the building and the consultant's recommendations, such requirements can only be redressed through a massive remodification of the building. This implies that building design and characteristics could limit some FM redress and negate the fulfilment of user requests.

Some participants believed that facility managers were not responsive enough in handling their requests. However, it is essential to note that FM timeliness is influenced by many factors such as the nature of requests and the availability of funds. It was noticed that facility managers were not proactive in redressing post-occupancy issues such as indoor temperature and illumination in some sections of the building. The timely redress of user post-occupancy feedback related to the building design including inadequate office and toilets spaces and noise control are difficult. Another example of user feedback that was not proactively resolved was the provision of a portable water and kitchenette in post graduate students' study spaces. The installation of the portable water and kitchenette involved redesigning and remodification which required planning, and had cost implications. Facility managers in charge of the building need to inform the users about any limitation influencing FM timeliness.

The participants claimed that the facility managers were characterised with an unconvincing apology and explanation. Additionally, sometimes facility managers were not polite and respectful in responding to user feedback. The findings reveal that facility man- 
agers lack the willingness to assist users and sometimes do not pay much attention to user requests. Despite the importance of facilitation, redress, timeliness, apology, explanation, attentiveness and effort and their impact on feedback satisfaction, the current FM response to user feedback was deemed inadequate. The FM response is important to maintain facility manager-user collaborative relationships. As the appropriate handling of user feedback could encourages more user's participation in day-to-day evaluation of facilities performance. The findings of the research support the hypothetical framework in Figure 2, indicating that FM responses corroborate organisational response criteria including facilitation, timeliness, redress, apology, explanation, attentiveness, and effort stipulated in previous studies. Besides, the findings provide new insights into the importance of FM responses to user post-occupancy feedback and a new insight that requires further research.

\subsection{User Post-Feedback Behaviours}

The second part of this section addresses the research question two on how facility managers' responses to user feedback influence post-feedback behaviour. The questions asked during the interviews were based on the idealised FM operational items of postfeedback behaviour dimensions in Table 2. According to the hypothetical framework in Figure 2, it was envisaged that there could be interrelationships between FM response dimensions, satisfaction, and user post-feedback behaviours (word-of-mouth and service acceptance) as discussed below:

\subsubsection{FM Relationship Satisfaction}

FM relationship satisfaction is the users' overall feeling with the way a facility manager handles their post-occupancy feedback. In the case study, participants indicated dissatisfaction with their relationship with the facility managers. Participants majorly complained about facility managers' neglect of users' participation, poor communication, and facility managers' reactive nature.

"I agree to that because I am not part of decisions. Honestly, we have some suggestions to give about the facilities, but we are not asked". (SE02)

"Oh, relationship between us and those facility managers is not good. I don't think collaboration will be easy". (SE03)

Ogbeifun et al. [70] stated that FM units lack customer relationship management because they have not been able to meet user needs and do not possess effective communication skills. Relationship satisfaction is essential for fostering collaboration [71] and based on our results, there is a need to improve facility manager-user relationship satisfaction to foster collaboration in the day-to-day evaluation of facilities performance. Importantly, the level of relationship satisfaction could influence post-feedback behaviour [18].

\subsubsection{FM Services Acceptance and Word-of-Mouth}

FM service acceptance is the willingness of a user to continuously utilise the facilities provided. Some of the participants were satisfied with the FM services provided, but they believed better FM services are needed.

"Yeah, I like the facility provided. Yes, I believe they can do more and better.

There are lots of things they can do better, and they can do more". (C1-SE03)

"We keep using some of the facilities because we got no other choices". (PS25)

Word-of-mouth is the information that people tell each other without being put in writing. In the case study, some of the participants engaged in both positive and negative word-of-mouth concerning the performance of the facilities. The findings showed that participants expressed their grievances negatively among themselves, and within and outside the institutions. This outcome aligns with Kwun et al. [47] who found that FM service quality has a positive significant impact on word-of-mouth intention. 
"It is going to be like a compliment in 1,2,3 scenarios where an emergency alarm tripped up. But, I do express my dissatisfaction with colleagues". (C1-AS04)

To explain the post-feedback behaviour further, a word cloud was generated based on the number of references indicated under the post-feedback behaviour dimensions extracted from the interview using NVivo Pro (refer to Table 4). The word cloud visualisation revealed that the issues of facility manager-user relationship satisfaction were the most referenced dimension, followed by FM service acceptance and word-of-mouth (see Figure 6). It seems that users are concerned with their relationships with the facility managers. The users also expressed their dissatisfaction with the performance of the facilities in the institution. Poor facilities performance has the potential to cause users to reject the FM services provided [48], which negatively influences the relationship satisfaction between the users and facility managers. According to Stauss [72], customer dissatisfaction negatively influences relationship satisfaction and repurchase intention. Repurchase intention, in this case, is FM services acceptance, that is, user willingness to continuously utilise the facilities. It is also a known fact that dissatisfaction leads to negative word-of-mouth.

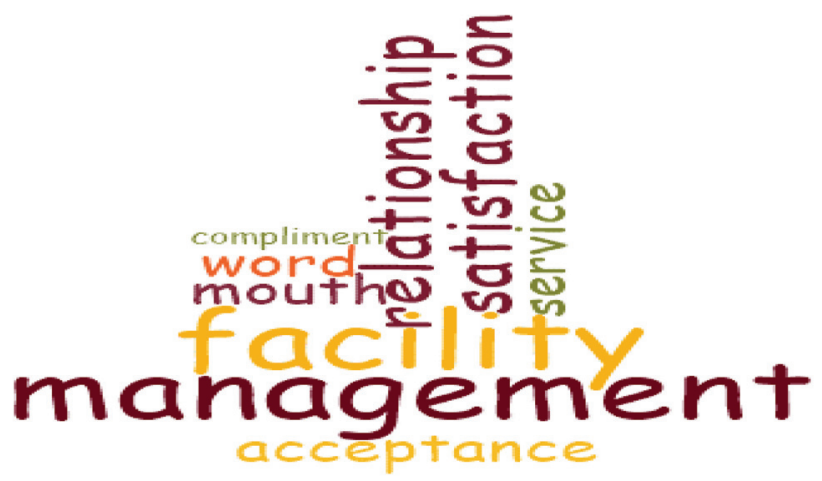

Figure 6. Word cloud for user post-feedback behaviour dimensions.

In order to establish the relationships between the dimensions, NVivo Pro was used to create a visualised circle graph indicating the similarity between the FM response dimensions and their impact on users' post-feedback behaviours. These similarities are indicated by connecting lines of varying thickness and colour. The similarity and dissimilarity are indicated by blue lines and red lines, respectively, whereas the thicker the lines, the stronger the similarity or dissimilarity (see Figure 7). The findings indicate there are possible interrelationships between the dimensions. For instance, a similarity relationship exists between relationship satisfaction, FM service acceptance and word-of-mouth (WOM). This finding shows that customer satisfaction could influence word-of-mouth and intention to repurchase $[18,35,37]$. According to Figure 7 , there is a strong similarity between relationship satisfaction and FM services acceptance. There is also an indication of a strong relationship between an FM apology and explanation and FM attention and effort. Other similarities also exist between relationship satisfaction and FM facilitation; between FM timeliness and FM attentiveness and efforts; between FM redress and FM attentiveness and efforts; and between word-of-mouth (WOM) and relationship satisfaction. Dissimilarities in opinions also exist between the dimensions. Dissimilarities occur between FM services acceptance and FM apology and explanation; FM timeliness and FM apology and explanation; relationship satisfaction and FM redress; relationship satisfaction and FM timeliness; and FM services acceptance and FM attentiveness and efforts. 


\section{Items clustered by word similarity}

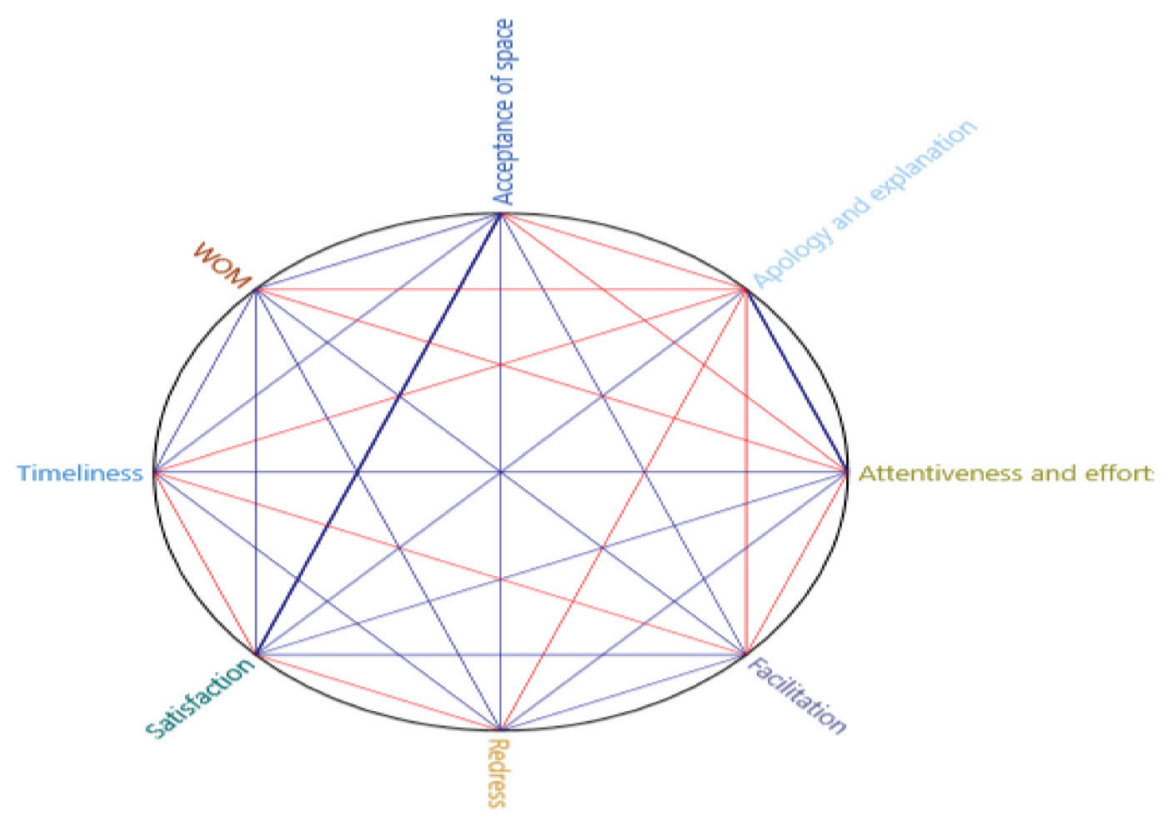

Figure 7. Word similarity of FM response dimensions and post-feedback behaviours.

User opinions about FM apology and explanation may not result in their satisfaction with FM services. This finding supports Einwiller and Steilen [45] and Ali et al. [46] that expressing regret or apologising alone does not have a significant impact on customer satisfaction, and their intention to repurchase the products. Facility managers should be more stakeholder friendly in handling user post-occupancy feedback. Further, facility managers should endeavour to render quality services to foster user satisfaction, word-ofmouth (WOM) and acceptance of FM services. This buttresses Coenen et al. [73] that the fulfilment of user expectations has a significant effect on user satisfaction. These findings show further evidence to the possibility of interrelationships between FM responses and user post-feedback behaviours, as indicated in the hypothetical framework in Figure 2.

The similarities and dissimilarities in the opinions of participants affirm the complexity of users' expectations. This aligns with Davidow's [20] argument that the customer will evaluate the service provider response in relation to the final outcome of the problems encountered. The difference in relationships between the FM response dimensions and user post-feedback behaviours could be due to certain factors such as user perception and FM approaches. This needs further investigation. In addition, the similarities and dissimilarities in the opinions of the users established in this research provoke the need for further quantitative approaches to confirm the causal relationships between the dimensions. Although research on user post-feedback behaviour in evaluation of facilities performance of HEIs context is rare, these findings channel a constructive avenue of future investigation to enhance the effectiveness of such practices in FM. 


\section{Conclusions}

This research was set within the context of organisational justice and response in the FM of a faculty building in an Australian university to address the lack of FM research into how facility managers handle user feedback and post-feedback behaviours. Achieving this, two research questions and a hypothetical framework were formulated to postulate possible relationships between FM response dimensions and user post-feedback behaviours in the day-to-day evaluation of facilities.

In answering research question one, the findings indicate that FM responses, including facilitation, timeliness, redress, apology and explanation, and attentiveness and efforts are potential effective techniques by which the facility managers can meet customer services responsibilities, particularly in HEIs. The case study result shows that FM responses to user feedback is poor, and there is a need to improve it. This can be achieved by the provision of effective means of communication, a clearly defined FM policy and procedures, acceptable FM redress, giving sincere apologies and credible explanations, and paying attention to and extending effort to resolve user needs. Some organisational barriers that could influence FM responses such as funds and availability of materials were highlighted. Based on the findings, it was suggested that facility managers need to be more user-friendly in their approach to foster collaboration in the day-to-day evaluation of facilities. Facility manageruser collaboration will facilitate the collection of user-centred information to inform existing and future design. It is essential for facility managers to develop institutional policy guidelines that stipulate their functions and how other stakeholders should relate with FM functions.

In answering research question two, the findings revealed that there are possible interrelationships between FM response dimensions and user post-feedback behaviours. It was shown that inadequate FM responses could negate facility manager-user relationship satisfaction, FM service acceptance (i.e., continue using the service) and positive wordof-mouth. Our results also established the fact that facility manager-user relationship satisfaction to some degree impacts the level of FM services acceptance and word-of-mouth. Furthermore, the research revealed that an improved facility manager-user satisfaction relationship can culminate to facility manager-user collaboration in POE. Facility managers should ensure that user feedback is properly handled to foster user participation in POE. This will advance the POE process in generating user-centred facilities performance data that can be employed to improve existing facilities and inform future design. In particular, our research contributes to the literature in FM organisational justice and responses, and post-feedback behaviours within FM research and practices by highlighting the importance of the need for appropriate user feedback handling by facility managers in the evaluation of facilities performance. Additionally, the research indicates the suitability of organisational justice and response to inform FM practice. This research supports the adoption of FM facilitation, FM timeliness, FM redress, FM attentiveness and effort and FM apology and explanation to measure performance of facility managers. It also positions FM services as a service organisation, particularly in educational settings.

The facility manager-user relationship would improve if the facility managers could adopt the organisational response dimensions in relating with the users during the postoccupancy phase. The practice of an acceptable FM response such as the provision of FM facilitation would support direct interaction between the facility manager and the user. This contributes to the efficient and effective practical way of improving user participation in providing post-occupancy feedback, and user involvement in FM decision making, particularly in managing educational facilities. The FM response framework has the potential to improve FM performance, increase user satisfaction and increase FM services acceptance. Acknowledging the inherent limitations of a case study approach, our small sample, and the complexity of FM and the relationship with the different user groups in the organisation, FM practices, diverse FM services provided, characteristics of the building, and the influence of institution management, further research is clearly needed to understand the impacts of FM responses on user post-feedback behaviours. Further research could 
examine larger samples in a single or multiple higher education institution(s), and in other facilities such as residential and commercial buildings. This research has also provoked the need for a quantitative research approach in establishing causal relationships between FM response dimensions and user post-feedback behaviours.

Author Contributions: Conceptualisation, data collection and analysis, original draft preparation, A.O.A.; methodology, review and editing, A.O.A., C.C.W. and R.Y.S.; supervision, C.C.W. and R.Y.S. All authors have read and agreed to the published version of the manuscript.

Funding: This research received no external funding.

Institutional Review Board Statement: The method used in this research was approved by the Human Research Ethics Committee of UNSW Built Environment (HC180574, Date: 24 October 2018).

Informed Consent Statement: Informed consent was obtained from all participants involved in the study.

Data Availability Statement: Data are available from the authors upon requests.

Conflicts of Interest: No potential conflict of interest was reported by the authors.

\section{References}

1. Preiser, W.F.E. Continuous quality improvement through post-occupancy evaluation feedback. J. Corp. Real Estate 2003, 5, 42-56. [CrossRef]

2. Hua, Y. Understanding POE for future building practices. Intell. Build. Int. 2013, 5, 133-134. [CrossRef]

3. Schoenefeldt, H. The House of Commons: A precedent for post- occupancy evaluation The House of Commons: A precedent for post-occupancy evaluation. Build. Res. Inf. 2019, 47, 635-665. [CrossRef]

4. Abisuga, A.O. Integrated Collaborative Facilities Management Framework for Post-Occupancy Evaluation of Higher Education Facilities. Ph.D. Thesis, University of New South Wales, Sydney, Australia, 2020. Available online: http://unsworks.unsw.edu. $\mathrm{au} / \mathrm{fapi} /$ datastream/unsworks:67407/SOURCE02?view=true (accessed on 20 November 2020).

5. Baird, G.; Dykes, C. The potential for the use of the occupants' comments in the analysis and prediction of building performance. Buildings 2012, 2, 33-42. [CrossRef]

6. Goins, J.; Moezzi, M. Linking occupant complaints to building performance. Build. Res. Inf. 2013, 41, 361-372. [CrossRef]

7. Abisuga, A.O.; Wang, C.C.; Sunindijo, R.Y. Facility managers' responses to user post-occupancy feedback: A conceptual framework. Facilities 2020, 38, 481-499. [CrossRef]

8. Mattila, A.S.; Wirtz, J. Consumer complaining to firms: The determinants of channel choice. J. Serv. Mark. 2004, 18, 147-155. [CrossRef]

9. Dalton, R.C.; Kuliga, S.F.; Hölscher, C. POE 2.0: Exploring the potential of social media for capturing unsolicited post-occupancy evaluations. Intell. Build. Int. 2013, 5, 162-180. [CrossRef]

10. Abisuga, A.O.; Wang, C.C.; Sunindijo, R.Y. A holistic framework with user-centred facilities performance attributes for evaluating higher education buildings. Facilities 2020, 38, 132-160. [CrossRef]

11. Coenen, C.; Alexander, K.; Kok, H. Facility management value dimensions from a demand perspective. J. Facil. Manag. 2013, 11, 339-353. [CrossRef]

12. Loftness, V.; Aziz, A.; Choi, J.H.; Kampschroer, K.; Powell, K.; Atkinson, M.; Heerwagen, J. The value of post-occupancy evaluation for building occupants and facility managers. Intell. Build. Int. 2009, 1, 249-268. [CrossRef]

13. Riratanaphong, C.; Limjaroensuk, S. Occupant satisfaction on facility services: Case studies of six multi-generational condominiums. Facilities 2020. [CrossRef]

14. Sanni-Anibire, M.O.; Hassanain, M.A.; Al-Hammad, A.-M. Holistic postoccupancy evaluation framework for campus residential housing facilities. J. Perform. Constr. Facil. 2016, 30, 04016026. [CrossRef]

15. Jensen, P.A.; Coenen, C.; van der Voordt, T.; Pfenninger, M.; von Felten, D.; Lindholm, A.; Nielsen, A.B.; Riratanaphong, C. In search for the added value of FM: What we know and what we need to learn. Facilities 2012, 30, 199-217. [CrossRef]

16. Bortolini, R.; Forcada, N. Analysis of building maintenance requests using a text mining approach: Building services evaluation. Build. Res. Inf. 2020, 48, 207-217. [CrossRef]

17. Campbell, L.; Finch, E. Customer satisfaction and organisational justice. Facilities 2004, 22, 178-189. [CrossRef]

18. Davidow, M. Organizational responses to customer complaints: What works and what doesn't. J. Serv. Res. 2003, 5, 225-250. [CrossRef]

19. Abisuga, A.O.; Wang, C.C.; Kamardeen, I. A Framework for Modeling FM Organizational Response to Users' Post-Occupancy Feedback. In Proceedings of the 42nd AUBEA Conference: Educating Building Professionals for the Future in the Globalised World, Singapore, 26-28 September 2018; Do, K., Sutrisna, M., Jonescu, E., Zaman, A., Eds.; Curtin University: Bentley, Australia, 2018; Volume 3, pp. 338-349. Available online: http:/ / handle.unsw.edu.au/1959.4/unsworks_55389 (accessed on 10 June 2019). 
20. Davidow, M. The bottom line impact of organizational responses to customer complaints. J. Hosp. Tour. Res. 2000, 24, 473-490. [CrossRef]

21. Ang, L.; Buttle, F. Complaints-handling processes and organisational benefits: An ISO 10002-based investigation. J. Mark. Manag. 2012, 28, 1021-1042. [CrossRef]

22. Abisuga, A.O.; Famakin, I.O.; Oshodi, O.S. Educational building conditions and the health of users. Constr. Econ. Build. 2016, 16, 19-34. [CrossRef]

23. Tucker, M.; Pitt, M. Improving service provision through better management and measurement of customer satisfaction in facilities management. J. Corp. Real Estate 2010, 12, 220-233. [CrossRef]

24. Gwynne, A.L.; Devlin, J.F.; Ennew, C.T. The zone of tolerance: Insights and influences. J. Mark. Manag. 2000, 16, 545-564. [CrossRef]

25. Ndubisi, N.O.; Ling, T.Y. Complaint behaviour of Malaysian consumers behaviour. Manag. Res. News 2005, 29, 65-76. [CrossRef]

26. Voorhees, C.M.; Fombelle, P.W.; Gregoire, Y.; Bone, S.; Gustafsson, A.; Sousa, R.; Walkowiak, T. Service encounters, experiences and the customer journey: Defining the field and a call to expand our lens. J. Bus. Res. 2017, 79, 269-280. [CrossRef]

27. Adams, J. Inequity in Social Exchange; Berkowitz, B., Ed.; Academic Press: Cambridge, MA, USA, 1965; pp. 267-299.

28. Maxham, J.G.; Netemeyer, R.G. Modelling customer perceptions of complaint handling over time: The effect of perceived justice on satisfaction and internet. J. Retail. 2002, 78, 239-252. [CrossRef]

29. Baldwin, S. Organisational Justice; Institute for Employment Studies: Brighton, UK, 2006.

30. Homburg, C.; Fürst, A. Handling drives customer loyalty: An analysis of the mechanistic and the organic approach. J. Mark. 2005, 69, 95-114.

31. Colquitt, J.A.; Rodell, J.B.; Zapata, C.P.; Scott, B.A.; Long, D.M.; Conlon, D.E.; Wesson, M.J. Justice at the millennium, a decade later: A meta-analytic test of social exchange and affect-based perspectives. J. Appl. Psychol. 2013, 98, 199-236. [CrossRef]

32. Colquitt, J.A. On the dimensionality of organizational justice a construct validation of a measure. J. Appl. Psychol. 2001, 86, 389-400. [CrossRef] [PubMed]

33. Karatepe, O.M. Customer complaints and organizational responses: The effects of complainants' perceptions of justice on satisfaction and loyalty. Int. J. Hosp. Manag. 2006, 25, 69-90. [CrossRef]

34. Saad, H.E.; Zaki, K.G. How do small hotels handle e-complaints in Egypt? Int. J. Herit. Tour. Hosp. 2017, 11, 228-243. [CrossRef]

35. Cai, R.; Chi, C.G.-Q. The impacts of complaint efforts on customer satisfaction and loyalty. Serv. Ind. J. 2018, 38, 1095-1115. [CrossRef]

36. Mateen, F.J.; Oh, J.; Tergas, A.I.; Bhayani, N.H.; Kamdar, B.B. Titles versus titles and abstracts for initial screening of articles for systematic reviews. Clin. Epidemiol. 2013, 5, 89-95. [CrossRef]

37. Olanrele, O.O.; Thontteh, E.O. FM service delivery and quality service measurement in public high rise residential buildings in Nigeria: The use of SERVQUAL and Satisfaction Index. J. Manag. Sustain. 2014, 4, 145-156. [CrossRef]

38. Karunasena, G.; Vijerathne, D.; Muthmala, H. Preliminary framework to manage tenant satisfaction in facilities management service encounters. Facilities 2018, 36, 171-194. [CrossRef]

39. Ladhari, R. A review of twenty years of SERVQUAL research. Int. J. Qual. Serv. Sci. 2009, 1, 172-198. [CrossRef]

40. Nardelli, G.; Rajala, R. The evolution of facility management business models in supplier-client relationships. J. Facil. Manag. 2018, 16, 38-53. [CrossRef]

41. Tucker, M.; Pitt, M. Customer performance measurement in facilities management: A strategic approach. Int. J. Product. Perform. Manag. 2009, 58, 407-422. [CrossRef]

42. Mulliner, E.; Tucker, M. Feedback on feedback practice: Perceptions of students and academics. Assess. Eval. High. Educ. 2017, 42, 266-288. [CrossRef]

43. Stevens, J.L.; Spaid, B.I.; Breazeale, M.; Jones, C.L. Timeliness, transparency, and trust: A framework for managing online customer complaints. Bus. Horiz. 2018, 61, 375-384. [CrossRef]

44. Estelami, H. Competitive and procedural determinants of delight and disappointment in consumer complaint outcomes. J. Serv. Res. 2000, 2, 285-300. [CrossRef]

45. Einwiller, S.A.; Steilen, S. Handling complaints on social network sites-An analysis of complaints and complaint responses on Facebook and Twitter pages of large US companies. Public Relat. Rev. 2015, 41, 195-204. [CrossRef]

46. Ali, I.; Gilal, R.G.; Shah, N. Impact of service recovery on repurchase intentions among customers of cellular industry of Pakistan. Grassroots 2017, 51, 76-92.

47. Kwun, D.J.-W.; Ellyn, E.; Choi, Y. Campus foodservice attributes and their effects on customer satisfaction, image, and word-ofmouth. J. Foodserv. Bus. Res. 2013, 16, 276-297. [CrossRef]

48. Kim, T.W.; Cha, S.; Kim, Y. Space choice, rejection and satisfaction in university campus. Indoor Built Environ. 2018, 27, $233-243$. [CrossRef]

49. Noor, K.B.M. Case study: A strategic research methodology. Am. J. Appl. Sci. 2008, 5, 1602-1604. [CrossRef]

50. Li, P.; Froese, T.M.; Brager, G. Post-occupancy evaluation: State-of-the-art analysis and state-of-the-practice review. Build. Environ. 2018, 133, 187-202. [CrossRef]

51. Price, I.; Matzdorf, F.; Smith, L.; Agahi, H. The impact of facilities on student choice of university. Facilities 2003, 21, 212-222. [CrossRef] 
52. Kamarazaly, M.A.; Mbachu, J.; Phipps, R. Challenges faced by facilities managers in the Australasian universities. J. Facil. Manag. 2013, 11, 136-151. [CrossRef]

53. Acharya, A.S.; Prakash, A.; Saxena, P.; Nigam, A. Sampling: Why and how of it? Indian J. Med. Spec. 2013, 4, 330-333. [CrossRef]

54. Bryman, A. Social Research Methods, 4th ed.; Oxford University Press: Oxford, UK, 2012.

55. Vrasidas, C. Constructivism and constitutionalism. Some implications for elementary mathematics education. Int. J. Educ. Telecommun. 2000, 6, 339-362. [CrossRef]

56. Yin, R.K. Case Study Research: Design and Methods; Sage publications: Thousand Oaks, CA, USA, 2009. [CrossRef]

57. Saunders, M.; Lewis, P.; Thornhill, A. Research Methods for Business Students, 7th ed.; Pearson Education Limited: London, UK, 2016. [CrossRef]

58. Bazeley, P.A.T. Qualitative Data Analysis: Practical Strategies; SAGE Publications: Thousand Oaks, CA, USA, 2013.

59. Mason, M. Sample size and saturation in PhD studies using qualitative interviews. Forum Qual. Soc. Res. 2010, 11. [CrossRef]

60. Perera, B.A.K.S.; Ahamed, M.H.S.; Rameezdeen, R.; Chileshe, N.; Hosseini, M.R. Provision of facilities management services in Sri Lankan commercial organisations: Is in-house involvement necessary? Facilities 2016, 34, 394-412. [CrossRef]

61. Alam, M.K. A systematic qualitative case study: Questions, data collection, NVivo analysis and saturation. Qual. Res. Organ. Manag. Int. J. 2020. [CrossRef]

62. Schweiker, M.; André, M.; Al-Atrash, F.; Al-Khatri, H.; Alprianti, R.R.; Alsaad, H.; Amin, R.; Ampatzi, E.; Arsano, A.Y.; Azar, E.; et al. Evaluating assumptions of scales for subjective assessment of thermal environments-Do laypersons perceive them the way, we researchers believe? Energy Build. 2020, 211, 109761. [CrossRef]

63. Beckers, R.; van der Voordt, T.; Dewulf, G. Learning space preferences of higher education students. Build. Environ. 2016, 104, 243-252. [CrossRef]

64. Yang, Z.; Becerik-Gerber, B.; Mino, L. A study on student perceptions of higher education classrooms: Impact of classroom attributes on student satisfaction and performance. Build. Environ. 2013, 70, 171-188. [CrossRef]

65. Kamaruzzaman, S.N.; Zawawi, E.M.A.; Shafie, M.O.; Noor, S.N.A.M. Assessing the readiness of facilities management organizations in implementing knowledge management systems. J. Facil. Manag. 2016, 14, 69-83. [CrossRef]

66. Odediran, S.J.; Gbadegesin, J.T.; Babalola, M.O. Facilities management practices in the Nigerian public universities. J. Facil. Manag. 2015, 13, 5-26. [CrossRef]

67. Eley, J. How do post-occupancy evaluation and the facilities manager meet? Build. Res. Inf. 2001, 29, 164-167. [CrossRef]

68. Amos, D.; Musa, Z.N.; Au-Yong, C.P. Performance measurement of facilities management services in Ghana's public hospitals. Build. Res. Inf. 2020, 48, 218-238. [CrossRef]

69. Abisuga, O.; Kamardeen, I.; Wang, C. Embedding Users in Collaborative FM Practice for Sustainable Post-Occupancy Evaluation of Higher Educational Buildings. In Proceedings of the 42nd AUBEA Conference: Educating Building Professionals for the Future in the Globalised World, Singapore, 26-28 September 2018; Do, K., Sutrisna, M., Jonescu, E., Zaman, A., Eds.; Curtin University: Bentley, Australia, 2018; Volume 3. Available online: https://docs.wixstatic.com/ugd/94be57_1da76390885d4923927 58eb95bbe7ac9.pdf (accessed on 10 June 2019).

70. Ogbeifun, E.; Mbohwa, C.; Pretorius, J.H.C. Facilities management unit: Improving self-image before its customers. Facilities 2016, 34, 956-975. [CrossRef]

71. Bond-Barnard, T.J.; Fletcher, L.; Steyn, H. Linking trust and collaboration in project teams to project management success. Int. J. Manag. Proj. Bus. 2018, 11, 432-457. [CrossRef]

72. Stauss, B. The dimensions of complaint satisfaction: Process and outcome complaint satisfaction versus cold fact and warm act complaint satisfaction. Manag. Serv. Qual. 2002, 12, 173-183. [CrossRef]

73. Coenen, C.; Waldburger, D.; von Felten, D. FM Servicebarometer: Monitoring customer perception of service performance. J. Facil. Manag. 2013, 11, 266-278. [CrossRef] 


\title{
Facilitating Building Projects' Short-Term and Long-Term Value Creation
}

\author{
Knut Boge ${ }^{1, *}$, Amin Haddadi ${ }^{2}$, Ole Jonny Klakegg ${ }^{3}$ and Alenka Temeljotov Salaj ${ }^{3}$ \\ 1 Department of Property and Law, Norwegian University of Life Sciences (NMBU), 1433 Ås, Norway \\ 2 Department of Civil Engineering and Energy Technology, Oslo Metropolitan University, 0130 Oslo, Norway; \\ danielam@oslomet.no \\ 3 Department of Civil and Environmental Engineering, Norwegian University of Science and Technology (NTNU), \\ 7491 Trondheim, Norway; ole.jonny.klakegg@ntnu.no (O.J.K.); alenka.temeljotov-salaj@ntnu.no (A.T.S.) \\ * Correspondence: knut.boge@nmbu.no
}

Citation: Boge, K.; Haddadi, A.; Klakegg, O.J.; Salaj, A.T. Facilitating Building Projects' Short-Term and Long-Term Value Creation. Buildings 2021, 11, 332. https://doi.org/ 10.3390/buildings11080332

Academic Editor: Per Anker Jensen

Received: 19 June 2021

Accepted: 22 July 2021

Published: 30 July 2021

Publisher's Note: MDPI stays neutral with regard to jurisdictional claims in published maps and institutional affiliations.

Copyright: (c) 2021 by the authors. Licensee MDPI, Basel, Switzerland. This article is an open access article distributed under the terms and conditions of the Creative Commons Attribution (CC BY) license (https:// creativecommons.org/licenses/by/ $4.0 /)$.

\begin{abstract}
Real estate and buildings are some of facility managers' most costly resources. Thus, knowledge about how to get the most out of building or renovation projects both in the short term and in the long term are of great importance for facility managers. This paper investigates which factors are most important for building and renovation projects' output or short-term value creation, and outcome or long-term value creation, i.e., the completed building's effect for owners and users. Thus, the focus is not primarily financial and the buildings' asset value. The study is based on a national questionnaire survey in Norway (550 respondents). Multivariate statistics (Principal Component Analysis and Linear Multiple Regressions validated with bootstrapping) were used to test the hypotheses. Short-term project management priorities, such as early involvement of technical contractors and FM providers, contract strategy and involvement of owners and users largely decide the qualities of the building, and thus the potential for long-term value creation. The most important factors for long-term value creation, i.e., buildings that facilitate the demand organisation's value creation are the qualities of the completed building, project governance and involvement of owners and users during early phase planning.
\end{abstract}

Keywords: facility management; Corporate Real Estate Management; real estate development; building projects; Norway; project governance; project management; early involvement; valuation; value creation; survey; multivariate statistics; bootstrapping

\section{Introduction}

The European standard EN15221-1:2006 [1] (p. 5) defines Facility Management (FM) as "integration of processes within an organisation to maintain and develop the agreed services which support and improve the effectiveness of its primary activities". A facility is similarly defined as a "tangible asset that supports an organisation" [1] (p. 5). Thus, from the standard's perspective, real estate and buildings are only facilities, and seen from a real estate and building perspective EN15221 is service-centric. The ISO 41000 series, the new global FM standard, has a somewhat broader and more realistic perspective on FM, real estate and buildings. In ISO 41011:2017 [2] (p. 1) FM is defined as an "organizational function which integrates people, place and process [ ... ] within the built environment [ ... ] with the purpose of improving the quality [... ] of life of people and the productivity of the core business". Where EN 15221-1 only had facilities, ISO 41011, also introduced the "built environment" defined as "collection of buildings, external works (landscaped areas), infrastructures and other construction works within an area" [2] (p. 3). By recognising the built environment's importance, the ISO41000-series has given real estate and buildings a more prominent position within the field of FM.

Real estate and buildings are some of the most important resources and inputs for facility managers [3]. Real estate and buildings are also some of the most capital-intensive 
and costly undertakings for organisations, particularly if the organisation in question is the owner of the buildings. The foundations for real estate management theory, is "real estate adding value to performance" $[4,5]$. However, many persons, particularly practitioners, find "added value a complex and ill-defined concept", and what is added value is often determined by the beholder [6] (p. 328). Many practitioners have also asked for a "clear operationalisation of added value" [6] (p. 328).

Geltner et al. [7] (pp. 2-14) distinguish between the space market and the asset market. The space market is the rental market, the market for the right to use a particular property or building, i.e., access to space or areas. The space market is therefore segmented according to the buildings' geographical location and intended use. The asset market is the market for ownership of real estate, as financial investments. The RICS (Royal Institute of Chartered Surveyors) with their IVS (International Valuation Standards) [8] and TEGOVA (The European Group of Valuers' Associations) with their EVS (European Valuation Standards) [9] provide precise and recognised definitions of property value and principles for valuation of real estate for different purposes in the asset market, such as valuation in case of market transactions, rent level, financial reporting and properties or buildings as collateral for mortgages. Valuations of real estate as assets and for financial purposes are typically based on due diligence and financial models based on clearly defined assumptions. Today, most private enterprises lease buildings or parts of buildings. Public administrations often own their buildings but during the last decades leasing of buildings has become more common even for public administrations. Buildings are usually not mobile.

Construction of a new building is one of the most significant Corporate Real Estate Management (CREM) interventions an organisation can do [10] (pp. 15-17). This is also the case for major renovations of existing buildings. However, even involvement in processes where an organisation has signed a long-term lease contract and a landlord erects a new building dedicated to the tenant may expose the tenant organisation to several of the same challenges as a building owner, except that the capital expenditures are smaller. Project governance, policies, functions and roles to control projects and to safeguard positive outcomes for the organisation, and also project management and application of methods and skills to deliver project results, are generally expected to be crucial to facilitate projects' value creation, namely increased worth. We would like to test this presumption. In practice, many project managers still base most of their performance metrics on the so-called iron triangle, i.e., the project's time, cost and quality [11], influencing the project's immediate output (short-term result or value creation) rather than having emphasis on the project's actual outcome (long-term value creation). Thus, project governance and project management can be highly relevant both for facility managers in organisations that have signed a long-term lease contract for a completely new building that is developed for the particular tenant, as well for organisations that own their own buildings, develop new buildings or renovate existing buildings.

An analysis of several articles from different academic fields concerning value and value creation in FM and CREM [12] (p. 69) concluded that "reliable quantitative data are still scarce". Van der Voordt and Jensen [6] (p. 332) gave several recommendations for further research. The most relevant recommendations for this paper were implications of time, i.e., the short and long-term effects of various interventions and lessons to be learned for FM from other disciplines, in this article on project management. The research reported here, based on quantitative data and methods, focuses on construction projects or building projects to be precise. Construction is a special context due to its on-site, one-off production with external resources and fragmented structure with long supply chains [13-15]. Many building owners rarely or seldom invest in new buildings; they are one-time actors. This is even the case for those facility managers who are responsible for a single building or a stable portfolio of buildings. Architects, consulting engineers, construction companies, technical contractors and other professionals take part in large numbers of building projects. Building and renovation projects are thus often characterized by an asymmetry between 
stakeholders. To facilitate value creation for the various stakeholders involved in building projects, project owners as well as project managers must establish project governance and project management that balance the various stakeholders' short and long-term objectives.

This paper presents findings from research that was initiated to develop knowledge from the early design phase to obtain value creation for building owners and users throughout buildings' lifetimes. Given the goal of creating long-term value for owners and users of buildings, this research project has investigated the various stages in building projects; from the strategic, early planning and design phase, through the construction and delivery phases, to the operational phase. The building process may be understood as a kind of relay race, where information and documentation are handed over during the phase transitions to secure the agreed value creation until the operational phase.

One of the learning points from the process of writing Facilities Management and Corporate Real Estate Management as Value Drivers-How to Manage and Measure Adding Value, was to distinguish between adding value to an organisation through FM and/or CREM, i.e., outcome, and adding value to FM and/or CREM processes and products (output) [6] (p. 323). Thus, van der Voordt and Jensen have a different perspective on value and added value than for instance RICS' IVS [8] and TEGOVA's [9] EVS standards for valuation of real estate. Van der Voordt and Jensen's distinction between adding value to an organisation through FM and/or CREM processes and products (output) and adding value to an organisation through FM and/or CREM (outcome) is thus very similar to the distinction in building or renovation projects where the completed building is the output, while the building's utility or benefits for the owners and/or users is the outcome. Thus, Facility Managers who become involved in building or renovation projects must be aware that for a construction company or consulting engineer, completion of the building within time and budget is the project and the ultimate goal. For the Facility Manager, the completed building is just the beginning. For the Facility Manager, the goal is every day to create value for the demand organisation, among others, through provision of buildings that satisfy the users' requirements and facilitate the demand organization's value creation. Turner and Zolin [16] have given a good account this situation, namely that stakeholders' perception of a project's success is not necessarily a question about whether the project was completed within time, cost and with the required quality, but whether the project provides the desired outcome and business objectives.

The short-term value of the building, beyond the economic interest of the parties to get paid for their engagement in the process, is purely potential. It is hypothetic until the building is actually built or renovated and delivered. The efforts by project management and other parties obviously influence the qualities that are built into the building and thus may create low or high potential value depending on how well they accommodate owners' and users' needs and priorities. However, they leave the project before the long-time value is created. The real value comes from using the building, preferably for its intended use, but other uses may also be valuable. Therefore, an office building may contribute not only to an efficient work environment for the immediate uses, but also to a positive or negative perception of the neighborhood by neighbors and visitors.

This study investigates how elements of project management and project governance influence building and renovation projects' value creation. We ask two research questions:

RQ1: Which factors are most important for building project's output or short-term value creation, i.e., the project's time, cost, and the completed building's qualities?

RQ2: Which factors are most important for building project's outcome or long-term value creation, i.e., the completed building's effects for owners and users?

This paper's further structure is first a literature review and a section about conceptual framework and hypotheses, and thereafter materials and methods, results, discussion of the findings and conclusions. 


\subsection{Literature}

In the field of FM, Jensen's [12,17] FM Value Map is a well-known conceptual tool. In the FM Value Map real estate is considered one of several inputs together with facilities, technology, manpower, activities, and know-how. The processes that result in outputs are managed through PDCA (Plan-Do-Check-Act) cycles. The output or provisions are among other basic products such as buildings and spaces, including workplaces, parking, meeting rooms, canteens, etc., and services, which in turn contribute to economic, social, spatial, and environmental outcomes or impacts.

To understand value creation for owners and users of a building, we should start with the term value, which is defined in a variety of ways in different contexts, with the common purpose to focus on customers and users and satisfying their needs. Based on Womack and Jones [18], the real value of goods or service can only be defined by the ultimate customer. However, in the context of building projects, the ultimate customer can be complicated to define. Although this leads us to the individuals using the building as the end users, the fact that every stakeholder has its own perception of value cannot be neglected.

Value creation in a building project depends on three main roles of whom their needs should be assessed: the owner, the suppliers and the users. Haddadi et al. [19] discuss that to create value, the owner's prerequisite can be summarized in profitable/optimal operation of the building and fulfilling the customer's needs. Based on the literature on manufacturing processes, the suppliers are required to minimize waste and non-value creating activities, and to fulfil the customer's (owners and users') needs to create value in the product they have manufactured. The ultimate objective of the project should then be to fulfil the user's needs to increase the "customer's perceived value". The relationships between the project's main roles and their requirements that can contribute to value creation are summarized in Figure 1.

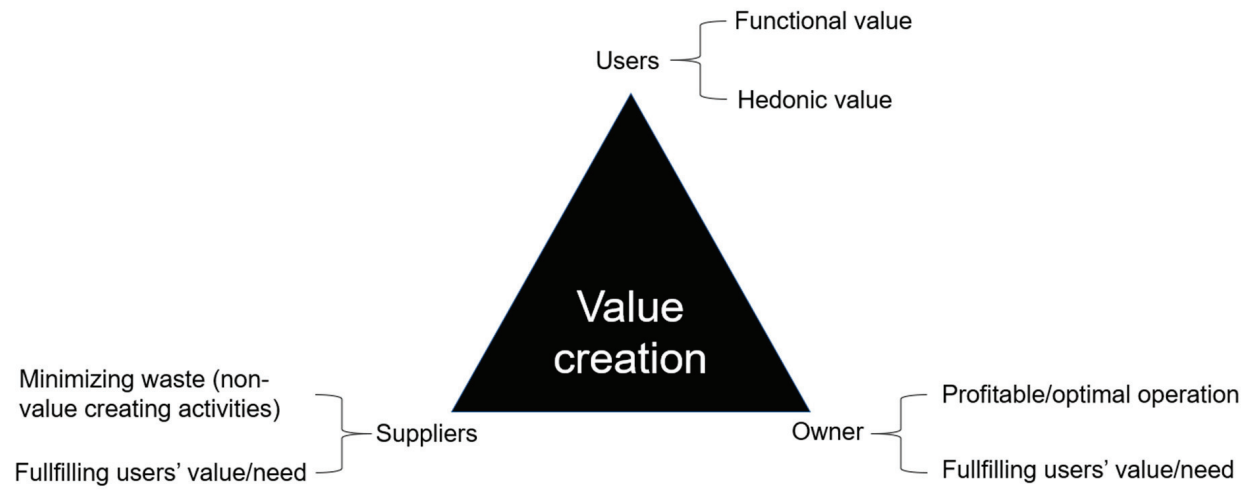

Figure 1. Main stakeholders' requirements for value creation [20].

Seen from an asset and financial perspective, valuation of commercial buildings such as office buildings, factories or store houses is very often based on the income approach, for instance, through application of the capitalisation method or the discounted cashflow (DCF) method [7-9]. A very important implication of the income approach for valuation of commercial buildings is that all other things equal, increased net rent income means a more valuable building, and vice versa. Thus, to make their operations as profitable as possible, financially oriented building owners often strive to maximize rent income from their portfolio of buildings.

The project success is usually linked with the project value [21,22], and perceived differently depending on stakeholder group, social group or individuals. Despite the fact that these elements can contribute to higher satisfaction of user's needs, Arge and Hjelmbrekke [23] argue that projects also must have organizational goals and business 
strategy as reasons for existence. According to Hjelmbrekke et al. [24], project strategies are the missing link in project planning and execution. Bjørberg et al. [25] emphasized the life cycle perspective in the early design phase. Haddadi et al. [19] discussed that value is created when needs are fulfilled and strategic goals are achieved, which means that value creation in a building in a life cycle perspective depends mainly on factors such as "fulfilment of the user's needs" and "fulfilment of owner and the corporate's strategy". Davis [26] concluded that "owner/client" and "user" as stakeholder groups have most success factors in common. The message is, thus, focus on these two stakeholder groups and align their needs for value creation.

Over decades, project management has been defined and redefined. We will return to classics that provide a useful perspective on the definition: Munns and Bjeirmi studied the current definitions of project and project management as basis for discussing project management's role in achieving success. They defined project management simply as "the process of controlling the achievements of the project objectives" [27] (p. 81). Atkinson followed up in the most cited project management article ever. He challenged both the definition of project management and of project success. Project management, he concluded, is better understood as "the definition offered by Turner $[\ldots]$ the art and science of converting vision into reality" [11] (p. 342).

Concerning project governance, in a literature review Ahola et al. [28] distinguish between project governance as external to a specific project and internal to a specific project. Project governance as external to a project is typically found in project-based organizations with principal-agent relations between the organisation and its projects because the project manager may prioritise the project or herself on the organisation's expense. On the other hand, project governance as internal to a specific project aims for projects that meet the various stakeholders' goals and expectations. In the present research, the perspective on project governance is internal to a specific project. Project governance may increase the likelihood of project success $[29,30]$.

In FM there is a gap between theory and practice concerning early-phase planning of buildings. Boge and Temeljotov Salaj [31] and Boge et al. [32] emphasized the earlyphase planning's importance for a building's lifetime value creation. Thus, project value should be specified in the early planning phase, positioned in the project governance strategy, reflected through choice of project delivery model $[33,34]$ and nurtured through project management.

Building qualities is hard to define precisely. Many different perspectives exist, from physical qualities and functional qualities to aesthetical qualities. Aesthetical qualities can for example be defined as three different variables: formal, symbolic and schemas [35]. Winch [36] (p. 55) used "value" as his lens and defined a balance scorecard with four categories: financial value, spatial quality, indoor environmental quality and symbolic quality. These definitions are situational in the sense that they are dependent on what they are intended for. As such, why not go back to the real roots of understanding and use the "Vitruvian values of firmitas (solidity, durability, structure), utilitas (utility) and venustas (beauty, delight)" first formulated by Marcus Vitruvius Pollio, Roman architect (approximately $70 \mathrm{BC}$ ) [37]?

Shenhar and Dvir [38] present an extensive study of the success/failure assessment of building projects based on evaluation of achieving the owner's objectives such as cost, time and quality, for which they state that three measures can provide an indication of success or failure, but not a proper picture of the long-term performance of the project. They introduce business results and preparing for the future as new success criteria. Turner and Zolin [16] stress that success, particularly in large project, should be assessed not only based on the different stakeholders' perspectives but also over different timescales. Turner and Zolin's [16] argument about timescale reflects Chan et al. [39] discussion of trends in measuring project success. Chan et al. [39] concluded that project performance has been a topic of great interest for scholars recently and present three trends in measuring project success: 
- Meeting objectives: Achieving client's objectives, both tangible (time, cost, quality) and less tangible criteria.

- Global Approach: Considering project success criteria from both subjective and objective perspectives.

- Beyond project: Considering positive effects brought about by the project and tangible means.

These trends suggest that a building project's success should be assessed with a life cycle perspective considering outcomes of the project, rather than just the short-term project perspective. Authors, such as Spencer and Winch [40], stressed an increased emphasis on building life-time costs influenced by using a value management approach during the design and development process; Morris [41] discussed achieving an objective during a defined life cycle. Breese [42] discusses the realization of benefits towards achieving the business objectives as a flawed process with a variety of issues and obstacles. Hjelmbrekke and Klakegg [43] emphasized that building projects have traditionally been based on project organizations that leave the users in a half-excluded/part-included position. The fact that value creation arises through future users and the importance of recognizing customer expectation in the pre-design phase leads us to the predesign phase's importance for value creation in projects.

Based on ideas from Professor Jeffrey Pinto, Samset [44] introduced tactical and strategic performance in construction projects. Tactical performance concerns delivering the agreed project outputs on time and within cost, and strategic performance includes longerterm perspectives, such as relevance, effect and sustainability. Arge and Hjelmbrekke [23] pointed out that working towards enhancing strategic performance (outcome focus) would enhance value for project owners and users.

According to Leiringer and Bröchner [45], the building industry is changing its focus from cost efficiency to added value, and this shift broadens the building industry's scope from product delivery to design, production and even FM. One implication of this shift is an increased importance of early-phase planning to improve the construction industry's ability to satisfy the clients' needs. Gottlieb and Haugbølle [46] suggested fundamental dynamics of collaboration in building industry could be understood as three activity systems of production, values, and interest. The activity system of values institutionalizes creation and maintenance of culture, community and professional identity. Culture, community, and professional identity in turn are important determinants for early-phase planning. El. Reifi and Emmitt [47] found that design time is one of the factors that seriously hinder development of design value. Other obstacles are lack of early contractor involvement, poor communication and management, the design team's attitudes and their ability to understand the clients' goals. The design is highly consequential for the buildings' ability to meet the clients and users' needs during the use phase. Even Wondimu et al. [48] concluded that early contractor involvement is beneficial for projects' value creation, but early contractor involvement may conflict with rules regulating public procurements. Thus, public procurement regulations may have side effects concerning building projects' value creation.

Thus, project governance and project management issues may represent significant obstacles for value creation and success in building projects. Middle management is in a key position as an information filter and action provider in any organization [49]. When the middle management level or project management does not provide relevant information or is unable to take adequate action, value creation immediately suffers. In terms of governance, the Board of Directors are responsible for the wellbeing of the organization and all its ongoing activity, including all projects. However, they are often not close to those projects and need a dedicated representative to follow them up and oversee the development in portfolios, programs, and projects. This role is termed project executive or project sponsor [50].

Contract strategy in projects is defined as "the division of the project into separate contracts, and the form and the conditions of the contract most likely to encourage satisfac- 
tory completion, whilst providing controls and opportunities to the owner or contractor to rectify problems before they cause serious difficulty to the project" [51] (p. 74). The contract strategy may thus influence project performance [52]. Watermayer puts contract strategy into the bigger concept of procurement strategy and defines: "Procurement strategy is all about the choices made in determining what is to be delivered through a particular contract, the procurement and contracting arrangements and how secondary procurement objectives are to be promoted" [53] (p. 223). Contract strategy is an important tool for most Facility Managers.

The literature review shows the recent years' growing and more specific focus on value creation in the construction field, but the knowledge about value creation in building projects is more developed in theory than in practice. Thus, our study of practitioners' perception of which factors that facilitate value creation in building projects addresses a topic where there is lack of evidence, even if most practitioners have rather clear ideas about what is value and what is not.

\subsection{Conceptual Framework and Hypotheses}

We designed a conceptual framework (Figure 2) to investigate the respondent's perception of what matters for building projects' short-term and long-term value creation. We divided into short- and long-term goals and both include project governance and project management process perspectives. Three main groups of parameters are important for the building process (planning, design, and execution): situational parameters, resources, and strategies and choices. The first two (situation and resources) are specific to each single case project and thus not directly included in this study. Our analysis includes strategies and choices made (through the whole lifecycle) and will mirror the respondents experience from a large number of cases, indirectly including situational parameters and resources.

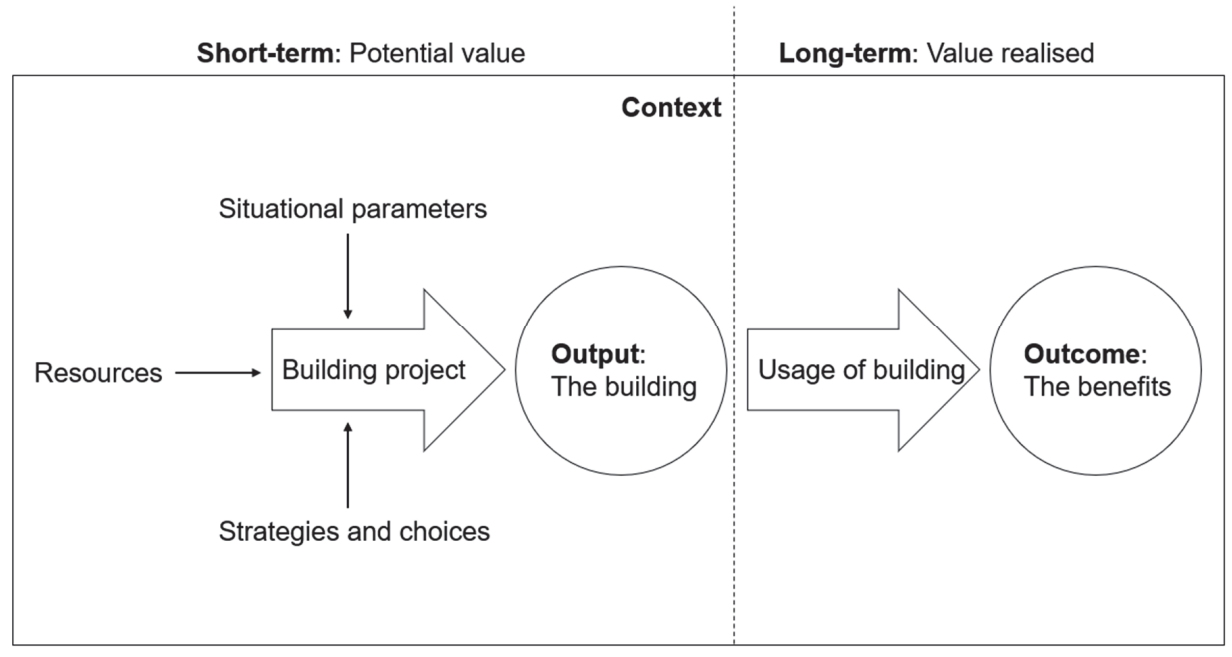

Figure 2. Conceptual framework.

The short-term value of the building, beyond the economic interest of the parties to get paid for their engagement in the process, is purely potential. It is hypothetic until the building is built and delivered. The efforts by project management and other parties obviously influence the qualities that are built into the building and thus may create low or high potential value depending on how well they accommodate owners' and users' needs and priorities. However, they leave the project before the long-time value is created. The real value comes from using the building, preferably for its intended use, but other uses may also be valuable. Therefore, an office building may contribute not only to efficient 
work environment for the immediate uses, but also a positive or negative perception of the neighborhood by neighbors and visitors.

To facilitate building projects that provide long-term value creation, long-term value creation needs to be in focus from the start. Project owner's project governance very much determines the regulatory framework and operating parameters for a building project's project management. However, in terms of logical sequence, the potential for value creation must be developed and built before the use value or return on investment can be realized. Thus, we start by questioning which factors are most important for project output.

Based on RQ1 and the literature review, we derived several hypotheses about which factors are most important for the building project's output or short-term value creation, such as the project's time, cost, and the completed building's qualities:

Hypothesis 1A (H1A). Project management is positively related to the completed building's qualities.

Hypothesis 1B (H1B). Early involvement of technical contractors is positively related the completed building's qualities.

Hypothesis $1 \mathrm{C}(\mathrm{H} 1 \mathrm{C})$. Early involvement of FM providers is positively related to the completed building's qualities.

Hypothesis 1D (H1D). Having a contract strategy is positively related to the completed building's short-term qualities.

Hypothesis 1E (H1E). Involvement of owners and users during the construction phase is positively related to the completed building's qualities.

Building qualities need to be understood in a wide sense. It includes not only architecture, design, and technical qualities, but all functions, capabilities and flexibility for users and operators.

Then we question what factors can give successful value creation in the long-term perspective. Based on RQ2 and the literature review, we derived several hypotheses about which factors are most important for the building project's outcome and long-term value creation, i.e., the completed building's effects for owners and users:

Hypothesis 2A (H2A). Project governance is positively related to the completed building's longterm value-creation.

Hypothesis 2B (H2B). The completed building's qualities are positively related to the completed building's long-term value creation.

Hypothesis $2 \mathrm{C}(\mathrm{H} 2 \mathrm{C})$. Project objectives are positively related to the completed building's longterm value creation.

Hypothesis 2D (H2D). Involvement of owners and users in early phase planning is positively related to the completed building's long-term value creation.

These long-term perspectives can only become successful if the right results are developed in the short-term perspective, even if there are exceptions and examples of unintended successes. One of the most prominent such examples is the Opera House in Sydney, which failed almost every possible short- and long-term objective, but still, incidentally, created a global-scale tourist magnet. However, projects such as the Opera House in Sydney are very unusual exceptions. 


\section{Materials and Methods}

A deductive approach was chosen to accommodate existing theory and new empirical evidence. The research design is a cross-sectional large $\mathrm{N}$ observational design [54] (pp. 118-124), where the variations in the explanatory variables are analysed across units but not across time. Cross-sectional designs are robust and one of the most common research designs in social sciences.

\subsection{Development of Questionnaire}

Several students have been involved in parts of the project and made valuable contributions. The questionnaire was developed through literature studies and findings from students' bachelor, master and $\mathrm{PhD}$ thesis, and the questions were validated through a series of workshops and meetings with the research consortium's partners, and discussions with stakeholders from the construction and FM industry. Involvement of stakeholders and pretesting clearly improved the data's validity.

The questionnaire consists of five sections. The first was about the respondents (demographic data) and project data (size, respondent's role, delivery model). Section 2 investigated the building owner's priorities in the particular project; measurement of deliveries against functional and performance requirements; whether the owner's specific and measurable requirements governed decisions; owner involvement; user involvement; early involvement of FM competencies; project management and early involvement of technical contractors. Section 3 was about phase transitions and decision-making processes. Section 4 was about the respondent's experiences with the completed building, effects of the project and the completed buildings' perceived value creation for owners and users. Section 5 was about perceived success factors. The present study emphasizes questions in the questionnaire's Sections $2-5$, where each question could be answered on a six-item Likert scale from 1 (disagree completely) to 6 (agree completely), or the alternative "Don't know/Not relevant".

\subsection{Data Collection}

The study population was Norwegian professional practitioners who have been involved in planning and construction of buildings, distributed via web-link to member organizations from the Norwegian Consulting Engineer's Association, the National Association of Norwegian Architects, and the Norwegian Facilities Management Association, and to the research project consortium. The estimated population of possible respondents was approximately 8500 persons. The data collection took place between June and September 2016, and 1034 respondents answered the survey. After cleansing respondents with more than 20 percent missing answers on the questions with six-item Likert scales, the effective sample was reduced to 550 respondents and had very few missing answers (genuine non-response) in most questions, which increases the likelihood for unbiased data.

\subsection{Analytical Methods}

The data were analysed by IBM SPSS Statistics version 27 . When making multivariate statistical analyses of data with a Likert scale supplemented with alternatives such as "Don't know/Not relevant" which are not part of the Likert scale, it is common practice to code such alternatives outside the Likert scale (for instance as 9) to differentiate these answers from genuine non-response (often coded as 99) in the analyses, and because calculations of statistical measures such as mean, standard deviation, etc., are based on the Likert scale. Small shares of non-response will usually not distort multivariate analyses. However, if the data have large shares of non-responses, either because of genuine nonresponse or many "Don't know/Not relevant" answers, then it is very useful to know which categories of respondents have not responded or responded "Don't know/Not relevant" for a particular question. To maintain control of non-responses, crosstabulations and other descriptive analyses were made of each question prior to the multivariate analyses 
to assess which categories of respondents that had not responded or answered, "Don't know/Not relevant".

Exploratory principal component analysis (PCA) was used to combine information from several Likert scales questions (items) into a smaller set of components (constructs or composite variables) with the smallest possible loss of information [55] (p. 94). Components based on two or more items also provide more robust measures than individual items and reduce measurement errors [55] (p. 96 ff.). The derived component matrix was rotated with Varimax rotation because rotation may simplify the interpretation. Orthogonal rotation, such as Varimax, maximizes the components' variance and usually provides clear separation of the components [55] (p. 113). It is common to report only items with component loadings $>0.30$. Component loadings of \pm 0.50 are considered practically significant, and the aim of any PCA or factor analysis is loadings $>0.70$, because component loadings $>0.70$ provide significant results with as small samples as 60 [55] (pp. 114-115). The derived components have been linked to theoretical concepts discussed in the literature review.

Use of multi-item scales (constructs or indexes) compared to single variables also improve the validity, i.e., that scales measure what they are supposed to measure [55] (p. 8). Construct C1 to C10 were defined as new variables in SPSS by adding the scores for those questions with component loadings $>0.30$ on the component in question and calculating each respondent's mean score for the component. The scores for questions with component loadings on more than one component were excluded if the separation between the components were less than approximately 0.30 . Construct validity was ensured through pilot testing and unrotated factor analysis (PCA). The constructs' reliability has been assessed through calculations of Cronbach's alpha [55] (p. 90). To investigate the two research questions, based on the literature review, initial examination of the data and the analytical model in Figure 2, several hypotheses were derived. These hypotheses have been tested with multiple linear regressions which facilitates control of the effect of the other factors included in the model.

Hair et al. [55] (pp. 22-24) recommends to always validate the results from multivariate analysis and recommends three different validation methods. The fist is to split the sample and use one subsample to estimate the model and the other to validate the model. The second method is to collect an additional sample to validate the model. The third method is to use bootstrapping. Bootstrapping means that SPSS draws a large random sample with replacement (bootstrap sample) from the respondents' answers to the questions included in the model [56] (p. 199), to assess if the bootstrapping parameters' (B) confidence intervals does not include zero. The estimated bootstrapping parameters are significant if they are different from zero [55] (p. 22). In the present research, bootstrapping has been used to validate the linear multiple regression analyses that were used to test the hypothesis.

\subsection{The Respondents}

The 550 respondents' age varied between 26 and 90 years. The respondents' mean and median ages were 52 and 53 years respectively. Respondents had education backgrounds in engineering (449), business administration (137), architecture (54), finance and investment, or law (23), marketing and communication (21) and social science (12). Several respondents had more than one education. All in all, these respondents well represented those involved in Norwegian building projects.

The respondents could choose more than one role. Table 1 shows the respondents represent a wide range of roles involved in building projects, which also indicates a representative sample. The respondents had from 1 to 65 years' experience in their roles, and the mean number of years in a role was 16 years. Thus, most respondents were experienced. The respondents' answers were based on different kinds of building projects: new building (352), refurbishment and renovation of existing buildings (254), and extension or appendage of existing buildings (122). Thus, some of the building projects included more than one activity. 
Table 1. The respondents' roles in their projects.

\begin{tabular}{cc}
\hline Role & N \\
\hline Building owner's project manager & 197 \\
Building owner & 141 \\
Consultant engineer & 107 \\
Internal project manager & 65 \\
Steward or building manager & 60 \\
Construction manager & 43 \\
Project group manager & 42 \\
User & 31 \\
Others & 26 \\
Construction contractor & 28 \\
Construction contractor's project manager & 28 \\
Architect & 23 \\
FM service provider (internal or external) & 16 \\
Technical contractor & 9 \\
\hline
\end{tabular}

The building projects' total cost inclusive value added tax (VAT) was divided into three categories: $0-150$ million NOK (MNOK) (approximately 0-15 million Euro or 0 to 17.5 million USD), 150-700 MNOK (approximately 150-70 million Euro or 17.5 to approximately 82 million USD) and more than 700 MNOK (MNOK) (more than 70 million Euro or 82 million USD), and "don't know". The findings indicate the sample of respondents very well represent the current Norwegian construction market. About 80 per cent of the 549 projects have a total cost less than 150 MNOK (219 respondents), or between 150 and 700 MNOK (211 respondents). About one fifth of the projects (107 respondents) have total costs above 700 MNOK. 12 respondents did not know their projects' total cost.

Regarding type of project ownership, respondents reported the building in the project they have based their answers on is owned by a private enterprise (217), a municipality or county municipality (146), a hybrid organisation (95) and a government body (40). A hybrid organisation is an organisation owned by a public administration and serving the common good but operating almost as a private enterprise.

The answers regarding kind of projects show the respondents' answers are based on a standard building with known solutions (323), a technically complex building (163) and an aesthetically or otherwise unique signal building (149). Some buildings, for instance signal buildings, may also be technically complex buildings.

The respondents have often been involved in more than one phase in the project their answers are based on. Respondents have been actively involved in the early phase (318), the project planning and design phase (437), in the construction phase (427), and in the operational/use phase (188). Thus, most respondents have been involved in the project planning and construction phases.

Table 2 shows that offices or business facilities, primary and secondary schools and housing are the respondents' volume projects. Table 2 also shows the distribution of standard buildings, technically complex buildings, and signal buildings. The respondents could choose more than one category of buildings, because some projects are complex and include more than one category of building. Many cultural facilities are, for instance, technically complex signal buildings. 
Table 2. The respondents' building projects.

\begin{tabular}{ccccc}
\hline Building Category & $\begin{array}{c}\text { Total Number } \\
\text { of Buildings }\end{array}$ & $\begin{array}{c}\text { Standard } \\
\text { Buildings }\end{array}$ & $\begin{array}{c}\text { Technically } \\
\text { Complex } \\
\text { Buildings }\end{array}$ & $\begin{array}{c}\text { Signal } \\
\text { Buildings }\end{array}$ \\
\hline Office and business & 201 & 115 & 63 & 66 \\
Schools & 94 & 74 & 17 & 16 \\
Housing & 86 & 71 & 12 & 20 \\
Assisted living & 65 & 50 & 13 & 11 \\
Hospitals & 54 & 22 & 38 & 7 \\
Higher education & 51 & 18 & 24 & 20 \\
and research & 49 & 15 & 15 & 31 \\
Culture facilities & 34 & 0 & 13 & 12 \\
Sports facilities & 3 & & 2 & 1 \\
Prisons & & & & \\
\hline
\end{tabular}

\section{Results}

This section presents the findings. The structure is first PCA to derive the constructs, thereafter analysis of the constructs and finally linear multiple regressions to test the hypotheses concerning which factors in building projects facilitate output or short-term value creation and which factors facilitate outcome or long-term value creation. The two regression models were validated with bootstrapping.

\subsection{Principal Component Analysis}

Data from the questionnaire's part about the completed building and other outcomes of the project, which had 10 questions, each with 6 item Likert scales from 1 (disagree completely) to 6 (agree completely) and "Don't know /Not relevant", about the completed building (3 questions) and outcomes of the project (7 questions) were suitable for PCA. This is because KMO's measure of sampling adequacy was 0.893, and Bartlett's test of sphericity gave an approximate $\chi^{2}(45,914.859), p<0.001$. Table 3 shows the rotated component matrix.

Table 3. Rotated component matrix-experiences with the completed building-positive effects from the project.

\begin{tabular}{crr}
\hline Rotated Component Matrix ${ }^{\text {a }}$ & \\
\hline Item & \multicolumn{2}{c}{ Component } \\
\cline { 2 - 3 } & C1 & C2 \\
\hline Market position & $\underline{\mathbf{0 . 8 2 9}}$ \\
\hline Reputation & $\underline{\mathbf{0 . 7 9 9}}$ \\
\hline Innovation & $\underline{\mathbf{0 . 7 4 3}}$ \\
\hline Productivity and effectiveness & $\underline{\mathbf{0 . 7 1 0}}$ & 0.338 \\
\hline Contributed to achievement of strategic goals & 0.664 & 0.414 \\
\hline Profitability & 0.574 & 0.469 \\
\hline Development of own competencies & 0.541 & 0.512 \\
\hline Technical systems and integration between systems worked as described & $\underline{\mathbf{0 . 8 7 4}}$ \\
\hline The project satisfies the value areas' expressed requirements (function, \\
performance)
\end{tabular}


PCA gave two components which explain 66.7 per cent of the variance: component C1 Projects outcomes $(\alpha=0.82)$ and component C2 Completed building's qualities $(\alpha=0.88)$. Thus, both components have acceptable reliability $(\alpha>0.70)$.

Prior to the PCA there were made crosstabulations of each question to investigate the non-response because of genuine non-responses and the coding of "Don't know / Not relevant". The question in component $\mathrm{C} 1$ about the outcome of the project about market position as positive effect for the organization that accomplished the project had 431 valid answers (8 non-responses and 111 "Don't know/Not relevant" answers). The most important categories of respondents who answered "Don't know/Not relevant" were building owners' project managers (56), building owners (39) and stewards or building managers (22). The question in component $\mathrm{C} 1$ about productivity and effectiveness as positive effects of the project had 482 valid answers (6 non-responses and 62 "Don't know / Not relevant" answers). The most important categories of respondents who answered "Don't know/Not relevant" were building owners' project managers (25), building owners (20), consulting engineers (11) and internal project managers (11). The question in C1 about innovation had had 356 valid answers (165 non-responses and 29 "Don't know/Not relevant"). The most important categories of respondents that chose not to answer this question about innovation as positive effect of the project were building owners (141), building owners' project managers (43), stewards or building managers (36), users (31) and internal project managers (23). The respondents could choose more than one role; therefore the different roles' numbers of non-responses can be higher than the actual number of non-responses. The respondents' answers concerning the outcome of the project may indicate that many building owners, their project managers, stewards and building managers are more financially oriented than concerned with the outcomes of building and renovation projects. The consultant engineers may similarly be more interested in the planning and construction process than in the outcome.

In component $\mathrm{C} 2$ about the project's output, the question about whether the technical systems in the completed building and the integration between the building's technical systems worked as supposed had 367 valid answers (145 non-responses and 38 "Don't know/Not relevant"). The most important categories of respondents that had not answered this question were again consulting engineers (45), building owners' project managers (40), building owners (32) and project group managers (16). The most import categories of respondents that chose "Don't know/Not relevant" were building owners' project managers (14), consulting engineers (13), architects (6) and building owners (5). The question in component $\mathrm{C} 2$ about whether the project (the completed building) satisfied the value areas' expressed requirements had 363 valid answers (145 non-responses and 42 "Don't know/Not relevant"). The most important categories of respondents that choose not to answer this question were again consulting engineers (45), building owners' project managers (40), building owners (32), project group managers (16) and internal project managers (9). The most import categories of respondents that chose "Don't know / Not relevant" were building owners' project managers (15), consulting engineers (13) and building owners (6). Component C2's question about training of the operational staff to optimize the operations had 351 valid answers (145 non-responses and 54 "Don't know / Not relevant"). The most important categories of respondents who choose not to answer this question were again consulting engineers (45), building owners' project managers (40), building owners (33), project group managers (16), and internal project managers (9). The most important categories of respondents who chose "Don't know / Not relevant" were consulting engineers (20), building owners' project managers (16), architects (10), and building owners (7). These answers may indicate that many building owners and their representatives are more financially oriented than concerned with the projects' output. For those who are financially oriented, one of the main parameters concerning office or factory buildings is the annual net rent income, due to the annual net rent income's importance for a building's value as collateral or resale value. 
The questionnaire's part concerning the project owner's priorities had 15 questions with six-item Likert scales ( $1=$ disagree completely, $6=$ agree completely) and "Don't know/Not relevant". The questions investigated the building owner's involvement in the decision making process concerning value areas given specific and measurable requirements (three questions); user involvement concerning choice of solutions influencing their functional or performance requirements (three questions); involvement of FM providers to safeguard operational matters (three questions); the project manager's priority of the building owner's measurable requirements (three questions); and involvement of technical contractors (three items). These data were suitable for PCA, because KMO's measure of sampling adequacy was 0.747 and Bartlett's test of sphericity gave an approximate $\chi^{2}$ $(105,3512.482), p<0.001$.

PCA of the questionnaire's part two about the project owner's priorities gave five components, which explain 77.0 per cent of the variance. Table 4 shows the rotated component matrix. These five components C3 Project management ( $\alpha=0.88)$, C4 Early involvement of FM providers $(\alpha=0.88)$, C5 Involvement of owners and users during construction phase $(\alpha=0.74)$, C6 Early Involvement of technical contractors $(\alpha=0.78)$, and C7 Involvement of owner and users during early phase planning $(\alpha=0.71)$ have acceptable reliability $(\alpha>0.70)$.

Table 4. Rotated component matrix-The project owner's priorities.

\begin{tabular}{|c|c|c|c|c|c|}
\hline \multicolumn{6}{|c|}{ Rotated Component Matrix ${ }^{a}$} \\
\hline \multirow{2}{*}{ Item } & \multicolumn{5}{|c|}{ Component } \\
\hline & C3 & C4 & C5 & C6 & C7 \\
\hline Building owner's project manager-Planning phase & 0.867 & & & & \\
\hline Building owner's project manager-Construction phase & $\overline{0.778}$ & & 0.323 & & \\
\hline Building owner's project manager-Early phase & $\overline{0.774}$ & & & & 0.390 \\
\hline FM provider involvement-Planning phase & & 0.861 & & & \\
\hline FM provider involvement-Construction phase & & $\underline{0.805}$ & 0.366 & & \\
\hline FM provider involvement-Early phase & & 0.735 & & & 0.419 \\
\hline Owner involvement-Construction phase & & & 0.802 & & \\
\hline User involvement-Construction phase & & & $\underline{0.719}$ & & \\
\hline Owner involvement-Planning phase & 0.364 & & $\overline{0.713}$ & & 0.300 \\
\hline Technical contractor actively involved-Planning phase & & & & 0.916 & \\
\hline Technical contractor actively involved-Early phase & & & & 0.840 & \\
\hline Technical contractor actively involved-Construction phase & & & 0.342 & $\underline{0.670}$ & \\
\hline User involvement-Early phase & & & & & 0.838 \\
\hline User involvement-Planning phase & & 0.380 & 0.448 & & $\overline{0.611}$ \\
\hline Owner involvement-Early phase & 0.327 & & 0.347 & & $\underline{0.576}$ \\
\hline
\end{tabular}

Extraction Method: Principal Component Analysis. Rotation Method: Varimax with Kaiser Normalization.

a Rotation converged in six iterations.

The three questions in component $\mathrm{C} 3$ about project management concerning involvement of the Building owner's project manager in the planning, construction, and early phases, had approximately 500 valid answers each and 3 genuine non-responses each. Most of the "Don't know / Not relevant" answers came from Consulting engineers (varying between 12-28 such answers in the three questions). These "Don't know/Not relevant" answers are interesting, because according to the literature review project management is assumed to facilitate the completed building's qualities.

In component $\mathrm{C} 4$ about $\mathrm{FM}$, the three questions about involvement of FM suppliers in the planning, construction, and early phases (452-475 valid answers and 3 genuine non-responses in each question), there were 72 "Don't know/Not relevant" answers in the planning phase, 94 in the construction phase, and 95 in the early phase. The most important categories of respondents that answered "Don't know / Not relevant" concerning the involvement of FM suppliers were consulting engineers $(25,40$ and 29 in the respective 
phases), building owners' project managers $(19,22$ and 24 in the respective phases), building owners (10, 13 and 12 in the respective phases), and construction company's project managers (9, 8 and 12 in the respective phases) indicate that FM is not necessarily some consulting engineers, building owners and construction companies' main concern, even if early involvement of FM competencies can facilitate more FM-friendly buildings and reduced operational costs.

In component $\mathrm{C} 5$ about owner and user involvement in the construction phase, the three questions had between 489 and 528 valid answers and 3 genuine non-responses in each question. The most important categories of respondents that answered "Don't know /Not relevant" in these three questions were again consulting engineers $(23,24$, and 5 in the respective questions) and building owners' project managers $(6,12$, and 2 in the three questions). The other "Don't know/Not relevant" answers were evenly distributed across the other categories of respondents.

In component $\mathrm{C} 6$ about involvement of technical contractors, the three questions had between 483 and 510 valid answers and each question had 4 genuine non-responses. The most important categories of respondents that answered "Don't know/Not relevant" were again consulting engineers $(12,18$ and 26 in the respective categories), building owners' project manager $(5,10$, and 9 in the respective questions), and building owners $(8,8$ and 12 in the respective questions). These "Don't know/Not relevant" answers are interesting because technical contractors can facilitate innovations in building and renovation projects.

In component C7 about involvement of owners and users in early phase planning, the three questions had between 501 and 519 valid answers and 3 non-responses in each question. The most important categories of respondents that answered "Don't know/Not relevant" in the three questions were again consulting engineers $(13,8$, and 11 in the respective questions) and building owners' project managers $(12,8$ and 8 in the respective questions). The other "Don't know/Not relevant" answers were evenly distributed across the other respondents. These "Don't know/Not relevant" answers are interesting because the involvement of owners and users increases the likelihood of development of buildings aligned to the users' needs, i.e., buildings that facilitate value creation.

The questionnaire's part five about success factors and obstacles concerning the building owners and users' goal attainment in the project included 14 questions with 6 item Likert scales ( 1 = disagree completely, 6 = agree completely) and "Don't know /Not relevant". These data were suitable for PCA, because KMO's measure of sampling adequacy was 0.870 and Bartlett's test of sphericity gave an approximate $\chi^{2}(91,1332.215), p<0.001$.

PCA of the questionnaire's part about success factors and obstacles concerning the building owners and users' goal attainment gave 3 components, which explain 61.2 per cent of the variance. Table 5 shows the rotated component matrix. The three components C8 Project objectives $(\alpha=0.82)$, C9 Project governance $(\alpha=0.75)$ and C10 Contract strategy $(\alpha=0.86)$ have acceptable reliability $(\alpha>0.70)$.

In component $\mathrm{C} 8$ about project objectives the five questions about environmental certification, innovation, life cycle costs, competitive tenant costs and co-location of actors in the project phases had between 297 and 462 valid answers. The five questions had 10 non-responses each, the remaining missing answers were "Don't know / Not relevant". The most important categories of respondents that answered "Don't know / Not relevant" in the five questions were again building owners' project managers $(29,31,19,84$, and $27)$, consulting engineers $(25,16,23,55$ and 19), building owners $(17,15,11,52$, and 21). The remaining "Don't know/Not relevant" answers were relatively evenly distributed across the other respondents. The building owners' project managers, the building owners and even the consulting engineers were clearly most skeptical to competitive tenant costs. They were also skeptical to environmental certification and innovations. The fact that rent income is one of the most important parameters concerning a building's market value and value as collateral may explain the building owners and their representatives' skepticism to competitive tenant costs, but their skepticism to environmental certification 
and innovations represents a puzzle since environmental certification and innovations may increase the value of a building.

Table 5. Rotated component matrix-Success factors and obstacles concerning attainment of the building owners' and the users' objectives.

\section{Rotated Component Matrix ${ }^{a}$}

\begin{tabular}{|c|c|c|c|}
\hline \multirow{2}{*}{ Item } & \multicolumn{3}{|c|}{ Component } \\
\hline & $\mathrm{C} 8$ & C9 & C10 \\
\hline Environmental requirements (certification of the completed building) & $\underline{0.794}$ & & \\
\hline The building owner's willingness to invest in innovations & $\underline{0.782}$ & & \\
\hline Life cycle costs & $\underline{0.737}$ & & \\
\hline Competitive tenant costs (lease and operational costs) & $\underline{0.655}$ & & \\
\hline Co-location of actors in the project phases & $\underline{0.616}$ & & \\
\hline Description and functional requirements from the early phase & & $\underline{0.756}$ & \\
\hline Building owner and project manager's competencies and experience & & $\underline{0.726}$ & 0.305 \\
\hline Owner's involvement & & $\underline{0.677}$ & \\
\hline Users' involvement & & $\underline{0.676}$ & \\
\hline Building contractor's project manager's competencies and experience & & 0.674 & 0.436 \\
\hline Transfer or responsibilities and information during phase transitions & 0.479 & 0.563 & \\
\hline Building contract & & & $\underline{0.857}$ \\
\hline Tender process & & & $\underline{0.829}$ \\
\hline Investment budget & 0.305 & & $\underline{0.631}$ \\
\hline
\end{tabular}

Extraction Method: Principal Component Analysis. Rotation Method: Varimax with Kaiser Normalization.

\footnotetext{
a Rotation converged in 5 iterations.
}

In component C9 about project governance, the four questions about descriptions and functional requirements from the early phases, the building owner and project manager's competencies, owner's involvement and users' involvement had between 512 and 531 valid answers. Each question had 10 non-responses; the remaining missing answers were "Don't know/Not relevant". The most important categories of respondents that answered "Don't know / Not relevant" were again consulting engineers $(6,5,6$, and 10$)$ and building owners' project managers $(3,1,4$, and 8$)$.

In component $\mathrm{C} 10$ about contract strategy, the three questions about building contract, tender process and investment budget had between 480 and 501 valid answers, and the three questions had 10 non-responses each. The remaining missing were "Don't know /Not relevant" answers. The most important categories of respondents that answered "Don't know /Not relevant" in the three questions were Consulting engineers $(19,26$, and 14), Internal project managers (6, 7, and 6), Users (6, 10, and 7), and Building owners (5, 13, and 4$)$.

\subsection{The Constructs and Their Associations}

Table 6 provides an overview of the 10 constructs derived through PCA, hereunder the constructs' bivariate correlations (Pearson's Rho) and reliability (Cronbach's alpha), which is shown on the table's diagonal, and the constructs' mean, standard deviation (SD) and number of observations (N), which is shown in the bottom rows. Pierson's Rho (r) is a measure of effect size, i.e., the magnitude of a phenomenon. According to Cohen [57], $r=0.50$ indicates a large effect size, $r=0.30$ indicates a medium effect size and $r=0.10$ indicates a small effect size. 
Table 6. The constructs' correlation matrix

\begin{tabular}{|c|c|c|c|c|c|c|c|c|c|c|c|}
\hline Construct $/ \alpha$ & & $\mathrm{C} 1$ & $\mathrm{C} 2$ & $\mathrm{C} 3$ & $\mathrm{C} 4$ & C5 & C6 & $\mathrm{C} 7$ & $\mathrm{C} 8$ & C9 & $\mathrm{C} 10$ \\
\hline \multirow{2}{*}{ C1 Project outcomes } & $\mathrm{r}$ & 0.82 & & & & & & & & & \\
\hline & $\mathrm{N}$ & 302 & & & & & & & & & \\
\hline \multirow{2}{*}{$\begin{array}{l}\text { C2 Completed building's } \\
\text { qualities }\end{array}$} & $\mathrm{r}$ & $0.482 * *$ & 0.88 & & & & & & & & \\
\hline & $\mathrm{N}$ & 177 & 340 & & & & & & & & \\
\hline \multirow{2}{*}{ C3 Project management } & $\mathrm{r}$ & $0.468^{* *}$ & $0.537^{* *}$ & 0.88 & & & & & & & \\
\hline & $\mathrm{N}$ & 243 & 316 & 464 & & & & & & & \\
\hline \multirow{2}{*}{$\begin{array}{l}\text { C4 Early Involvement of FM } \\
\text { providers }\end{array}$} & $\mathrm{r}$ & $0.359 * *$ & $0.464^{* *}$ & 0.461 ** & 0.88 & & & & & & \\
\hline & $\mathrm{N}$ & 216 & 286 & 405 & 422 & & & & & & \\
\hline \multirow{2}{*}{$\begin{array}{l}\text { C5 Involvement of owners and } \\
\text { users during construction phase }\end{array}$} & $\mathrm{r}$ & $0.323^{* *}$ & $0.403^{* *}$ & $0.436^{* *}$ & 0.419 ** & 0.74 & & & & & \\
\hline & $\mathrm{N}$ & 249 & 321 & 435 & 400 & 471 & & & & & \\
\hline \multirow{2}{*}{$\begin{array}{l}\text { C6 Early Involvement of } \\
\text { technical contractors }\end{array}$} & $\mathrm{r}$ & $0.319^{* *}$ & $0.496^{* *}$ & 0.409 ** & $0.369^{* *}$ & $0.258^{* *}$ & 0.78 & & & & \\
\hline & $\mathrm{N}$ & 243 & 305 & 428 & 394 & 424 & 449 & & & & \\
\hline \multirow{2}{*}{$\begin{array}{l}\text { C7 Involvement of owners and } \\
\text { users during early phase planning }\end{array}$} & $\mathrm{r}$ & $0.357^{* *}$ & $0.299 * *$ & $0.401^{* *}$ & $0.524^{* *}$ & $0.541^{* *}$ & $0.295^{* *}$ & 0.71 & & & \\
\hline & $\mathrm{N}$ & 257 & 306 & 437 & 401 & 445 & 420 & 480 & & & \\
\hline \multirow{2}{*}{ C8 Project objectives } & $\mathrm{r}$ & $0.398^{* *}$ & $0.306^{* *}$ & $0.230^{* *}$ & $0.402 * *$ & $0.318^{* *}$ & $0.377^{* *}$ & $0.281 * *$ & 0.82 & & \\
\hline & $\mathrm{N}$ & 154 & 164 & 218 & 206 & 220 & 218 & 222 & 247 & & \\
\hline \multirow{2}{*}{ C9 Project governance } & $\mathrm{r}$ & $0.502 * *$ & $0.425^{* *}$ & $0.412 * *$ & $0.413^{* *}$ & $0.380^{* *}$ & $0.360^{* *}$ & $0.511 * *$ & $0.474 * *$ & 0.75 & \\
\hline & $\mathrm{N}$ & 279 & 314 & 434 & 400 & 440 & 419 & 448 & 242 & 496 & \\
\hline \multirow{2}{*}{ C10 Contract strategy } & $\mathrm{r}$ & $0.293^{* *}$ & $0.442 * *$ & $0.403^{* *}$ & $0.346^{* *}$ & $0.280 * *$ & $0.390 * *$ & 0.261 ** & $0.465 * *$ & $0.428^{* *}$ & 0.78 \\
\hline & $\mathrm{N}$ & 255 & 298 & 401 & 366 & 408 & 391 & 406 & 236 & 425 & 447 \\
\hline $\mathrm{N}$ & & 302 & 340 & 464 & 422 & 471 & 449 & 480 & 247 & 496 & 447 \\
\hline Mean & & 4.34 & 4.41 & 4.85 & 3.82 & 4.44 & 4.14 & 4.68 & 3.69 & 4.68 & 4.26 \\
\hline SD & & 0.99 & 1.12 & 1.01 & 1.40 & 1.07 & 1.18 & 1.07 & 1.11 & 0.93 & 1.01 \\
\hline
\end{tabular}

Construct C1 Project outcomes has a slightly lower mean (4.34, SD 0.99) than C2 Completed building's qualities mean (4.41, SD 1.12). Thus, the respondents are slightly more satisfied with the completed buildings than with the project outcomes, but there is slightly more variation in the respondents' answers concerning the completed building than project outcomes. Construct C8 Project objectives (3.69, SD 1.11) and C4 Early involvement of FM providers (3.82, SD 1.40) have the lowest means.

Given the strength of $\mathrm{r}$, when comparing construct C3-C10's influences on construct C1 Project outcomes and construct C2 Completed building's qualities, the most important constructs concerning C1 Project outcomes are C2 Completed building' qualities, C7 Involvement of owners and users during early phase planning, C8 Project objectives and C9 Project governance. Table 6 similarly shows that given the strength of $r$, the most important constructs concerning C2 Completed building's qualities are C3 Project management, C4 Early involvement of FM providers, C5 Involvement of owners and users during construction phase, C6 Early involvement of technical contractors and C10 Contract strategy. However, the bivariate correlations (r) shown in Table 6 are not controlled for the effect of the other variables. Thus, relying on $r$ only to investigate how construct C2, C7, C8 and C9 influence construct C1 Project outcomes and how construct C3, C4, C5, C6 and C10 influence construct C2 Completed building's qualities might give misleading conclusions. Thus, further testing of the hypotheses is needed before we can draw any conclusions.

\subsection{Which Variables Are Most Important for the Project's Output and Short-Term Value Creation?}

To test H1A-E and to control for the effects of the different explanation factors on one another, we used a multiple regression model with C2 Completed building's qualities as the dependent variable. Table 7 shows the results of multiple regressions with C2 Completed 
building's qualities as the dependent variable, and C3 Project management, C4 Early involvement of FM providers, C5 Involvement of owners and users during construction phase, C6 Early involvement of technical contractors and C10 Contract strategy as the independent variables. This model explains $\left(\mathrm{r}^{2}\right) 48.7$ percent of the dependent variable C2 Completed building's qualities' variance.

Table 7. Multiple regression with project output C2 Completed building's qualities as dependent variable.

\begin{tabular}{|c|c|c|c|c|c|c|c|}
\hline IV & B (CI 95\%) & SE & Beta & $\mathbf{t}$ & $p$ & $\begin{array}{l}\text { Part } \\
\text { Corr. }\end{array}$ & VIF \\
\hline Constant & $0.047(-0.583-0.678)$ & 0.320 & & 0.147 & 0.883 & & \\
\hline C3 Project management & $0.322(0.185-0.460)$ & 0.070 & 0.274 & 4.613 & $<0.001$ & 0.217 & 1.58 \\
\hline $\begin{array}{l}\text { C6 Early involvement of } \\
\text { technical contractors }\end{array}$ & $0.199(0.095-0.303)$ & 0.053 & 0.216 & 3.757 & $<0.001$ & 0.177 & 1.49 \\
\hline $\begin{array}{l}\text { C4 Early involvement of FM } \\
\text { providers }\end{array}$ & $0.105(0.014-0.197)$ & 0.047 & 0.130 & 2.263 & 0.025 & 0.107 & 1.48 \\
\hline C10 Contract strategy & $0.214(0.092-0.335)$ & 0.062 & 0.193 & 3.459 & $<0.001$ & 0.163 & 1.40 \\
\hline $\begin{array}{l}\text { C5 Involvement of owners and } \\
\text { users during construction phase }\end{array}$ & $0.139(0.023-0.254)$ & 0.059 & 0.133 & 2.366 & 0.019 & 0.112 & 1.43 \\
\hline
\end{tabular}

In this case, all the independent variables shown in Table 7 are significant. In other words, hypotheses H1A Project management is positively related to the completed building's qualities holds when controlled for the other independent variables in the model. Hypothesis H1B Early involvement of technical contractors is positively related to the completed building's qualities, hypothesis H1C Early involvement of FM providers is positively related to the completed building's qualities, hypothesis H1D Having a contract strategy is positively related to the completed building's qualities, and hypothesis H1E Owner and user involvement during the construction phase is positively related to the completed building's qualities hold when controlled for the other independent variables in the model.

The regression model has been validated through 10,000 random bootstrap samples from the initial sample. This bootstrapping validated the model because B C3's 95 percent CI was between 0.159 and 0.482 , B C6's CI was between 0.093 and 0.309 , B C4's CI was between 0.014 and 0.196 , B C10's CI was between 0.083 and 0.352 and B C5's CI was between 0.020 and 0.262 . Thus, none of these CIs included zero, and the bootstrapping $p$-values for B C3, C6, C4, C10 and C5 respectively were <0.001, <0.001, 0.014, 0.001 and 0.026 .

Multicollinearity, i.e., perfect linear relationships between the variables, can be a problem in multiple regressions. The variance inflation factor (VIF) is a common measure of indications of multicollinearity. The rule of thumb, according to Field [56] (pp. 325-326), is that a VIF larger than 10 is "cause for concern", and an average VIF "substantially greater than 1" can indicate biased regressions. Thus, given Field's rule of thumb, Table 7 gives no indications of multicollinearity. Thus, there are good reasons to trust the findings from the multiple regression model concerning hypotheses H1A, H1B, H1C, H1D and H1E, about positive relations between C2 Completed building's qualities and project management, early involvement of technical contractors, early involvement of FM providers, contract strategy and involvement of owners and users during the construction phase.

Table 7 also shows the part correlation, which is a measure of the unique relationships between each independent variable and the dependent variable [56] (p. 341), i.e., the net effect of each independent variable on the dependent variable controlled for the effect of the other independent variables. The part correlation is usually significantly smaller than the zero-order correlation (The standardized Beta in Table 7 is almost equal to $r$ in Table 6). In Table 7 the part correlation varies from 0.217 for C3 Project management to 0.107 for C4 Early involvement of FM providers. Thus, when controlling for the other 
independent variables included in the model, C3 Project management have most influence on C2 Completed building's qualities and C4 Early involvement of FM-providers have least influence on C2 Completed building' qualities.

\subsection{Which Variables Are Most Important for the Project's Outcomes and Long-Term Value Creation?}

To test whether the Hypotheses 2A-D concerning long-term value creation hold when controlled for other explanation factors, we also undertook a multiple linear regression analysis with C1 Project outcome as dependent variable and C9 Project governance, C2 Completed building's qualities, C8 Project objectives and C7 Involvement of owners and users during early phase planning as independent variables. Table 8 shows the results of a multiple regression with $\mathrm{C} 1$ Outcome as dependent variable. This model explains $\left(\mathrm{r}^{2}\right) 51.6$ percent of the dependent variable's variance.

Table 8. Multiple regression with C1 Project outcome as dependent variable.

\begin{tabular}{|c|c|c|c|c|c|c|c|}
\hline IV & B (CI 95\%) & SE & Beta & $\mathbf{t}$ & $p$ & $\begin{array}{l}\text { Part } \\
\text { Corr. }\end{array}$ & VIF \\
\hline Constant & $\begin{array}{c}-0.332 \\
(-1.328-0.663)\end{array}$ & 0.501 & & -0.664 & 0.509 & & \\
\hline C9 Project governance & $0.363(0.118-0.607)$ & 0.123 & 0.286 & 2.953 & 0.004 & 0.219 & 1.71 \\
\hline $\begin{array}{l}\text { C2 Completed building's } \\
\text { qualities }\end{array}$ & $0.366(0.205-0.528)$ & 0.081 & 0.372 & 4.504 & $<0.001$ & 0.334 & 1.24 \\
\hline C8 Project objectives & $0.149(-0.026-0.324)$ & 0.088 & 0.147 & 1.698 & 0.093 & 0.126 & 1.36 \\
\hline $\begin{array}{l}\text { C7 Involvement of owners and } \\
\text { users during early phase } \\
\text { planning }\end{array}$ & $0.188(0.063-0.275)$ & 0.083 & 0.192 & 2.251 & 0.027 & 0.167 & 1.33 \\
\hline
\end{tabular}

Table 8 shows that all independent variables except C8 Project objectives are significant.

Thus, Hypothesis H2A Project governance is positively related to the completed building's long-term value-creation holds when controlled for the model's other explanation factors. That is also the case for Hypothesis H2B The completed building's qualities are positively related to the completed building's long-term value creation and hypothesis H2D Involvement of owners and users in early phase planning is positively related to the completed building's long-term value creation holds. However, Hypothesis H2C Project objectives are positively related to the completed building's long-term value creation does not hold when controlled for other explanation factors, even if C8 includes questions about environmental requirements, innovations, life cycle costs, tenant costs and co-location of actors in the project phases, which may have positive influence on a building project's outcome.

Even this model was validated through 10,000 random bootstrap samples from the initial sample. The bootstrapping validated even this model because B C9's 95 percent CI was between 0.131 and 0.621 , B C2's CI was between 0.140 and 0.549 , B C8's CI was between -0.038 and 0.338 which includes zero, and B C7's CI was between 0.029 and 0.370 . Thus, bootstrapping confirmed that B C8's CI included zero, which indicates B C8 is not significant, while the other constructs' B CIs do not include zero, which indicates that B C9, $\mathrm{C} 2$ and $\mathrm{C} 7$ are significantly different from zero. The bootstrapping $p$-values for B C9, C2, C8, C10 and C7 respectively were $0.005,0.001,0.126$, and 0.033 .

In this regression model there are also no problems with multicollinearity, because VIF is around 1. Table 8 also shows the part correlation, which varies from 0.334 for C2 Completed Building' qualities to 0.126 for C8 Project objectives. Thus, C2 Completed Building's qualities has the most influence on C1 Outcome, and C8 Project objectives has least influence on C1 Project outcome when controlled for the other independent variables included in the multiple regression model. 
Thus, the most important factors for a building project's outcome or positive effects for owners and users when controlling for the other factors are C2 Completed building' qualities, C9 Project governance and C7 Involvement of owners and users during early phase planning.

\subsection{What Matters for Short-Term and Long-Term Value Creation?}

In Section 1.2 we derived several hypotheses from the two research questions. In Section 3.3 and Section 3.4 we tested these hypotheses. For a better overview, we have summarized the results in Table 9.

Table 9. Hypothesis testing results.

\begin{tabular}{|c|c|c|}
\hline \multicolumn{3}{|c|}{ Short-Term Value Creation } \\
\hline & Hypothesis & Result \\
\hline $\mathrm{H} 1 \mathrm{~A}$ & $\begin{array}{l}\text { Project management is positively related to the completed } \\
\text { building's qualities. }\end{array}$ & Supported \\
\hline H1B & $\begin{array}{l}\text { Early involvement of technical contractors is positively } \\
\text { related the completed building's qualities. }\end{array}$ & Supported \\
\hline $\mathrm{H} 1 \mathrm{C}$ & $\begin{array}{l}\text { Early involvement of FM providers is positively related to } \\
\text { the completed building's qualities. }\end{array}$ & Supported \\
\hline H1D & $\begin{array}{l}\text { Having a contract strategy is positively related to the } \\
\text { completed building's short-term qualities. }\end{array}$ & Supported \\
\hline H1E & $\begin{array}{c}\text { Involvement of owners and uses during the construction } \\
\text { phase is positively related to the completed building's } \\
\text { qualities. }\end{array}$ & Supported \\
\hline \multicolumn{3}{|c|}{ Long-Term Value Creation } \\
\hline $\mathrm{H} 2 \mathrm{~A}$ & $\begin{array}{l}\text { Project governance is positively related to the completed } \\
\text { building's long-term value-creation. }\end{array}$ & Supported \\
\hline $\mathrm{H} 2 \mathrm{~B}$ & $\begin{array}{l}\text { The completed building's qualities are positively related to } \\
\text { the completed building's long-term value creation. }\end{array}$ & Supported \\
\hline $\mathrm{H} 2 \mathrm{C}$ & $\begin{array}{c}\text { Project objectives are positively related to the completed } \\
\text { building's long-term value creation. }\end{array}$ & $\begin{array}{l}\text { Not } \\
\text { supported }\end{array}$ \\
\hline $\mathrm{H} 2 \mathrm{D}$ & $\begin{array}{c}\text { Involvement of owners and users in early phase planning is } \\
\text { positively related to the completed building's long-term } \\
\text { value creation. }\end{array}$ & Supported \\
\hline
\end{tabular}

These results seem to support most expectations about the connection between explanation factors and results. On the surface, given what we know about building projects, the factors that determine the output and outcome seem plausible. However, hypothesis $\mathrm{H} 2 \mathrm{C}$ is not supported. We will investigate further the realities behind these results in the discussions that follow.

\section{Discussion}

The study is oriented towards identifying the facilitators that facilitate value creation for the various stakeholders involved in building projects, hereunder facility managers These factors include project owners' as well as project managers' efforts to establish effective project governance and project management. These efforts must balance the various stakeholders' short term and long-term objectives. From the literature, we have observed that value orientation is broadly mentioned in the construction field, but that findings may point in different directions and this may be a problem for practical implementation. Our analysis of a large empirical material highlights which concrete parameters practitioners perceive as important. 
Our discussion is designed to answer the two research questions, based on the theoretical background and empirical part: Which factors are most important for the building project's output or short-term value creation, i.e., the project's time, cost, and the completed building's qualities? Which factors are most important for the building project's outcome or long-term value creation, i.e., the completed building's effect for owners and users? Thus, this section has two parts accordingly.

\subsection{Factors That Facilitate Project Output and Short-Term Value Creation for Building Owners and Users}

This paper has hopefully contributed to clarification and operationalisation of value creation, and even such as requested by van der Voordt and Jensen [6] (p. 328) contributed to clarification and operationalisation of the concept added value. Project output represents the short-term perspective on value creation-what the project actually delivers. From the literature review, we found that many authors emphasised short-term value creation parameters, such as: achieving client's tangible and intangible criteria [39], better communication, better management, and early contractor involvement $[30,47]$. We also note that project governance as a regulatory framework influences strategy and project output and performance measurements [24,28,34]. All these conclusions find support in this analysis.

This analysis also shows similarities with other findings from literature. C3 Project management priorities are important in the early phase, planning and design phase, and in the construction phase, as previously indicated by Leiringer and Bröchner [45], Hjelmbrekke et al. [24] and Haddadi et al. [19].

Differently from the literature, our respondents' perception of the FM providers' involvement in the early phase was among the least important, given the part correlation shown in Table 7. Did the respondents indicate status quo (as it is) rather than how it should be? In hindsight, we cannot eliminate this interpretation. Highly experienced individuals may continue to do what they always have done and find arguments as to why this should continue. Authors once again emphasize the importance of changing focus from cost efficiency to added value [45] and from product delivery to creation of value design and value production [25]. The early phase is the first important planning phase to establish foundations for value creation.

We find it very interesting to note from the analysis that five short-term oriented factors appeared as significant for the output, four of them from the project management perspective (C3 Project management priorities, C6 Early involvement of technical contractors, C10 Contract strategy, and C4 Early involvement of FM providers) and one from the governance perspective (C5 Involvement of owners and users during construction phase).

Further, the respondents perceive C6 Early involvement of technical contractors as one of the most significant measures in the early phase. In practice, it is usual to start a direct communication with a technical contractor in the construction phase, but in this study the respondents answered that to create value a technical contractor is a key person to be involved in all phases, starting from the early phase. It is possible that respondents see technical contractors as bringing innovative contributions. However, Wondimu et al. (2018) found that public procurement regulations may prevent early involvement of technical contractors. Rules and regulations concerning public procurements may thus in worst case also represent an obstacle against innovation. Innovation itself is one of the items in C8 Project objectives in our analysis. We also note the current trend to call for early contractor involvement but find it especially interesting that the focus here is on technical contractors. One potential explanation may be the increasing amount of complex technical solutions and systems integrated in buildings (smart buildings, etc.). This role may actually become more important.

In the literature review, for value creation the need for owner and user involvement from the early phase was mentioned many times, i.e., "fulfilment of the user's needs" and "fulfilment of owner's and corporate strategy" [19], or to recognize customer expectation in pre-design phase [31,32,43]. The respondents' perception seems slightly different. The analysis indicates they do not perceive the importance of C7 Involvement of owners and 
users during early phase planning for C2 Completed building's qualities (output) as most important. This can be explained by practical experience, such that that owners and users do not have the technical competence needed to take part in discussions about the output. The questionnaire may not have identified this nuance. We interpret these results to indicate there is still a gap between theory and practice and may indicate that what it takes to achieve value creation in building projects is not fully understood, neither in theory nor in practice.

\subsection{Factors That Facilitate Project Outcome and Long-Term Value Creation for Building Owners and Users}

Project outcome represents the long-term perspective on value creation, as indicated by, among others, Jensen's [17] FM Value Map. From the literature review, we find that many authors emphasised long-term value creation parameters, such as stakeholder benefits [11], achieving client's tangible and intangible criteria [39], changing focus to added value orientation [45] and strategic performance [44]. Further, understanding the client's goals and involvement from the early phase [20,31,32,43,44], defining project value [24] and better contractual relation [52]. Among the Norwegian respondents, such as shown in Section 3.4, only three factors were significantly important for creating value for the project outcome: C2 Completed building' qualities, C9 Project governance, and C7 Involvement of owners and users during early phase planning.

Returning to the hypothesis that was not supported, H2C Project objectives are positively related to the completed building's long-term value creation. Some of the priorities in C8 Project objectives are mostly governance oriented (Environmental requirements, Life Cycle Cost, the building owner's willingness to invest in innovations, and Competitive tenant costs). Two of them (Environmental requirements and LCC) are expected and in accordance with the sustainable orientation of the European and Norwegian building sector and society, for instance, through Horizon 2020, EERA, and BREEAM, etc. The new finding is the respondents' perception of willingness to invest in innovation. This, in combination with Competitive tenant costs, may indicate that building owners should be interested in smart and innovative solutions and not only cutting costs, because smart and innovative solutions may increase the value of buildings. The other important and interesting finding seen from the project governance perspective is co-location of actors in the project phases, which is one of the items in C8 Project objectives. Such co-location may facilitate cooperation and co-creation, and thereby contribute to establishment of outcome focus.

According to Table 6, there is a significant and medium strong bivariate effect ( $r=0.398, p=0.01$ ) between C1 Project outcomes and C8 Project objectives. However, when controlling for the other variables in the multivariate regression model C8 Project objectives were not significant contributors to project outcome and long-term value creation for building owners and users, and this finding was confirmed by the bootstrapping validation of the model. One possible explanation of this counter-intuitive finding that C8 Project objectives is not a significant explanation of the project's outcome, indicated by the high number of "Don't know/Not relevant" answers in the questions included in C8, namely 97 "Don't know / Not relevant" answers in the question about environmental requirements (certification of the finished building), 78 in the question about the building owner's willingness to invest in innovations, 97 in the question about life cycle costs, and 243 in the question about competitive tenant costs and 96 in the question about co-location of actors in the project phases. It is also worth noting that many of the "Don't know / Not relevant" answers were given by consulting engineers, building owners and the building owners' project managers. The particularly high number of "Don't know / Not relevant" answers (243) in the question concerning competitive tenant costs may be a consequence of the fact that particularly financially oriented building owners would like to maximise their rental incomes. If the income approach is used to estimate the buildings' value, such as described by among others RICS' IVS [8] and TEGOVA's EVS [9], the net rental income is very important for buildings' value as collateral for mortgages and for buildings' resale 
value. Thus, there are good reasons to assume that many building owners carefully monitor their buildings' net rental income. The building owners' emphasis on net rental income may influence the building users' outcome of building or renovation projects.

C9 Project governance is also intriguing. It is hard, even for professionals, to keep a clear division between project management and project governance perspectives. Description and functional requirements from the early phase, building owner and project manager's competencies and experience and user involvement have high priority. In literature we found many contributions that indicate those priorities or characteristics $[24,25,28,29,31-33]$, but terms such as strategies, goals and value creation may be somewhat alienating to practitioners. Therefore, we were positively surprised that in practice the benefit from the early-phase requirements and user involvement is highly recognised. Owner's experience is seen as a significant factor for long-term value creation priority.

In the bigger picture, this may be interpreted as confirmation of the idea that practitioners think "governors should govern, and managers should manage". Owners need to make clear priorities supporting long-term value creation, but, as seen in Section 4.1, users and owners may not have the technical competence to actively engage in the technical debates on the outcome. From the analysis results, it seems that practitioners think this should be left to technical experts. Knowing that buildings are becoming even more technically advanced, and acknowledging the tendency to promote more integrated processes, this may seem either as a warning that the emerging trend will meet serious challenges in this field, or that we should see an upcoming rise in initiatives to increase the technical knowledge among building owners and users.

\subsection{Generalisation of Results}

This analysis is based on a large dataset from Norway and is highly representative for the Norwegian context. Even if the sampling is not randomized, it mirrors the situation in Norwegian construction industry and building projects. The uniform context gives some limitations for generalization. It is likely to be difficult to transfer some of the findings to countries in regions with a different economic situation and judicial framework. The level of professionalization is considered high in Norway, so it is reasonable to assume these results also will be valid in other countries with the same level of professionalism. Thus, there are good chances of finding similar tendencies in other western countries as shown in the findings and discussions in this paper.

\section{Conclusions}

Norwegian respondents perceived some priorities of project governance and project management as significant for value creation. To facilitate value creation for the various stakeholders involved in building projects, project owners and project managers must establish project governance and project management that balance the various stakeholders' long-term and short-term objectives.

\subsection{Which Factors Are Most Important for the Project Output (Short-Term Result), i.e., the Qualities of the Completed Building?}

Short-term value creation means maximizing the potential for future value creation. The analyses confirm that practitioners see project management priorities and early involvement of technical contractors as most important. Contract strategy and owner and user involvement during construction phase are also significant. Early involvement of FM providers was found less important, but still significant for the project output. This finding is important for facility managers who become involved in building or renovation projects.

The authors find the technical contractors' importance-from the early phase through the planning and construction phases-especially interesting and puzzling. We understand the technical contractors' importance for the innovative outputs, and an indication of current development in construction towards higher levels of technical complexity. Seeing this together with long-term value creation priorities, such as the building owner's willingness 
to invest in innovations, and competitive tenant costs, it means that Norwegian respondents assume that technical contractors can bring in new knowledge and experience and thereby contribute to innovation and value creation, at least in the short time perspective.

5.2. Which Factors Are Most Important for the Building Project's Outcome and Long-Term Value Creation, i.e., the Effect of the Building for Owners and Users?

Long-term value creation is the ultimate realization of the building's potential for users and owners, and even its contribution to society. Long-term value creation depends primarily on the qualities of the building itself, on project governance, and involvement of owners and users during early phase planning. Governance needs to define a framework for development that from the start put long-term value creation at the very forefront of development. Thus, it is also natural that owners and users' involvement in the early phase planning is confirmed as significant. However, when controlling for the other explanation factors the project owner's project objectives were not significant, even if correlation analysis indicates that project objectives contribute positively to the achievement of project outcomes.

This paper's analyses show it is neither governance alone, nor project management separated from governance, but the adequate combination of governance and management elements that can secure maximum value creation for building owners and users. Thus, the analyses have identified success factors and enablers for value creation seen from a combined governance and management perspective. To put it short: facilitation of value creation in building or renovation projects is all about having the right focus and involving the right parties at the right time. This finding is of great importance among others for facility managers and real estate developers. Another take-home message from this paper is that facility managers who get involved in building or significant renovation projects should be aware of consulting engineers who might be more concerned with the process and the output of the building process, than the outcome. If involved in in building or renovation projects, facility managers should also be aware of financially oriented building owners and their project managers that might be more concerned with the building's financial value than the building's contribution to the demand organisation's value creation.

During the analysis, we also noticed there is a gap between theory and practice. Neither academia nor practitioners have still developed adequate concepts and understanding to achieve value creation in building and renovation projects. Questions for further research are among others project objectives' importance for building and renovation project's long-term value creation. Management research (work psychology, business strategy, etc.) have for decades established that objectives usually facilitate obtainment of goals, but in this paper, when controlled for other explanation factors, project objectives had no significant effect on building projects' outcomes. Even if this paper has indicated some possible explanations, this puzzle requires further investigation. Another future research question is the implications in building and renovation projects for project governance and project management because of the buildings' increasing technical complexity (smart buildings, etc.). A third research question is how to develop rules and regulations of public procurements that facilitate innovation in building projects, such as early involvement of technical contractors and FM-providers.

Author Contributions: Conceptualization, K.B., A.H., O.J.K. and A.T.S.; methodology, K.B., A.H. and A.T.S.; validation, K.B., A.H. and A.T.S.; formal analysis, K.B. and A.T.S.; investigation, K.B., A.H. and A.T.S.; data curation, K.B.; writing—original draft preparation, K.B., A.H., O.J.K. and A.T.S.; writing-review and editing, K.B., A.H., O.J.K. and A.T.S.; visualization, K.B.; supervision, O.J.K. and A.T.S.; project administration, K.B. All authors have read and agreed to the published version of the manuscript.

Funding: This research was funded by The Research Council of Norway, grant number 2352940/O30.

Institutional Review Board Statement: Not applicable. 
Informed Consent Statement: Informed consent was obtained from all subjects involved in the study.

Data Availability Statement: Data are available on request from the corresponding author.

Acknowledgments: The authors thank all the respondents and the reviewers.

Conflicts of Interest: The authors declare no conflict of interest.

\section{References}

1. NS-EN15221-1:2006. Facility Management Part 1: Terms and Definitions; Standards Norway: Lysaker, Norway, 2007.

2. ISO 41011:2017(E). Facility Management Vocabulary; The International Organization for Standardization: Geneva, Switzerland, 2017.

3. Introduction and Overall Framework. In Facilities Management and Corporate Real Estate Management and Value Drivers; Jensen, P.A.; van der Voordt, T. (Eds.) Routledge: Oxford, UK; New York, NY, USA, 2017; pp. 3-13.

4. den Heijer, A.; de Jonge, H. Linking Decisions and Performance: Adding Value Theories Applied to the University Campus. In The Added Value of Facilities Management Concepts, Findings and Perspectives; Jensen, P.A., van der Voordt, T., Coenen, C., Eds.; Polyteknisk Forlag: Lyngby, Denmark, 2012; pp. 177-194.

5. den Heijer, A. Managing University Campuses-In Theory and Practice. In Dear is Durable: Liber Amicorum for Hans de Jonge; Arkesteijn, M., van der Voordt, T., Remøy, H., Chen, Y., Curvelo Magdaniel, F., Eds.; TU Delft Open: Delft, The Netherlands, 2016; pp. 161-170.

6. Reflections, Conclusions and Recommendations. In Facilities Management and Corporate Real Estate Management as Value DriversHow to Manage and Measure Adding Value; van der Voordt, T.; Jensen, P.A. (Eds.) Routledge: London, UK; New York, NY, USA, 2017; pp. 323-333.

7. Geltner, D.M.; Miller, N.G.; Clayton, J.; Eichholtz, P. Commercial Real Estate Analysis and Investments, 3rd ed.; On Course Learning: Mason, WI, USA, 2014.

8. International Valuation Standards Council. International Valuation Standards (IVS) Effective 31 January 2020; International Valuation Standards Council: London, UK, 2019.

9. TEGOVA. European Valuation Standards-2020, 9th ed.; TEGOVA Secretariat: Brussels, Belgium, 2020.

10. FM and CREM Interventions. In Facilities Management and Corporate Real Estate Management and Value Drivers; Jensen, P.A.; van der Voordt, T. (Eds.) Routledge: Oxford, UK; New York, NY, USA, 2017; pp. 14-28.

11. Atkinson, R. Project management: Cost, time and quality, two best guesses and a phenomenon, it's time to accept other success criteria. Int. J. Proj. Manag. 1999, 17, 337-342. [CrossRef]

12. Jensen, P.A.; van der Voordt, T.; Coenen, C.; von Felten, D.; Sarasoja, A.-L.; Nielsen, S.B.; Riratanaphong, C.; Pfenninger, M. The Concept of Added Value of FM. In The Added Value of Facilities Management Concepts, Findings and Perspectives; Jensen, P.A., van der Voordt, T., Coenen, C., Eds.; Polyteknisk Forlag: Lyngby, Denmark, 2012; pp. 58-74.

13. Vrijhoef, R.; Koskela, L.J. A Critical Review of Construction as a Project-Based Industry: Identifying Paths Towards a Projectindependent Approach to Construction. In CIB Symposium, Combining Forces, Advancing Facilities Mangement E Construction through Innovation Series; Kähkönen, K., Ed.; Proceedings CIB Combining Forces: Helsinki, Finland, 2005; pp. 13-24.

14. Vrijhoef, R.; Koskela, L.J. Revisiting the Three Peculiarities of Production in Construction; University of Salford: Manchester, UK, 2005.

15. McKinsey. Reinventing Construction: A Route to Higher Productivity; McKinsey's Capital Projects \& Infrastructure Practice McKinsey Global Institute: New York, NY, USA, 2017.

16. Turner, R.; Zolin, R. Forecasting Success on Large Projects: Developing Reliable Scales to Predict Multiple Perspectives by Multiple Stakeholders over Multiple Time Frames. Proj. Manag. J. 2012, 43, 87-99. [CrossRef]

17. Jensen, P.A. The Facilities Management Value Map: A conceptual framework. Facilities 2010, 28, 175-188. [CrossRef]

18. Womack, J.P.; Jones, D.T. Lean Thinking: Banish Waste and Create Wealth in Your Corporation; Touchstone: New York, NY, USA, 1996.

19. Haddadi, A.; Johansen, A.; Andersen, B. A conceptual Framework to Enhance value Creation in Construction projects. International Conference on project Management. Procedia Comput. Sci. 2016, 100, 565-573. [CrossRef]

20. Haddadi, A.; Temeljotov-Salaj, A.; Foss, M.; Klakegg, O.J. The Concept of Value for Owners and Users of Buildings-A Literature Study of Value in Different Contexts. Procedia Soc. Behav. Sci. 2016, 226, 381-389. [CrossRef]

21. Laursen, M.; Svejvig, P. Taking stock of project value creation: A structured literature review with future directions for research and practice. Int. J. Proj. Manag. 2016, 34, 736-747. [CrossRef]

22. Chan, A.P.C.; Chan, A.P.L. Key performance indicators for measuring construction success. Benchmark. Int. J. $2004,11,203-221$. [CrossRef]

23. Arge, K.; Hjelmbrekke, H. Value enhancing processes in building and real estate. In Proceedings of the Joint CIB W70, W092 Conference, Cape Town, South Africa, 23-25 January 2012.

24. Hjelmbrekke, H.; Hansen, G.K.; Lohne, J. A Motherless Child-Why do Construction Projects Fail. Procedia Econ. Finance 2015, 21, 72-79. [CrossRef]

25. Bjørberg, S.; Larssen, A.K.; Temeljotov Salaj, A.; Haddadi, A. Optimizing building design to contribute to value creation. In Proceedings of the IPMA 29th World Congress, Westin Playa Bonita, Panama, 28-30 September 2015.

26. Davis, K. Different stakeholder groups and their perceptions of project success. Int. J. Proj. Manag. 2014, 32, 189-201. [CrossRef]

27. Munns, A.; Bjeirmi, B. The role of project management in achieving project success. Int. J. Proj. Manag. 1996, 14, 81-87. [CrossRef] 
28. Ahola, T.; Ruuska, I.; Artto, K.; Kujala, J. What is project governance, and what are its origins? Int. J. Proj. Manag. 2014, 32, 1321-1332. [CrossRef]

29. Badewi, A. The impact of project management (PM) and benefits management (BM) practices on project success: Toward developing a projects benefits governance framework. Int. J. Proj. Manag. 2016, 34, 761-778. [CrossRef]

30. Musawir, A.U.; Serra, C.E.M.; Zwikael, O.; Ali, I. Project governance, benefit management, and project success: Towards a framework for supporting organizational strategy implementation. Int. J. Proj. Manag. 2017, 35, 1658-1672. [CrossRef]

31. Boge, K.; Salaj, A.T. Practice vs theory: Short-term financials trumps long-term value creation. J. Corp. Real Estate 2017, 19, 186-204. [CrossRef]

32. Boge, K.; Temeljotov Salaj, A.; Bjørberg, S.; Larssen, A.K. Failing to plan-Planning to fail: How early phase planning can improve building's lifetime value creation. Facilities 2018, 36, 49-75. [CrossRef]

33. Hjelmbrekke, H.; Klakegg, O.J.; Lohne, J. Governing value creation in construction project: A new model. Int. J. Manag. Proj. Bus. 2017, 10, 60-83. [CrossRef]

34. Klakegg, O.J.; Lichtenberg, S. Successive Cost Estimation-Successful Budgeting of Major Projects. Procedia Soc. Behav. Sci. 2016, 226, 176-183. [CrossRef]

35. Nasar, J.L. Urban Design Aesthetics. Environ. Behav. 1994, 26, 377-401. [CrossRef]

36. Winch, G.M. Managing Construction Projects, 2nd ed.; Wiley-Blackwell: Oxford, UK, 2014.

37. Paden, R. Values and Planning: The Argument from Renaissance Utopianism. Ethic Place Environ. 2001, 4, 5-30. [CrossRef]

38. Shenhar, A.J.; Dvir, D. Reinventing Project Management: The Diamond Approach to Successful Growth and Innovation; Harvard Business School Press: Boston, MA, USA, 2007.

39. Chan, A.P.C.; Scott, D.; Lam, W.M. Framework of Success Criteria for Design/Build Projects. J. Manag. Eng. 2002, 18, 120-128. [CrossRef]

40. How Buildings Add Value for Clients; Spencer, N.C.; Winch, G. (Eds.) Thomas Telford: London, UK, 2002.

41. Morris, P.W.G. Science, objective knowledge and the theory of project management. Civ. Eng. 2002, 150, 82-90. [CrossRef]

42. Breese, R. Benefits realisation management: Panacea or false dawn? Int. J. Proj. Manag. 2011, 30, 341-351. [CrossRef]

43. Hjelmbrekke, H.; Klakegg, O.J. The new common ground: Understanding value. In Proceedings of the 7th Nordic Conference on Construction Economics and Organisation, Trondheim, Norway, 12-14 June 2013; pp. 269-281.

44. Samset, K. Early Project Appraisal: Making the Initial Choices; Palgrave Macmillan: New York, NY, USA, 2010.

45. Leiringer, R.; Bröchner, J. Editorial: Service-led construction projects. Constr. Manag. Econ. 2010, 28, 1123-1129. [CrossRef]

46. Gottlieb, S.C.; Haugbølle, K. Contradictions and collaboration: Partnering in-between systems of production, values and interests. Constr. Manag. Econ. 2013, 31, 119-134. [CrossRef]

47. Reifi, M.H.E.; Emmitt, S. Perceptions of lean design management. Arch. Eng. Des. Manag. 2013, 9, $195-208$.

48. Wondimu, P.A.; Hosseini, A.; Lohne, J.; Laedre, O. Early contractor involvement approaches in public procurement. J. Public Procure. 2018, 18, 355-378. [CrossRef]

49. Klakegg, O.J.; Shannon, D. Board of Directors' Responsibility for Construction Projects. In Proceedings of the 7th Nordic Conference on Construction Economics and Organisation, Trondheim, Norway, 12-14 June 2013; pp. 257-268.

50. Crawford, L.; Cooke-Davies, T.; Hobbs, B.; Labuschagne, L.; Remington, K.; Chen, P. Governance and Support in the Sponsoring of Projects and Programs. Proj. Manag. J. 2008, 39, S43-S55. [CrossRef]

51. Griffiths, F. Project contract strategy for 1992 and beyond. Int. J. Proj. Manag. 1989, 7, 69-83. [CrossRef]

52. Suprapto, M.; Bakker, H.L.; Mooi, H.G.; Hertogh, M.J. How do contract types and incentives matter to project performance? Int. J. Proj. Manag. 2016, 34, 1071-1087. [CrossRef]

53. Watermeyer, R.B. A framework for developing construction procurement strategy. Proc. Inst. Civil Eng.-Manag. Procure. Law 2012, 165, 223-237. [CrossRef]

54. Gerring, J.; Christenson, D. Applied Social Science Methodology: An Introductory Guide; Cambridge University Press: Cambridge, UK, 2017.

55. Hair, J.F.; Clack, W.C.; Babin, B.J.; Anderson, R.E. Multivariate Data Analysis, 7th ed.; Pearson New International Edition; Pearson Education Limited: Harlow, UK, 2014.

56. Field, A. Discovering Statistics Using IBM SPSS Statistics, 4th ed.; Sage Publications: London, UK, 2013.

57. Cohen, J. Statistical Power Analysis for the Behavioral Sciences, 2nd ed.; Lawrence Erlbaum Associates: Hillsdale, NJ, USA, 1988. 
MDPI

St. Alban-Anlage 66

4052 Basel

Switzerland

Tel. +41616837734

Fax +41 613028918

www.mdpi.com

Buildings Editorial Office

E-mail: buildings@mdpi.com

www.mdpi.com/journal/buildings

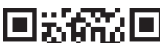

$5,4+4$

74

回䗆郭: 

MDPI

St. Alban-Anlage 66

4052 Basel

Switzerland

Tel: +41 616837734

Fax: +41 613028918 